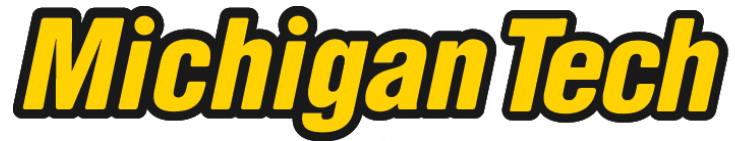 \\ Michigan Technological University Create the Future Digital Commons @ Michigan Tech
}

Dissertations, Master's Theses and Master's Reports - Open

Dissertations, Master's Theses and Master's

Reports

2015

\section{MODELLING AND CONTROL OF COMBUSTION PHASING OF AN RCCI ENGINE}

Kaveh Khodadadi Sadabadi

Michigan Technological University

Follow this and additional works at: https://digitalcommons.mtu.edu/etds

Part of the Mechanical Engineering Commons

Copyright 2015 Kaveh Khodadadi Sadabadi

\section{Recommended Citation}

Khodadadi Sadabadi, Kaveh, "MODELLING AND CONTROL OF COMBUSTION PHASING OF AN RCCI

ENGINE", Master's Thesis, Michigan Technological University, 2015.

https://doi.org/10.37099/mtu.dc.etds/966

Follow this and additional works at: https://digitalcommons.mtu.edu/etds

Part of the Mechanical Engineering Commons 


\title{
MODELLING AND CONTROL OF COMBUSTION PHASING OF AN RCCI ENGINE
}

\author{
By
}

Kaveh Khodadadi Sadabadi

\section{A THESIS}

Submitted in partial fulfillment of the requirements for the degree of

MASTER OF SCIENCE

In Mechanical Engineering

MICHIGAN TECHNOLOGICAL UNIVERSITY

2015

(C) 2015 Kaveh Khodadadi Sadabadi 
This thesis has been approved in partial fulfillment of the requirements for the Degree of MASTER OF SCIENCE in Mechanical Engineering.

Department of Mechanical Engineering-Engineering Mechanics

Thesis Advisor: Dr. Mahdi Shahbakhti

Committee Member: Dr. Jeffery Naber

Committee Member: Dr. Jeffery Burl

Department Chair: Dr. William W. Predebon 


\section{Contents}

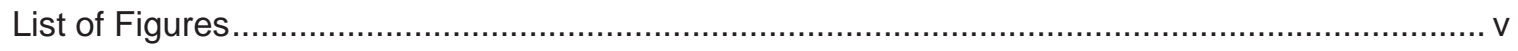

List of Definitions/Abbreviations .........................................................................................ii

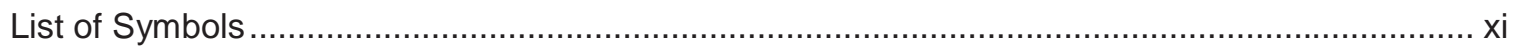

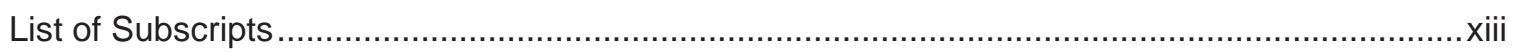

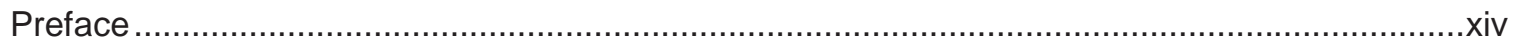

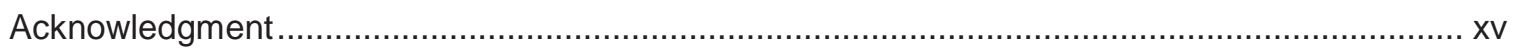

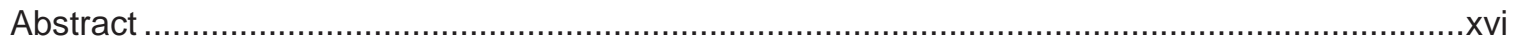

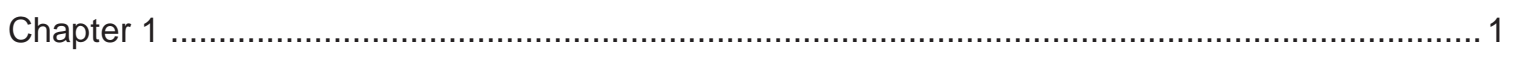

$1.1 \quad$ Motivation for Reactivity Controlled Combustion Strategy .............................................. 3

1.2 Charge stratification and $\mathrm{RCCl}$ combustion strategy ........................................... 5

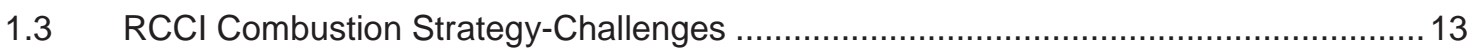

1.4 Research Scope and Thesis Organization ......................................................... 14

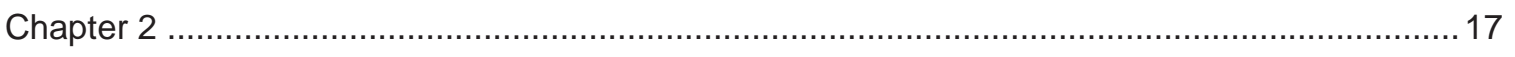

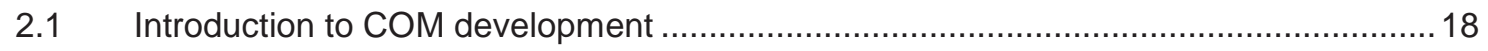

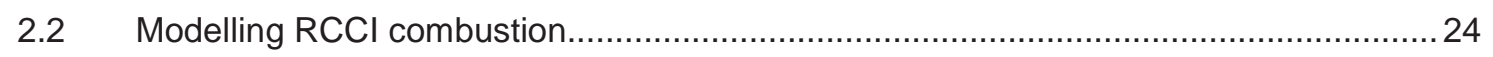

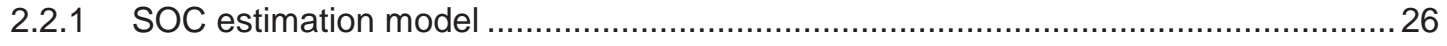

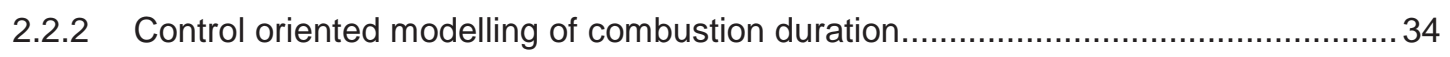

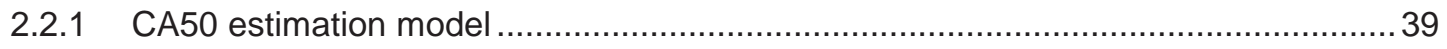

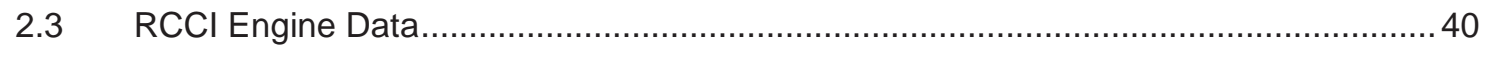

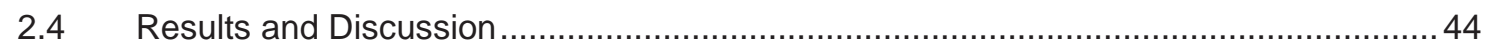

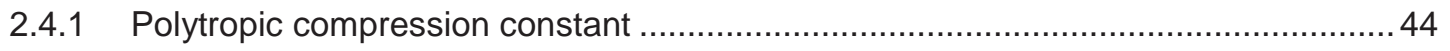

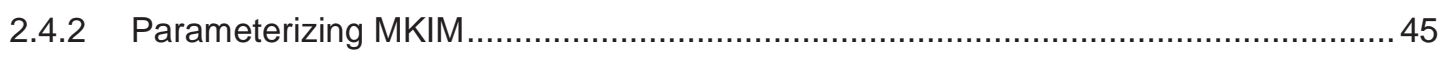

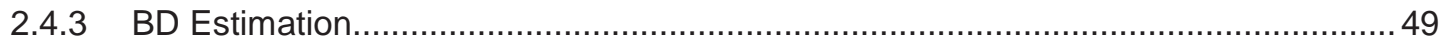

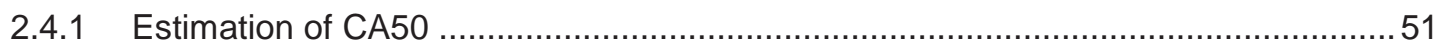

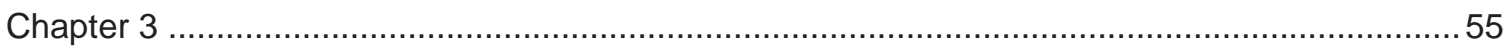

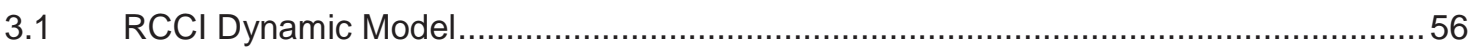




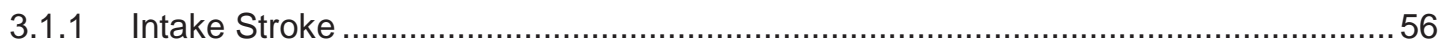

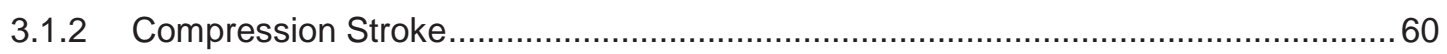

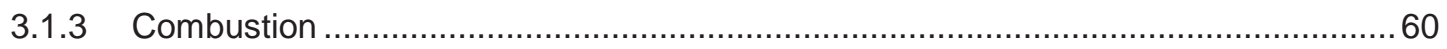

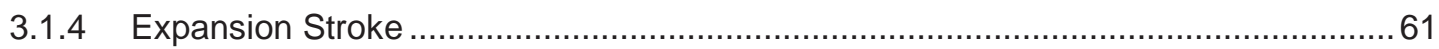

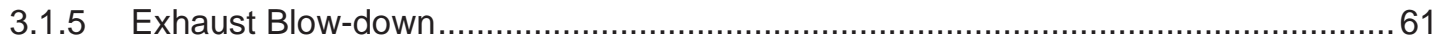

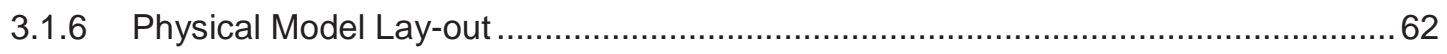

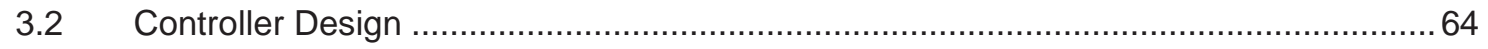

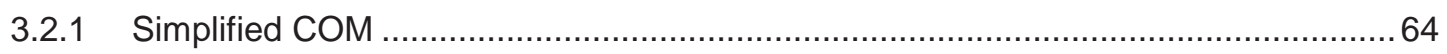

3.2.2 Model Linearization and Linear Quadratic Integral (LQI) Design............................. 68

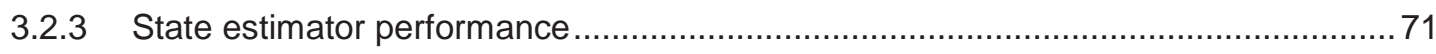

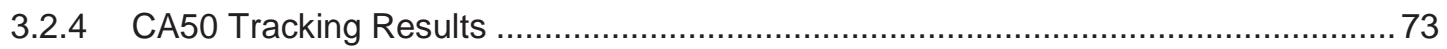

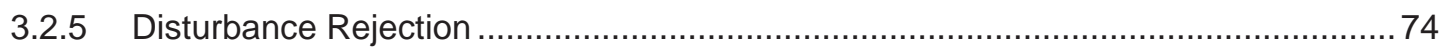

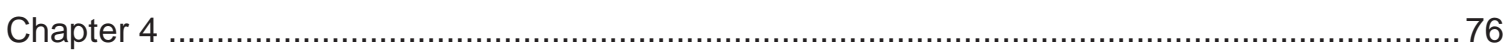

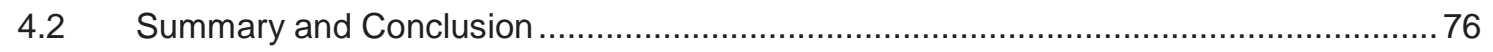

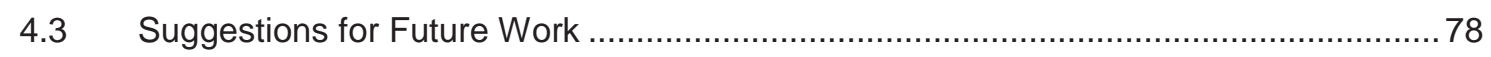

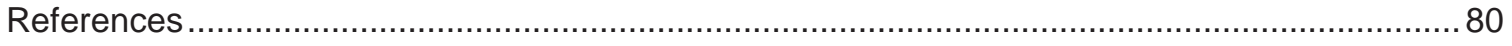

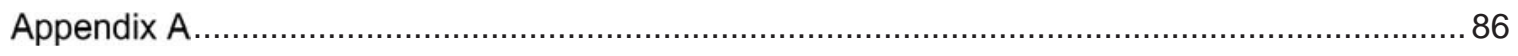

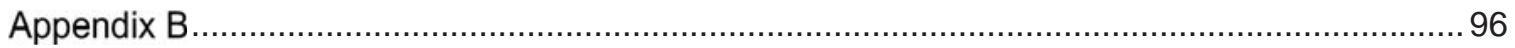

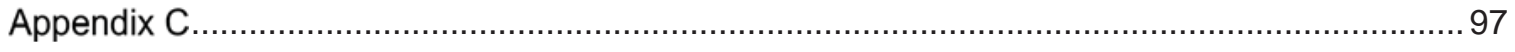

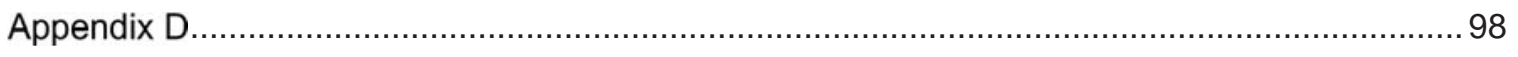

Appendix E 


\section{List of Figures}

Figure 1-1. EPA green house gas (GHG) and fuel economy regulations. The data in reference [1] was used to produce this figure.

Figure 1-2. $\varphi$ versus temperature for $\mathrm{CD}$ and $\mathrm{RCCl}$ combustion at $5^{\circ}$ aTDC [4] .......................10

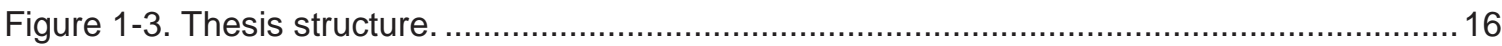

Figure 2-1. Control-oriented auto-ignition models for compression ignition combustion concepts20

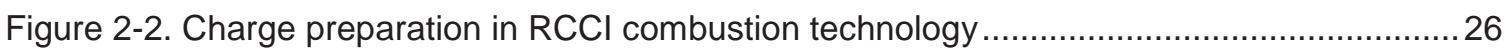

Figure 2-3. RCCI combustion phenomenological model (Formation of auto-ignition pockets and

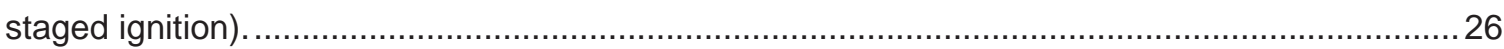

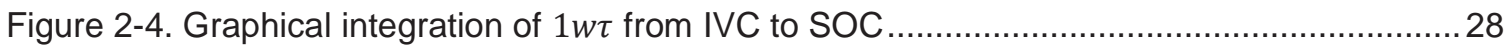

Figure 2-5. KIVA simulation and experimental results for 1 bar BMEP experiment. The data to generate this figure is taken from [10-11].

Figure 2-6. KIVA simulation and experimental results for 2.6 bar BMEP experiment. The data to generate this figure is taken from [10-11] 42

Figure 2-7. Estimated SOC pressures vs. SOC pressures from KIVA simulations using the best numerical fit of $k c=1.35$. eave, $\sigma a v e$, emax indicate average error, standard deviation of error and maximum error, respectively. 44

Figure 2-8. MKIM SOC prediction and KIVA simulation Data...................................................... 46

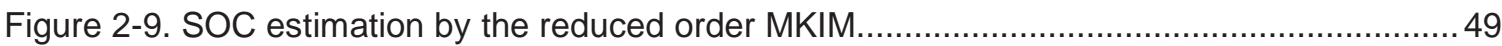
Figure 2-10. Comparison between predicted BDs from the BDM and those from KIVA simulation data

Figure 2-11. Comparison between predicted CA50s from the Wiebe function and those from KIVA simulation 51

Figure 2-12.Crank angle resolved of the estimated mass fraction burned by Wiebe function and mass fraction burned computed using KIVA heat release for 1 bar BMEP case.

Figure 2-13. Crank angle resolved of the estimated mass fraction burned by Wiebe function and mass fraction burned computed using KIVA heat release for 2.6 bar BMEP case. 53

Figure 2-14. CA50 estimation using a simplified linear CA50 model (Equation 2-25)...................54

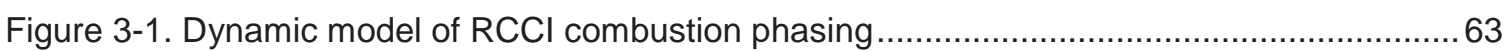

Figure 3-2. The SOC predictions of MKIM and the empirical correlation. ...................................65

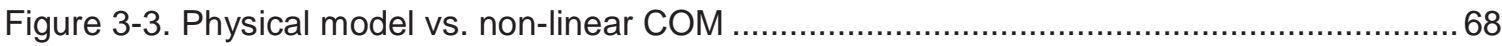

Figure 3-4. Structure of designed RCCI combustion phasing controller …................................. 71

Figure 3-5. State estimation performance of observer under transient conditions.......................72

Figure 3-6. Tracking performance of the designed CA50 controller........................................... 73 
Figure 3-7. Controller performance in disturbance rejection................................................. 75 


\section{List of Tables}

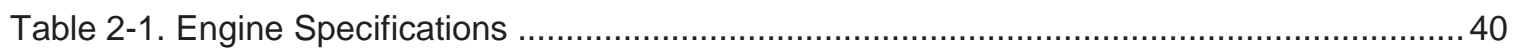

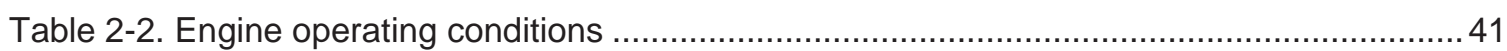

Table 2-3. Combustion parameters; KIVA predictions vs. experimental results.......................... 43

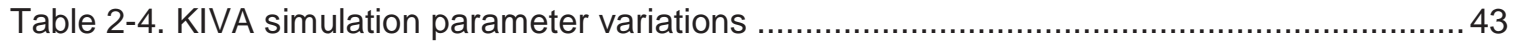

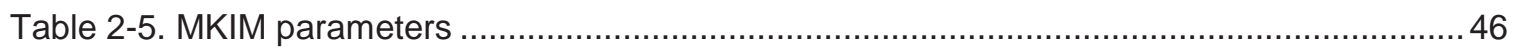

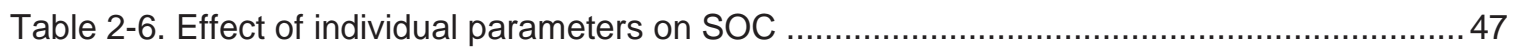

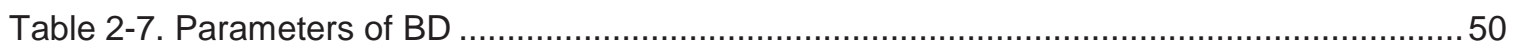

Table 3-1. The sweep range performed for developing the SOC correlation ............................... 65

Table 3-2. The nominal operating/linearization point............................................................... 69

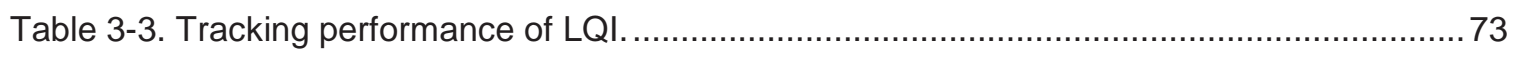




\section{List of Definitions/Abbreviations}

\begin{tabular}{|c|c|}
\hline aTDC & after Top Dead Center \\
\hline $\mathrm{BD}$ & Burn Duration \\
\hline $\mathrm{BDM}$ & Burn Duration Model \\
\hline bTDC & before Top Dead Center \\
\hline BMEP & Brake Mean Effective Pressure \\
\hline CAD & Crank Angle Degrees \\
\hline $\mathrm{CDC}$ & Conventional Diesel Combustion \\
\hline $\mathrm{COM}$ & Control Oriented Model \\
\hline DARE & Discrete-time Algebraic Riccati Equation \\
\hline DI & Direct Injection \\
\hline DICI & Direct Injection Compression Ignition \\
\hline DOC & Diesel Oxidation Catalyst \\
\hline $\mathrm{DPF}$ & Diesel Particulate Filter \\
\hline EOC & End of Combustion \\
\hline EGO & Exhaust Gas Oxygen \\
\hline EGR & Exhaust Gas Recycling \\
\hline $\mathrm{EVC}$ & Exhaust Valve Closure \\
\hline EVO & Exhaust Valve Opening \\
\hline GHG & Green House Gas \\
\hline HCCI & Homogeneous Charge Compression Ignition \\
\hline HECC & High-Efficiency Clean Combustion \\
\hline
\end{tabular}




\begin{tabular}{|c|c|}
\hline HRR & Heat Release Rate \\
\hline HTO & High Temperature Oxidation \\
\hline IC & Internal Combustion \\
\hline IMEP & Indicated Mean Effective Pressure \\
\hline IVC & Intake Valve Closure \\
\hline IVO & Intake Valve Opening \\
\hline KIM & Knock Integral Model \\
\hline LHV & Lower Heating Value \\
\hline LQI & Linear Quadratic Integral \\
\hline LNT & Lean NOx Trap \\
\hline LTO & Low Temperature Oxidation \\
\hline MKIM & Modified Knock Integral Model \\
\hline ON & Octane Number \\
\hline PCI & Premixed Compression Ignition \\
\hline PCCI & Partially Premixed Compression Ignition \\
\hline PFI & Port Fuel Injection \\
\hline PFS & Partial Fuel Stratification \\
\hline PPRR & Peak Pressure Rise Rate \\
\hline RCCI & Reactivity Controlled Compression Ignition \\
\hline $\mathrm{RCM}$ & Rapid Compression Machine \\
\hline $\mathrm{RON}$ & Research Octane Number \\
\hline RI & Ringing Intensity \\
\hline
\end{tabular}


SCR Selective Catalytic Reduction

SOC Start of Combustion

SOI Start of Injection

VGT Variable Geometry Turbine

RHS Right Hand Side 


\section{List of Symbols}

\begin{tabular}{|c|c|}
\hline$\varphi$ & Fuel to charge equivalence ratio (-) \\
\hline$\theta$ & Crank angle (CAD) \\
\hline$\tau$ & Ignition delay (sec) \\
\hline$B D$ & Burn Duration (CAD) \\
\hline$C_{v}$ & Constant volume specific heat capacity $\left(\frac{\mathrm{kJ}}{\mathrm{kg} \cdot \mathrm{K}}\right)$ \\
\hline $\mathrm{CA} i$ & $i \%$ mass fraction burned (CAD) \\
\hline$C N$ & Cetane Number (-) \\
\hline$D_{e}$ & Exhaust valve inner seat diameter (m) \\
\hline$D_{i}$ & Intake valve inner seat diameter (m) \\
\hline$E_{a}$ & Activation energy $\left(\frac{J}{m o l e}\right)$ \\
\hline$e_{S S}$ & Steady-state error (CAD) \\
\hline$F A R$ & Fuel to Air Ratio (-) \\
\hline$I D$ & Ignition Delay (CAD) \\
\hline$k_{c}$ & Polytropic constant (-) \\
\hline$L_{e}$ & Exhaust valve lift (m) \\
\hline$L H V$ & Lower Heating Value (J/kg) \\
\hline$L_{i}$ & Intake valve lift (m) \\
\hline$m$ & Mass (kg) \\
\hline$N$ & Engine speed (RPM) \\
\hline
\end{tabular}




$\begin{array}{ll}O F & \text { Overlap Factor }\left({ }^{\circ} / \mathrm{m}\right) \\ P & \text { Pressure }(\mathrm{kPa}) \\ Q_{L H V} & \text { Lower heating value of fuel }\left(\frac{\mathrm{MJ}}{\mathrm{kg}}\right) \\ R & \text { Gas constant }\left(\frac{\mathrm{Jg}}{\mathrm{kg} \cdot \mathrm{K}}\right) \\ S_{i g} & \text { Spontaneous ignition front speed }\left(\mathrm{sec}^{-1}\right) \\ S O C & \text { Start of Combustion (CAD) } \\ T & \text { Temperature (K) }\end{array}$




\section{List of Subscripts}

$\begin{array}{ll}b c & \text { Before combustion } \\ b d & \text { Blow-down } \\ D I & \text { Direct Injection } \\ e g & \text { Exhaust gases } \\ f & \text { Fuel } \\ f c & \text { Fresh charge } \\ h e p & \text { n-heptane } \\ i s o & \text { Iso-octane } \\ P F I & \text { Port Fuel Injection } \\ r g & \text { Residual gas } \\ s t & \text { Stoichiometric } \\ t & \text { Total }\end{array}$




\section{Preface}

The second chapter of this thesis is partially based on my paper [10] for which I am the corresponding author. I developed, parameterized, and validated a control-oriented model. Anand N Bharath validated a KIVA CFD code and performed a sweep, thus providing 69 data points. Dr. Rolf Reitz revised and made corrections to the joint manuscript [10]. Dr. Mahdi Shabakhti, my academic advisor, made corrections and provided comments for the manuscript [10].

The remainder of the thesis is solely based on my own work. 


\section{Acknowledgment}

I would like to thank my mother for providing the opportunity for me to pursue my graduate studies in the US. Also I would like to thank my sister for being an inspiration to me.

I am also grateful to both Dr. Jeffery Naber and Dr. Jeffery Burl for accepting to become members of my committee, as well as the having the privilege for being their student in the graduate courses they offered at MTU which greatly assisted me in extending my knowledge of IC engines and controls. Their insightful teachings allowed me to make significant progress during my research and motivated me to pursue higher graduate studies in the field.

I would also like to take the opportunity to thank Dr. Mahdi Shahbakhti for his assistance and patience to make me become an expert technical writer and his academic supervision and persistence.

I wish to thank Paul Dice, Anupkumar Ketkale, Harshith, and Deepak in assisting me with the design and fabrication of the PFI system. I thank Mehran Bidarvatan for his valuable comments and assistance in simplification and linearization process of my control-oriented model.

I am also thankful to Anand for providing the KIVA simulation data necessary for designing the COM and his insightful comments which assisted me in developing an extensive understanding of RCCI combustion. I am also grateful to Dr. Rolf Rietz for his invaluable comments on the RCCI paper. 


\section{Abstract}

Reactivity controlled compression ignition (RCCI) is a novel combustion strategy introduced to achieve near-zero NOx and soot emissions while maintaining diesel-like efficiencies. Meanwhile, precise control of combustion phasing is a key in realization of high fuel conversion efficiency as well as meeting stringent emission standards. Modelbased control of RCCI combustion phasing is a great tool for real-time control during transient operation of the engine, which requires a computationally efficient combustion model that encompasses factors such as, injection timings, fuel blend composition and reactivity. In this thesis, physics-based models are developed to predict the combustion metrics of an RCCI engine. A mean value control-oriented model (COM) of RCCI is then developed by combining the auto-ignition model, the burn duration model, and a Wiebe function to predict combustion phasing. Development of a model-based controller requires a dynamic model which can predict engine operation, i.e., estimation of combustion metrics, on a cycle-to-cycle basis. Hence, the mean-value model is extended to encompass the full-cycle engine operation by including the expansion and exhaust strokes. In addition, the dynamics stemming from the thermal coupling between cycles are accounted for, that results in a dynamic RCCI control-oriented model capable of predicting the transient operation of the engine. This model is then simplified and linearized in order to develop a linear observer-based feedback controller to control the combustion phasing using the premixed ratio (the ratio of the PFI fuel to the total fuel injected) of the gasoline/diesel fuel. The designed controller depicts an accurate tracking performance of the desired 
combustion phasing and successfully rejects external disturbances in engine operating conditions. 


\section{Chapter 1}

\section{Introduction}

Internal combustion engines (IC engines) are the prime source of global ground transportation. They are one of the major contributors to the global warming process through the greenhouse gas emissions as well as other hazardous tailpipe emissions which are deleterious to the environment. Moreover, the sheer number of automobiles which utilize IC engines as their main propulsion systems, makes them one of their major consumers of fossil fuel, a non-renewable source of energy. Hence, IC engines, due to their contribution to emissions and fuel consumption, have been on the limelight, and subject of the focus of many researchers who have been working on improving them. The goal has been to improve fuel conversion efficiencies while mitigating the tailpipe emissions. Several novel approaches have been proposed to deliver this, from hybrid electric vehicles to fuel cell technologies. However, despite their near-zero emissions and higher efficiencies, these alternative methods to IC engines are facing challenges as they require costly overhaul in the infrastructure of the transportation system.

The US Department of Transportation's National Highway Traffic Safety Administration (NHTSA) has issued fuel economy projections for vehicle model years 2017 through 2025, with targeted fuel economy increasing by $53 \%$ (35.5 to $54.5 \mathrm{mpg}$ ) [1] as shown in Figure 1-1. Vehicle manufacturers need to utilize a variety of technologies to meet these fuel economy targets, while not violating EPA emission limits. One major area of improvement 
is expected to arise from improving the fuel economy of internal combustion engines, including compression ignition engines [1].

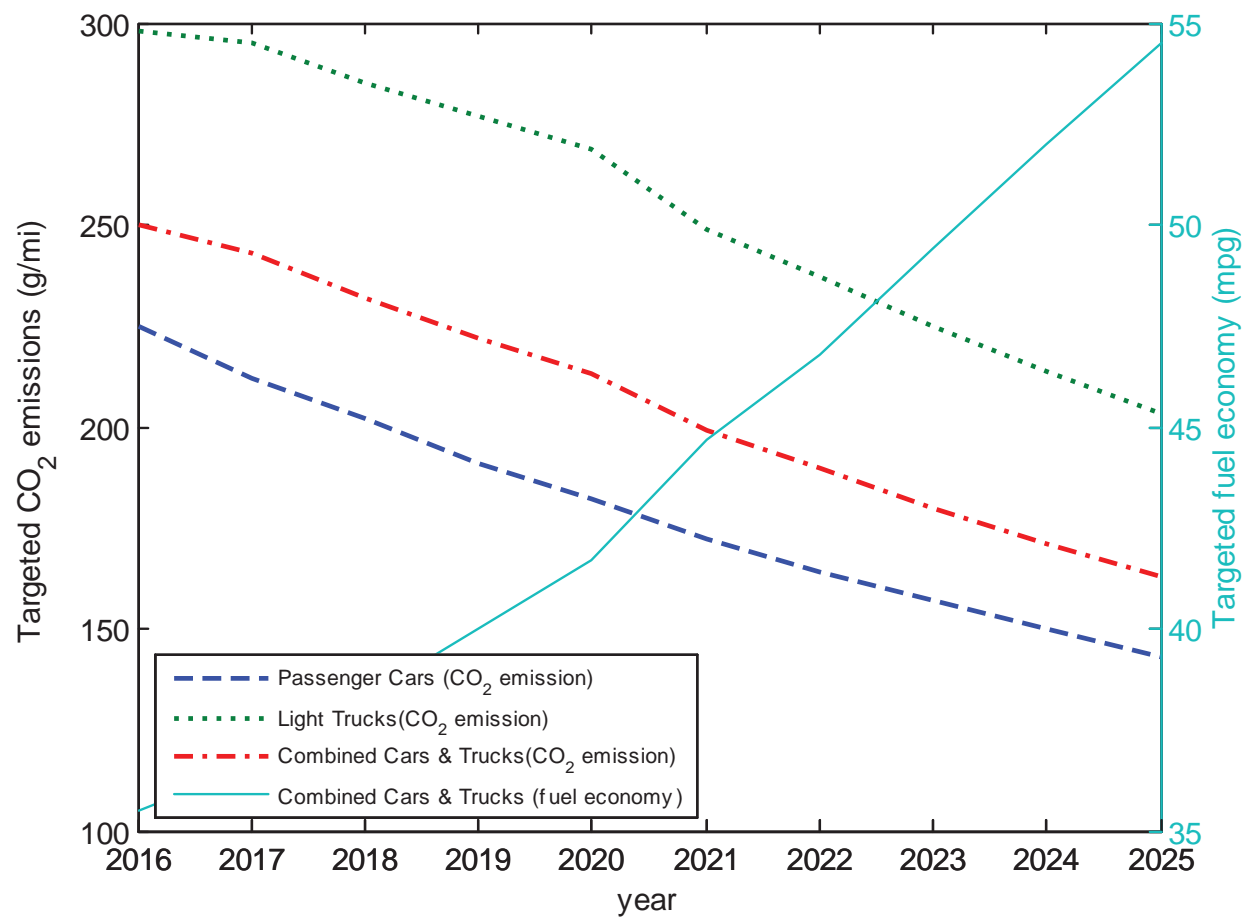

Figure 1-1. EPA green house gas (GHG) and fuel economy regulations. The data in reference [1] was used to produce this figure.

The ever-becoming stringent emission regulations have encouraged engineers to develop extremely efficient after-treatment systems. Three-way catalytic converters (TWC) have been utilized for reducing NOx, and oxidizing CO and UHC emissions in SI engines which have emission reduction efficiencies above $90 \%$. However, their optimum efficiencies are only obtainable when mixture is near stoichiometric (slightly lean) rendering them incompatible with diesel engines which have a lean global operation. Diesel engines utilize a set of after-treatment systems to reduce NOx, burn soot and UHC, i.e. lean NOx traps 
(LNT), selective catalytic reduction (SCR), diesel oxidation catalysts (DOC), and diesel particulate filters (DPF). However, none of these methods correspond to optimizing the combustion process itself which is the sole source of power generation in IC engines. Thus, an optimal combustion mode can be achieved to both reduce emissions, without the need for after-treatment systems, as well as maintaining optimum efficiencies. One of such methods is low temperature combustion (LTC) engine concepts which include, homogenous charge compression ignition (HCCI), premixed charge compression ignition (PCCI), and reactivity controlled compression ignition (RCCI) engines. These novel approaches have distinguishing merits with regards to fuel economy and emissions, however, these combustion strategies require further investigation for them to be utilizable in transportation fleets. The challenges facing LTC engines, range from precise control, proper after-treatment to restrictions on operating range.

\subsection{Motivation for Reactivity Controlled Combustion Strategy}

Compression ignition engines have higher efficiencies compared to SI engines due to lack of throttling and higher compression ratios. However, after treatment in this type of engine is challenging. Due to highly heterogeneous nature of combustion in CI engines locally rich mixtures induce excessive temperatures contributing to production of NOx. Since diesel engines operate under overall lean conditions utilization of TWC converters is not feasible. In order to reduce NOx either lean NOx traps or selective catalytic converters could be used. In the case of lean NOx traps, NOx is reduced by products of rich combustion such as $\mathrm{CO}, \mathrm{UHC}$ and $\mathrm{H}_{2}$. Thus, due to its lean operation, the engine is required 
to undergo periodic rich conditions to reduce the stored NOx which reduces the engine fuel conversion efficiency. SCR requires the introduction of urea as a reducing agent for reduction of NOx which is stored in the vehicle and injected in the exhaust manifold. The injected urea does not contribute to torque generation of the engine. Similarly, urea used to reduce NOx could be perceived of a surplus fuel consumed, imposing a fuel economy penalty on engine [2]. The local hot-rich regions in the mixture contribute to production of soot in diesel engines. The soot could be oxidized using after treatment systems such as diesel particulate filters. These filters require regenerations to remove the collected soot. This procedure either entails of dosing fuel in the exhaust manifold or late injection. Both of these approaches reduce the fuel conversion efficiency and the merit of CI engine over their SI counterpart is undermined. Thus the notion of reducing the emissions within the cylinder without utilizing after treatment comes to mind. LTC combustion regimes, also known as high-efficiency clean combustion (HECC), have enabled substantial reduction in NOx and particulate matter while maintaining efficiencies similar to diesel engine [3].

HCCI combustion strategy, as a low temperature combustion, may appear thermodynamically appealing but it has faced difficulties using either gasoline, which has poor auto ignition properties causing difficulties in combustion at low loads, or diesel, superior auto ignition but combustion phasing is difficult to control at high loads [4]. Moreover it sacrifices two combustion control aspects. First, there is a lack of direct trigger for control of combustion phasing. Start of combustion is not controlled directly by fuel injection timing like in direct injection compression ignition (DICI) engine operation or by spark in SI engines. Second, similar to combustion phasing pressure rise rate cannot be 
controlled directly either by the rate of fuel injection as in DICI engine, or by finite turbulent flame propagation as in SI engines. Due to homogenous nature of the charge all the mixture auto ignites almost simultaneously contributing to excessive peak pressure rise rates [4].

\subsection{Charge stratification and RCCl combustion strategy}

Dec et al. [5] used partial fuel stratification to reduce the knocking possibility of HCCI engines. They suggested that if the fuel being used has $\varphi$ sensitive auto ignition and two stage combustion characteristics, the stratification of equivalence ratio in the mixture would expand the knock load limit by confining the heat release rate through introduction of gradients in the auto ignition properties of the mixture. Partial fuel stratification (PFS) was realized by port fuel injection of gasoline and subsequently direct injection of remainder of the fuel later in the compression stroke. The PFI portion of the fuel creates a homogeneous mixture whereas the role of DI fuel is to introduce stratification of equivalence ratio in the charge (both being gasoline). However, they concluded that for the naturally aspirated HCCI engine gasoline does not depict auto ignition properties sensitive to equivalence ratio and two staged combustion characteristics. Hence, PFS is not an effective approach for reduction of peak pressure rise rate (PPRR) in naturally aspirated HCCI engines.

Inagaki [6] used an injection of gasoline in the intake manifold and an early injection of diesel to promote a moderate inhomogeneity of fuel equivalence ratio as well as cetane number of fuel. They examined the combustion characteristics of HCCI and premixed compression ignition (PCI) engines using different fuels. By examining different blends of 
fuel, they inferred that by changing the ratio of high research octane number (RON) fuel the ignition timing could be controlled through the change in the crank angle at which the in cylinder temperature reaches a critical value due to variations in cumulative heat release during low temperature oxidation (LTO). Also an analysis on the parameters affecting the HCCI/PCI combustion using fuels with different octane numbers was performed. Then, based on the knowledge obtained a dual fuel combustion strategy by stratification of equivalence ratio and octane number of fuel was developed to realize near zero NOx and soot emissions as well as low combustion noise. Based on the experimental results, they concluded that as RON increases the LTO timing advances and its rate of heat release rises. Moreover, the start of ignition, i.e. high temperature oxidation (HTO), advances as well. Furthermore, they investigated the relation between temperature and heat release. As the RON of fuel increased the onset temperature of LTO increased but the ignition temperature was barely affected. Therefore, the variation in ignition timing with RON of fuel was attributed to the change in LTO heat release which determines the temperature distribution before the start of combustion. As the heat release rate (HRR) increased the charge temperature reaches its critical value sooner, thus the ignition onset is advanced. A more significant observation was the fact that the addition of higher RON fuel has negligible effect on the ignition of the more reactive fuel which was attested by addition of isopentane whilst keeping the n-pentane amount constant. They also explored the effect of injection timing on combustion rate. As the SOI was advanced from -33 to -40.5 crank angle degrees (CAD) aTDC the LTO profile remained essentially constant, whereas the HRR at the early stage of HTO became smaller causing an increase in burn duration. These results are consistent with those of Sage Kokjohn [4]. In order to delve more onto the effect 
of equivalence ratio and RON on preventing simultaneous ignition of the charge two different fuel blends with the same RON, i.e. n-heptane plus iso-octane as port fuel injected (PFI) and diesel fuel as direct injection (DI), were injected and they observed that the mere stratification of $\varphi$ is not sufficient to control the combustion duration since as the fraction of DI fuel is changed, which contributed to level of stratification of $\varphi$, the burn duration is not affected. In order to examine the effect of RON stratification on combustion duration CFD analysis using KIVA2 code was performed. In their calculation only the more reactive fuel was considered as the high RON fuel has little effect on ignition of low RON fuel. The stratification for low RON fuel caused local heat release during LTO and a wide range of temperature distributions just before the ignition causing a milder combustion process.

It was shown that by stratification of fuel reactivity peak efficiencies could be maintained by moving from net diesel fuel to a 50-50 blend of diesel and gasoline. The notion of fuel blending strategy which provided low emissions and high efficiency (peak indicated thermal efficiency of 53\% from 4 to 14.5 bar indicated mean effective pressure (IMEP) [7]) was called RCCI combustion strategy. However, engine is required to operate over the entire range of speed and load in an LTC regime, if not possible it should switch to other combustion strategies (e.g. CI) depending upon the base engine platform. Unlike other LTC techniques which are limited by compression ratio and reactivity of fuel, RCCI allows the stratification of mixture reactivity by utilizing two fuels.

Recent studies have shown that RCCI combustion strategy is capable of attaining high indicated thermal efficiencies, e.g. 56\% at 9.3 IMEP and 1300rpm, along with near zero NOx and soot emissions over a wide range of loads and speeds. Kokjohn [1] used detailed 
CFD modeling to clarify the results achieved through experiments. These results were also compared to conventional diesel combustion (CDC) and it was shown that NOx and soot emissions are reduced by 3 orders of magnitude and a factor of 6 and the gross indicated efficiency was increased by 16.4 percent. The increase in efficiency was attributed to less heat losses and more control over combustion phasing.

Kokjohn [4] explored the RCCI combustion strategy over a load sweep (4.6-5.9-9.3-11.614.6 IMEPg bar) on a Caterpillar 3401 SCOTE $\left(\mathrm{r}_{\mathrm{c}}=16.1: 1\right)$. A KIVA-3v code coupled with the CHEMKIN II solver were utilized for chemistry calculations. The simulation results were validated against the experimental data and used afterwards to elaborate on trends observed.

They concluded that as the load is decreased from a peak efficiency point, the main reason for the drop in efficiency is the increase in combustion loss, since exhaust loss and heat transfer losses cancel each other out. The same trend holds for the loads past the peak efficiency point since the combustion approaches stoichiometric conditions $(\varphi=$ 0.97 at 14.6 bar) thus, indicating that combustion inefficiency has major role in determining the gross IMEP trend. Therefore, simulations were utilized to comprehend the combustion efficiency trend. For the case of 4.6 IMEP bar UHC and CO are mainly formed near the cylinder liner due to overly lean mixture. In the 9.3 bar case UHC formed near the crevice region is unreacted gasoline and $\mathrm{CO}$ formed in the liner is due to low temperatures caused by heat transfer to the liner. In the last case UHC formation is the same as previous one but $\mathrm{CO}$ is formed both near the liner and crevice volume. Formation of $\mathrm{CO}$ near the cylinder liner is due to rich region $(\varphi=0.97)$. 
Kokjohn [4] performed a comparison between CDC and RCCI combustion strategies. The RCCI 9.3 bar IMEPg and $1300 \mathrm{rpm}$ case was chosen to compare with a CDC engine operating at $1208 \mathrm{rpm}$ and 9.9 bar IMEPg. Since the difference between the speeds was less than $100 \mathrm{rpm}$ its effect has been neglected. Moreover RCCI engine operated under $41 \%$ EGR as compared to not utilizing EGR in the CDC case.

It has been noted from the experiments and simulation that RCCI demonstrates three order of magnitude lower NOx, and soot levels have decreased by a factor of four $(0.012$ compared to $0.076 \mathrm{~g} / \mathrm{kW}$-hr for RCCI and CDC, respectively). Moreover, 16.4 percent higher gross indicated efficiency ( $\sim 8 \%$ more fuel converted to useful work) has been achieved by RCCI. However, an order of magnitude of increase in UHC and CO has been noted, i.e. combustion losses. Furthermore, ringing intensity (RI) has increased roughly four times (3.3 vs. $\left.0.9 \mathrm{MW} / \mathrm{m}^{2}\right)$ which still satisfies the requirement of not exceeding 5 $\mathrm{MW} / \mathrm{m}^{2}$. 


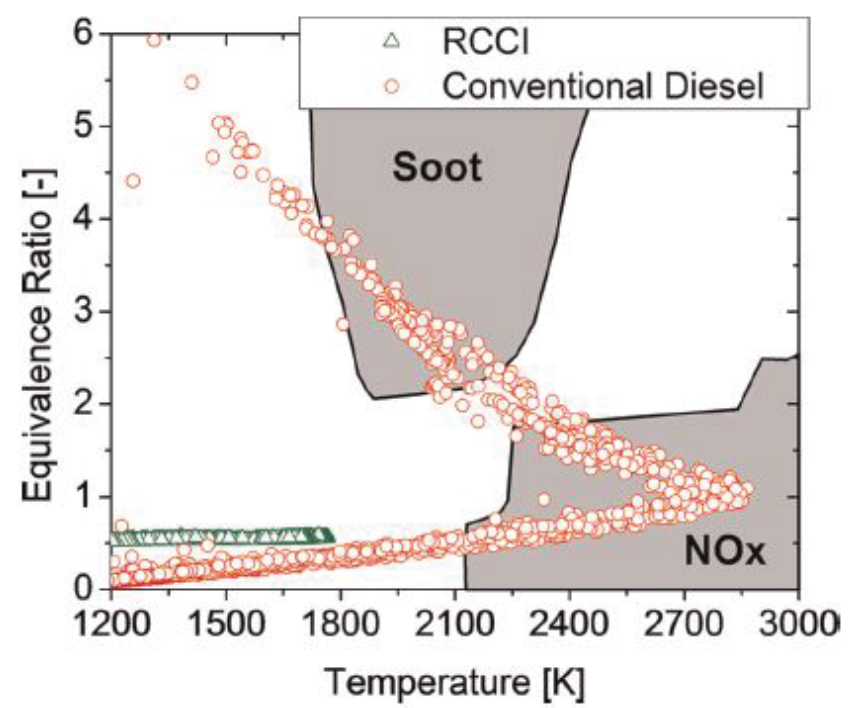

Figure 1-2. $\varphi$ versus temperature for $\mathrm{CD}$ and $\mathrm{RCCl}$ combustion at $5^{\circ}$ aTDC [4]

Figure 1-2 depicts that CDC case has significantly lean high temperature and rich regions producing NOx and soot, respectively as compared to RCCI which has a peak of $\varphi=0.6$ , due to lean operation and dilution (EGR), the flame temperature remains below the NOx formation region. Furthermore it has been discussed that the increase in indicated efficiency is attributed to lack of locally high temperature regions near the piston bowl, thus reduced heat transfer losses (a decrease equivalent to $8 \%$ of the fuel energy) and a more controlled start of combustion (SOC) and end of combustion (EOC). EOC occurs at 16 and $40^{\circ}$ aTDC for RCCI and CDC combustion, respectively. This reduces the late cycle burning which increases the efficiency, implying lower combustion duration, which is in fact the reason for higher RI.

Niemen [7] performed genetic algorithm optimization on a natural gas/diesel RCCI Caterpillar 3401E SCOTE engine geometry (16.1:1 stock compression ratio) over a wide range of loads, speed and intake pressures. Based on the optimum strategies premixed ratio 
is maximum at 13.5 bar (90\%) and as the load increases or decreases, at higher loads due high EGR levels which are utilized to reduce NOx and at lower loads due to lower equivalence ratio $(\approx 0.25)$ a more reactive fuel blend is required to ignite the fuel, thus percentage of Methane decreases (PFI\% of 73\% at 4 bar and $85 \%$ at 23.6 bar). Furthermore, Niemen [7] explored the sensitivity of combustion phenomena to mass split of diesel fuel in the two injection. Two cases, $65 / 35$ and 54/46 mass splits (resulting from moving about $2 \mathrm{mg}$ from the first to the second injection), were considered. Heat release shape was sensitive to the injected mass split, whereas SOC and EOC were relatively unaffected, since the combustion phasing in RCCI is mainly dependent on the global reactivity of fuel blend. In the 65/35 case an abrupt in AHRR was noted, which was the result of high levels of premixing, leading to higher levels of RI and PPRR (1.8 MW/m2 and $4.7 \mathrm{bar} / \mathrm{deg}$, higher, respectively). The 54/46 case had higher residence times at high temperatures leading to slightly higher levels of NOx (0.01 g/ikW-hr). Since the 65/35 case burned the hydrocarbons in squish region it had lower levels of UHC and CO (0.4 and 0.1 g/ikW-hr lower, respectively).

Curran [3] used E85 which provided a higher reactivity gradient, in addition to cooling effect of E85, expanded the operating load of RCCI by reducing the pressure rise rate (which is a function of intake valve closure (IVC) temperature). Curran [3] investigated the effect of E85 on RCCI performance and emissions on a multi-cylinder light-duty diesel engine. Due to significant difference in ethanol lower heating value (LHV) (30 MJ/kg compared to $43 \mathrm{MJ} / \mathrm{kg}$ ) and high heat of vaporization a substantial change in RCCI performance has been noted. It has been shown that due to these factors, premixed ratio is 
lower for the RCCI operation with E85. Moreover SOI is retarded. Both being desirable properties since maximum efficiency is achieved through utilizing lower premixed ratio and retarded SOI, since both make the combustion more stable and less HCCI like. A split injection was utilized to reach 8.8 bar brake mean effective pressure (BMEP) with E85. This modal point was not reachable using unleaded test gasoline (UTG-96) due to high PPRR, thus expanding the load operation of RCCI. It was noted that the break thermal efficiency is $11 \%, 1 \%$ lower for RCCI with gasoline than the one for CDC at 1 and 2 bar BMEP, respectively. At 2.5 bar they are roughly the same and at 4.2 bar it is $2.2 \%$ higher than CDC. RCCI operation with E85 resulted in even lower efficiencies at lower loads but increased it (due to lower premixed ratio) by $8.8 \%$ and $6.9 \%$ at 4.2 bar and 8.8 bar, respectively [3].

In general NOx emissions are reduced for RCCI either with gasoline or E85 (66\% lower than CDC) except for the 1 bar $1500 \mathrm{rpm}$ case where RCCI with E85 demonstrated the highest amount of NOx due to extremely low premixed ratio (20\%) [3]. PM emissions for both RCCI operations were observed to be near zero as measured using filter smoke number (Soot emission index was decreased by $97 \%$ compared to CDC). In contrary, UHC emissions were much higher for RCCI operation with both PFI fuels (UHC was lowered by using E85 compared to gasoline due to lower premixed ratio). Mean UHC emissions in RCCI were 2600 ppm and 3200 ppm for RCCI with E85 and UTG-96, respectively [3]. $\mathrm{CO}$ emissions followed the same trend as UHC emissions. Averaged $\mathrm{CO}$ emissions were 3800 and $3300 \mathrm{ppm}$ for RCCI UTG-96 and E85, respectively [3]. Due to the lower $r_{p}$ of E85, E85 RCCI NOx emissions were higher than UTG-96 RCCI whereas HC and CO 
emissions were lower [3]. Moreover, since alcohol act as radial sinks they retard the auto ignition, thus enabling higher diesel fuel injection, increasing break thermal efficiency at higher loads. However, despite the reduction in NOx emission (by a factor of 2), NOx after treatment is required to meet EPA Tier 2 Bin 5 NOx regulations and DOC is required to reduce $\mathrm{UHC}$ and $\mathrm{CO}[3]$.

\subsection{RCCI Combustion Strategy-Challenges}

Despite its promising notion to achieve near-zero NOx and soot emissions while accomplishing peak-indicted thermal efficiencies as high as 53\%, the RCCI combustion faces several challenges in its operation as listed below:

- Limited operating range: as compared to the CDC counterpart, the RCCI engine faces constraints on its operating range both at high and low loads. At high loads, its operation is constrained by high levels of PPRR and combustion noise. At low load operating region, RCCI combustion loses its merits over its CDC counter-part, as CDC is capable of achieving similar efficiencies and NOx emission while RCCI suffers from higher UHC and $\mathrm{CO}$ emissions [8]. In order to overcome these challenges, mode switching in operation of the RCCI engine has been proposed [8]. Optimal mode-switching operation requires modelling of the dynamics of the operation of the engine which can be utilized in model-based control strategies.

- Combustion phasing control: Combustion phasing has significant effect on engine efficiency. There has been some attempts in combustion phasing control of 
RCCI engine [12]. However, a controller which has the capability to optimize the operation of RCCI engine during its transients is yet to be designed.

- Emission control: Emissions are a significant factor in RCCI engine operation and impose significant constraints on its operation. The necessity to meet the stringent EPA emission standards, requires optimal control of emission which can be achieved through model-based control strategies.

\subsection{Research Scope and Thesis Organization}

According to Department of Energy - Energy, Efficiency and Renewable energy (EERE) it is more convenient to mitigate $\mathrm{CO}$ and $\mathrm{HC}$ emissions from IC engines than NOx and soot. RCCI engines have near zero NOx and soot emissions which along with their high indicated thermal efficiencies (as high as 53\%) represent a promising prospect to resolve the IC engine emissions (even though their UHC and $\mathrm{CO}$ emissions are at higher levels as compared to CDC engines [3]) issues while simultaneously boosting the efficiency [7]. Moreover, as compared to HCCI engines they introduce a direct control knob for controlling the combustion phasing by direct injection of more reactive fuel.

Combustion phasing greatly impacts the thermal efficiency of the engine, therefore its precise control is critical, in terms of attaining the optimal thermal efficiency [4]. Primarily the combustion phasing control in an RCCI engine is achieved via adjustment of premixed ratio since it is the most efficient control knob for tracking a desired CA50. Hence the variations in blending ratio of the fuels changes the reactivity of the charge and therefore in-cylinder temperature which is a major contributing factor in engine out emissions. Ergo, 
in addition to thermal efficiency, proper control of combustion phasing has a significant role in reduction of $\mathrm{NOx}, \mathrm{CO}$, soot and $\mathrm{UHC}$ emissions [9].

In this work, a novel physics-based model was developed to predict the SOC, burn duration (BD) and ultimately combustion phasing, i.e. 50\% mass fraction burned (CA50). This mean value model was parameterized and validated using simulation data from an experimentally validated detailed CFD combustion model developed in KIVA-V3. This is the first study in which a COM for RCCI combustion phasing is developed and subsequently model-based control of RCCI is performed.

The structure of thesis is shown in Figure 1-3. In Chapter 1, a literature review on RCCI engine has been performed, pointing out its merits and de-merits as well as the motivation behind its development. In Chapter 2, a mean-value COM is developed to predict the combustion metrics of an RCCI engine. In the next chapter, Chapter 3, the mean-value COM is extended to encompass the full-cycle operation of the engine. This extended dynamic model is capable of predicting the aforementioned variables during the engine transients which is a necessity for designing a model-based controller. Subsequently an observer-based state feedback controller is designed track a desired CA50 value by using the premixed ratio as a control knob. In the final chapter, Chapter 1, the conclusion are drawn and suggestions for future work are made. 


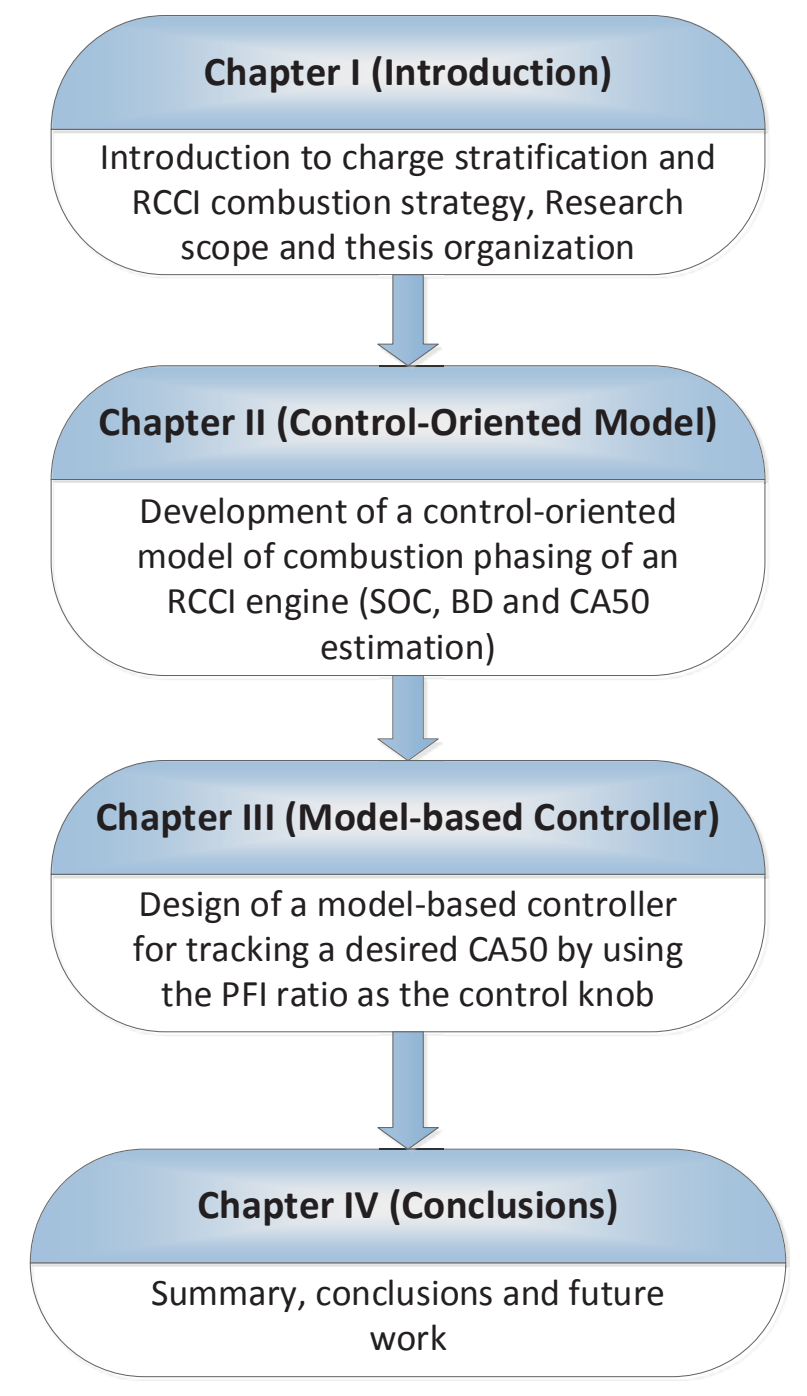

Figure 1-3. Thesis structure. 


\section{Chapter 2}

\section{Control-oriented model of combustion phasing of an $\mathrm{RCCl}$ engine ${ }^{1}$}

Reactivity controlled compression ignition (RCCI) is a promising combustion strategy to achieve near-zero NOx and soot emissions and diesel-like efficiencies. Model-based control of RCCI combustion phasing requires a computationally efficient combustion model that encompasses factors such as, injection timings, fuel blend composition and reactivity. In this work, physics-based models are developed to predict the onset of autoignition in RCCI and to estimate the burn duration (BD) based on an approximation of the spontaneous ignition front speed. A mean value control-oriented model (COM) of RCCI is then developed by combining the auto-ignition model, the BD model, and a Wiebe function to predict combustion phasing. The COM is parameterized and validated using simulation data from an experimentally validated, detailed CFD combustion model using the KIVA$3 \mathrm{~V}$ code. The validation results show that the COM can predict the start of combustion (SOC), BD, and crank angle of 50\% burnt fuel (CA50) with an average error of less than 2 CAD. Thus, the COM demonstrates sufficient accuracy in predicting RCCI combustion phasing for control applications. The COM is an integral part of designing a model-based

\footnotetext{
${ }^{1}$ The results of this chapter are partially based on [10].
} 
controller, which in the case of RCCI is of paramount importance due to various attributes concerning combustion, particularly for transient engine operation.

\section{$2.1 \quad$ Introduction to COM development}

The RCCI combustion strategy is a novel approach that falls in the category of diesel combustion concepts. A dual-fuel engine technology, it utilizes a combination of port fuel injection of a high RON fuel and direct injection of high cetane number $(\mathrm{CN})$ fuel. This strategy, by introduction of a reactivity gradient in the charge via different fuel blends, enables the realization of diesel-like efficiencies, as well as near-zero NOx and soot emissions [12]. Furthermore, by application of in-cylinder blending of gasoline and diesel, the combustion duration is extended, which curbs the peak pressure rise rate. This allows realization of peak-indicated thermal efficiencies as high as 53\% in light duty engines [7]. Hence, RCCI combustion strategy is a promising means for attaining high fuel economy rates, while meeting EPA emission standards [4].

To maintain optimum efficiency during the transient operation of an engine, precise control of the combustion phasing is of paramount importance (with respect to fuel economy and emissions) [13], [14]. The aim of this work is to develop a control-oriented model (COM) that would facilitate designing a model-based controller to accomplish control of RCCI combustion phasing during steady state and transient operating conditions.

Although there is already a plethora of auto-ignition correlations available for diesel combustion concepts, e.g., conventional diesel combustion, homogenous charge compression ignition (HCCI), and partially premixed compression ignition (PCCI), they 
either consider only the physical delay time [15], or are only valid for a specific fuel and do not account for the effect of direct injection [16]. The auto-ignition process in the RCCI combustion strategy is a blend of conventional diesel and HCCI engines. The homogeneous charge created by port fuel injection of high RON fuel resembles the conditions in an HCCI engine whereas the direct injection of high $\mathrm{CN}$ fuel introduces a charge stratification similar to conventional diesel engines [17]. Thus, to develop a COM for RCCI combustion strategy certain characteristics of each of these combustion strategies should be adapted.

The use of detailed thermo-kinetic CFD tools for modelling the combustion in RCCI engines is of great importance for developing an understanding of the combustion process [7]. However, the computational effort required for these detailed combustion models is too expensive, which renders them impractical for designing a controller. COMs are used to predict the combustion timing in a period that is suitable for real-time controller implementation. Hence, a COM must be able to provide predictions of combustion phasing with sufficient accuracy within a minimum computational load [16]. Researchers have proposed various types of models regarding the auto-ignition process in diesel combustion concepts, which vary in complexity. Previous studies conducted in control-oriented modeling of the auto-ignition process in diesel combustion concepts are summarized in Figure 2-1. 


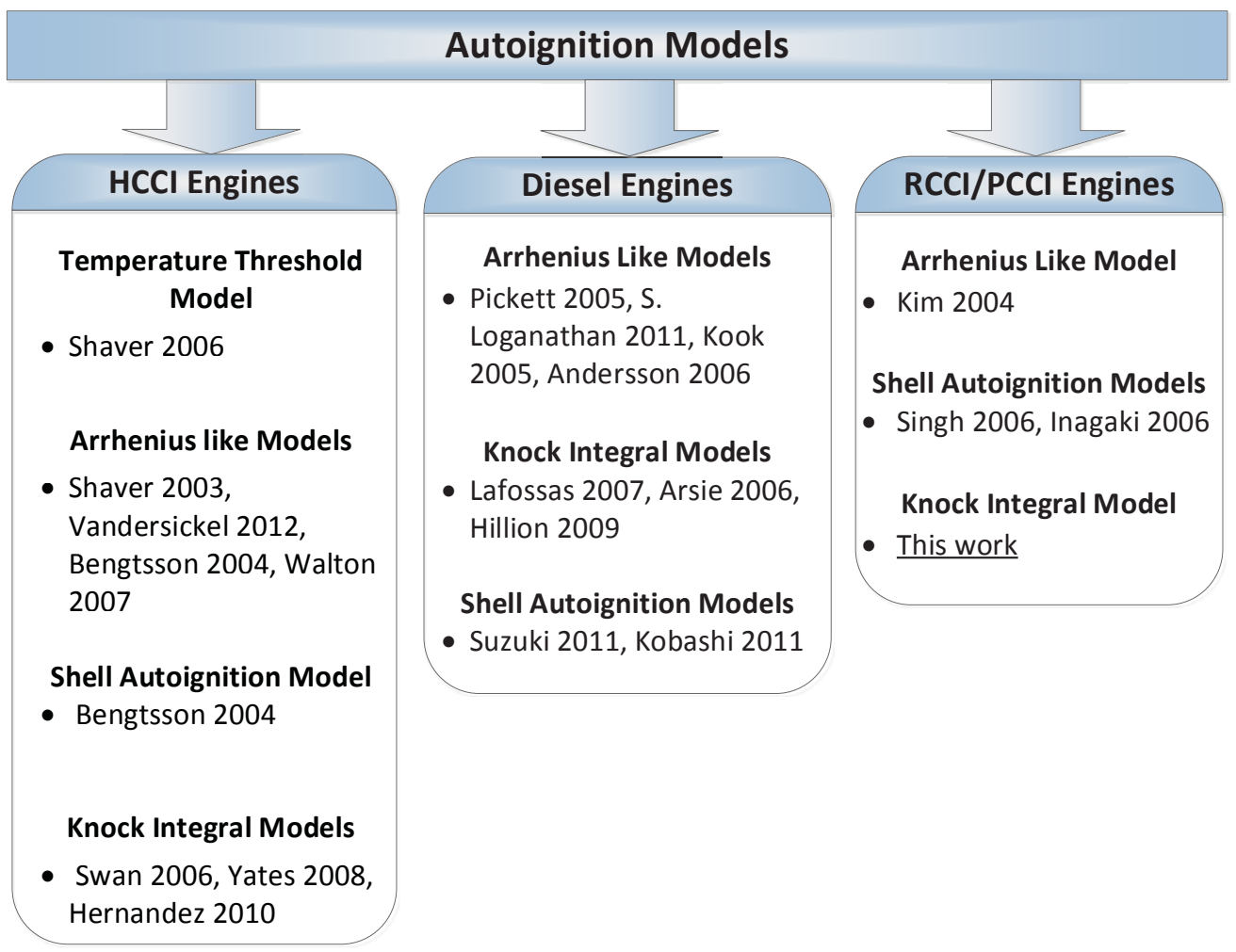

Figure 2-1. Control-oriented auto-ignition models for compression ignition combustion concepts

As Figure 2-1 shows, one simple model to predict auto-ignition is by defining a temperature threshold based on the assumption that ignition happens when the charge within the cylinder reaches a critical temperature. However, this model is not capable of predicting combustion phasing under varying operating conditions because SOC is dependent on not only temperature, but also the oxygen and fuel concentrations [18].

Another category of COMs is Arrhenius-like models. A threshold describing the onset of combustion for HCCI engines was defined by Shaver et al. [19], integrating an Arrheniuslike reaction rate. When this integrated global Arrhenius rate threshold is reached, it marks the SOC. In a similar approach, Vandersickel et al. [20] developed an empirical formula 
for low, intermediate and high temperature reactions at conditions similar to those of inherent in HCCI engines. Arrhenius form-like models can also capture the combustion initiation in DI diesel engines [21-24] as well as PCCI engines [25]. Even though the Arrhenius-like model has been used to estimate the onset of combustion with reasonable accuracy, the major drawback is the requirement of specifying the local in-cylinder oxygen and fuel concentration [26], rendering it impractical in real engine controller design as these measurements are not available for production ECUs. A simplified Arrhenius-based $\mathrm{COM}$, approximating the fuel and oxygen concentrations using equivalence ratio of the charge, would need to be developed that does not directly require knowledge of the incylinder oxygen and fuel concentration [27].

Another set of models for SOC prediction in diesel-like combustion models includes the Shell auto-ignition model. The Shell auto-ignition model was developed by Halstead et al. [28], and has been widely used for SOC estimation in HCCI combustion by researchers including, Bengtsson et al. [29]. Sazhina et al. [30] extended the application of the Shell model to diesel engine combustion. Hamosfakidis and Reitz [31] used a genetic algorithm to determine the set of kinetic parameters for the Shell model for n-heptane and tetradecane reference fuels, which are common in modelling diesel combustion. Kobashi et al. [32] utilized the Shell auto-ignition model to predict SOC of dual-fuel spray diesel engine. They observed that the kinetic parameters in the Shell model are dependent upon the $\mathrm{CN}$ of the fuel blend. Suzuki et al. [33] used the Shell model to consider the effect of negative temperature coefficient and low temperature reactions on prolonging the ignition delay during the premixed portion of the combustion process. However, in the RCCI combustion 
strategy the fuel composition in the charge is heterogeneous, and hence a CFD model is required to take into account the effects of this inhomogeneity ([32] and [33]), thus limiting utilization of the Shell model in developing a COM for RCCI combustion.

Knock Integral Models (KIM) are another approach originally proposed by Livengood et al. [34] to predict knock in an SI engine. The onset of combustion in this model is marked by reaching a critical concentration of species. Shahbakhti [26] used this model to estimate SOC in HCCI combustion and modified the original KIM to improve the model such that it would include the effects of varying air fuel ratios (AFR) and exhaust gas recycling (EGR) rates, and to alleviate the need for in-cylinder measurement of pressure and temperature. Several other researchers (e.g., Vandersickel et al. [20], Yates et al. [35] and Hernandez et al. [36]) made modifications to the original model to include cool flame phenomena and low, intermediate, and high temperature reaction regimes. Hillion et al. [37], Lafossas et al. [38] and Arsie et al. [39] used KIM to predict the SOC in diesel engines. They modified the KIM such that it would also encompass the effect of injection timing.

The KIM is less accurate compared to the shell model for predicting SOC, however the KIM requires less computational effort. The KIM is a non-linear model; thus, it is challenging to use the KIM for developing linear controllers. However, the KIM can be linearized around certain operating points which allows for designing linear controllers [40]. Hence, the KIM with the capability of SOC estimation of both diesel and HCCI combustion is a promising model that could be modified to estimate the SOC in RCCI 
combustion as it provides sufficient accuracy and requires the low computational effort for designing a COM.

In this work, a KIM is adapted such that it accounts for the various attributes of RCCI combustion and is applicable for different engine operating conditions, including variations in fuel blend composition, DI injection timing, and equivalence ratio. Moreover, the adapted model alleviates the need for in-cylinder temperature and pressure measurements to predict SOC. In addition to the SOC estimation, since knowledge of SOC is not sufficient for characterizing the combustion process, BD, and consequently CA50 are also approximated using a physics-based model and a Wiebe function, respectively. CA50 is chosen as the major output of the COM since it is a robust feedback parameter for combustion phasing control [13], [26], [40].

To the best of the authors' knowledge, this is the first study undertaken in developing a mean value COM for the RCCI combustion strategy. The COM from this work can be extended to a dynamic model by incorporating residual gas thermal coupling [41-42]. Moreover, the COM can be augmented by intake charge flow dynamics [43-44], engine rotational dynamics [45], and control actuator dynamics [46] to incorporate the required dynamics for different RCCI control applications.

The structure of the paper is as follows. First, the methodology to develop the model for RCCI combustion is explained. Then the proposed COM is presented along with the assumptions made. Next, engine experimental results are presented along with the KIVA 
code simulation conditions. KIVA simulation data is then used to parameterize the COM. Finally, the model is validated and conclusions are presented.

\subsection{Modelling RCCl combustion}

In this section, a COM is developed for the RCCI combustion strategy. First, by utilizing a modified knock integral model (MKIM), a prediction of SOC is derived. Afterwards, based on an estimation of the spontaneous ignition front speed, a correlation for BD is developed. Eventually, CA50 is approximated using a Wiebe function.

RCCI is a dual-fuel combustion technology that uses in-cylinder fuel blending of two fuels with different reactivities to enable more direct control over combustion phasing than its HCCI counter-part, as shown in Figure 2-2. Due to its inherent complexity, several simplifying assumptions need to be made such that a COM could be designed. The assumptions corresponding to each sub-model (i.e., SOC and BD) are explained in the respective sections. Figure 2-3 depicts the primary concept behind RCCI combustion which has been used in this paper to develop the COM. The contours demonstrate the isoequivalence ratio values that correspond to the $\mathrm{CN}$ values. The more reactive fuel spray, which is injected at the cylinder centerline, penetrates through the charge towards the bowl rim area due its high injection pressure. Hence, in these areas of the charge the mixture becomes more reactive due to presence of higher diesel fuel fractions. Thereafter, the mixture ignites in these areas as a result of high temperatures and pressures within the cylinder during the late compression stroke. The formation of auto-ignition pockets happens in the proximity of the piston bowl rim area where the reactivity of the mixture is at its maximum value [17]. The expansion of reaction zones occurs through a combination 
of different auto-ignition pockets that are formed starting from regions with maximum reactivity and propagating through the less reactive regions after the formation of autoignition pockets in those areas. This way combustion initiates from the piston bowl rim and propagates near the cylinder center liner and at the location of the injector where the reactivity is the lowest. The term staged combustion is used to denote the successive formation of auto-ignition pockets by in-cylinder reactivity gradients that controls the combustion mechanism in an RCCI engine. This is for the case of 50-30 CAD before top dead center (bTDC) start of injection (SOI) timing, typical of RCCI operation, used to attain the desired level of mixing to control the heat release rate. Very early DI injection timings of the order of 140 CAD bTDC cause high levels of mixing and the mixture becomes virtually homogenous [17]. Such homogeneity in the mixture removes the reactivity stratification and leads to similar auto-ignition timings throughout the whole mixture, similar to HCCI combustion. This causes abrupt combustion and an excessive peak heat release rate. In very late injection timings, such as 15 CAD bTDC, the more reactive fuel ignites at the outer edge of the spray cloud and rapidly propagates upstream in the jet due to the similar ignitability of the mixture within the spray cone. This rapid combustion causes high ringing intensities and detrimental peak heat release rates similar to those with very early injection timings [12]. High levels of ringing intensity and peak heat release rate limit the operating conditions of the engine, due to the lack of a controlled heat release rate and combustion phasing. Instead, for successful RCCI operation with a single DI injection, the distribution of charge reactivity is as depicted in Figure 2-3. 


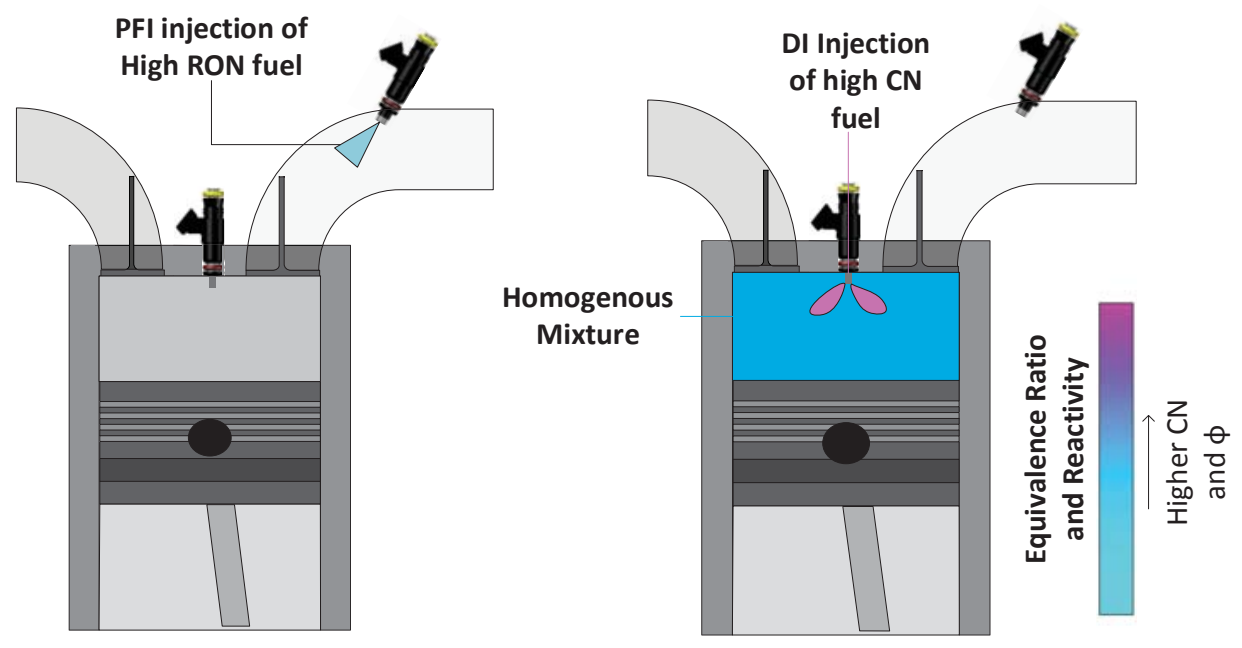

Figure 2-2. Charge preparation in RCCI combustion technology

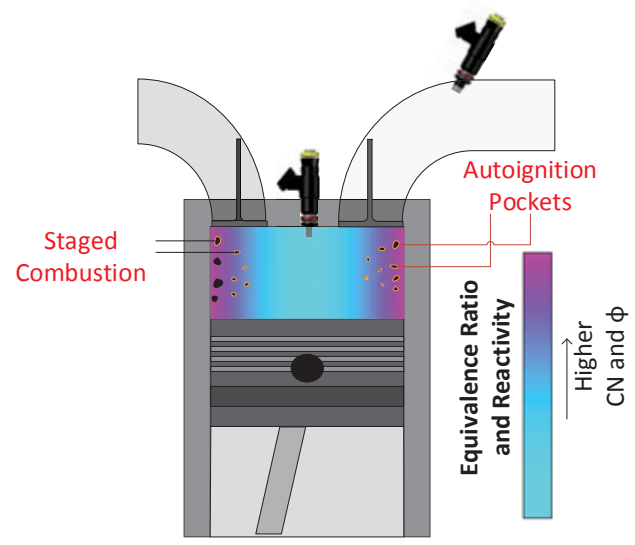

Figure 2-3. RCCI combustion phenomenological model (Formation of auto-ignition pockets and staged ignition).

\subsubsection{SOC estimation model}

Because the RCCI combustion strategy falls in the category of chemically modulated combustions [17], a modified version of the KIM developed by Livengood et al. [34] is utilized to predict the ignition delay, which is defined as the time period between SOI of diesel fuel and CA10. 
Livengood et al. [34] developed a KIM to predict knock in an SI engine. Based on tests on different fuels in a rapid compression machine (RCM), an empirical correlation for predicting the ignition delay for different fuels was proposed. The general form of the ignition delay under different end of compression temperatures and pressures is in the form:

$$
\tau=A e^{\left(-\frac{b}{T}\right) P^{n}}
$$

in which, $T$ is temperature $(\mathrm{K}), P$ is the charge pressure $(\mathrm{kPa})$, and $A, b$ and $n$ are empirical constants used to fit the correlation for each engine.

However, Livengood et al. [34] suggested that to interpret real engine condition behavior in terms of a rapid compression machine, it is necessary to develop a correlation to account for time varying conditions in the engine. They argued that reaction time is the sum of fractional ignition delays corresponding to different states under which the engine is operating. Moreover, they stated that a shift into a high reaction rate defines the concept of a critical concentration value. The onset of combustion is marked by reaching this critical concentration of species. This also implies that the critical concentration is a constant value under varying engine-operating conditions. They assumed that there is a functional relationship between the concentration ratio, $\left(\frac{x}{x_{c}}\right)$, and the relative time, $\left(\frac{t}{\tau}\right)$. The following formula was used to adapt the ignition delay derived from an RCM for varying engine conditions:

$$
\frac{x}{x_{c}}=\int_{I V C}^{S O C} \frac{1}{w \tau} d \theta=\int_{I V C}^{S O C} \frac{1}{A w e^{\left(\frac{b}{T}\right) P^{n}}} d \theta
$$


where $x_{c}$ is the concentration of species at SOC, $w$ is engine speed in (rpm), pressure is in kilopascals $(\mathrm{kPa})$ and temperature is in Kelvin $(\mathrm{K}) . I V C$ is intake valve closure and $S O C$ is start of combustion crank angle. As the point of auto-ignition is approached, the integral increases, as shown graphically in Figure 2-4.

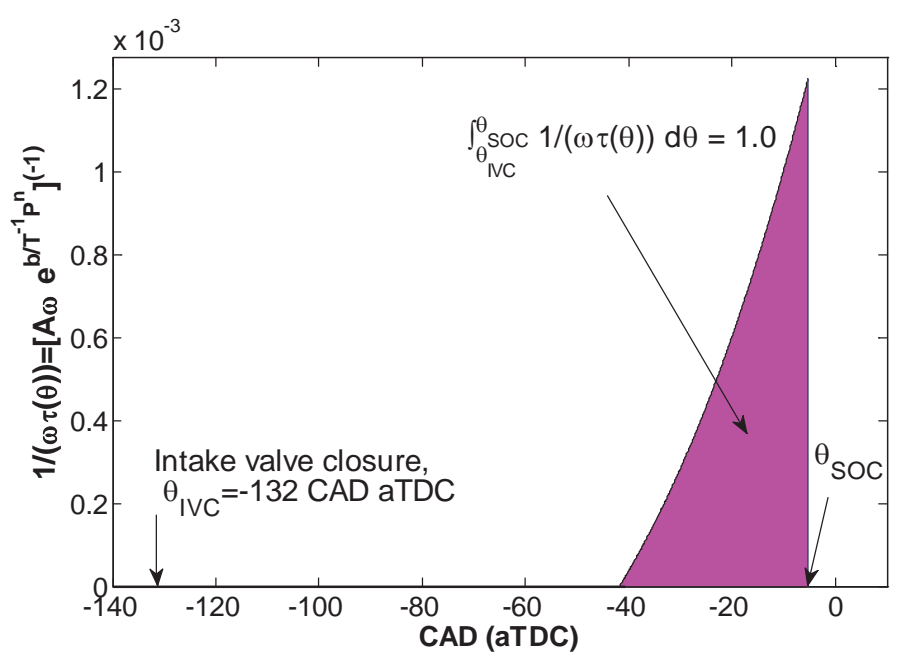

Figure 2-4. Graphical integration of $\frac{1}{w \tau}$ from IVC to SOC

The onset of combustion in an RCCI engine is marked by auto-ignition of the charge in the cylinder that is of the same mechanism as knock in an SI engine. Hence, the KIM developed by Livengood et al. [34] is enhanced to encompass all parameters affecting the autoignition process in RCCI combustion. The SOC in RCCI is dependent upon the states of the charge at intake valve closure [13], as well as the injection timing and in-cylinder mixture composition, i.e. equivalence ratio, premixed ratio, and EGR [47].

The following modifications are made to the KIM for it to become applicable in RCCI combustion: 
- Polytropic compression: Measurement of in-cylinder pressure and temperature as a function of crank angle during the normal operation of the engine is not practical. However, these measurements are necessary for the prediction of ignition delay. To circumvent the measurement of pressure and temperature, it is assumed that the charge within the cylinder undergoes a polytropic compression from IVC until SOC [26].

In order to calculate the polytropic constant, $k_{c}$, one method is to use the NASA polynomials [48] knowing the charge composition and conditions at IVC. However, this method requires extraneous calculations based on the charge composition and in-cylinder temperatures [48]. A more practical approach is used in this study. An optimization method is designed to find $k_{c}$ based on the KIVA simulation data. A polytropic relation is fitted to relate the KIVA simulated gas pressure at IVC, i.e. $P_{I V C}$, to the pressure at SOC, i.e. $P_{S O C}$.

Using the polytropic correlation, the in-cylinder temperatures and pressures are estimated by:

$$
T=T_{I V C} v^{k_{C}-1}
$$

and

$$
P=P_{I V C} v^{k_{c}}
$$

where 


$$
v=\frac{V_{I V C}}{V(\theta)}
$$

$T_{I V C}$ is temperature at IVC, $V_{I V C}$ is cylinder volume at IVC and $V$ is the cylinder volume at crank angle $\theta$.

- Fuel concentration: In-cylinder fuel concentration has a significant impact on RCCI combustion timing [13], [17]. Ideally, the in-cylinder fuel and oxygen concentration could be used in an MKIM. However, measurement of these concentrations in a real engine is impractical (but can be approximated using the equivalence ratio of the charge [27]). Fuel equivalence ratios, either gasoline or diesel, are an indication of the fuel concentration [26]. Equivalence ratio measurement is possible via a wide band exhaust gas oxygen (EGO) sensor in production engines. Hence, the equivalence ratio is used to account for the effect of fuel concentration on combustion timing.

- Premixed ratio: At each load the ratio of high $\mathrm{RON}$ fuel to the total fuel injected, i.e., the premixed ratio, is a major contributing factor in determining the SOC in RCCI combustion [6], [17], [49]. As this ratio varies, the reactivity of the fuel blend changes, introducing an extra control knob for combustion phasing. This effect embodies itself in the auto-ignition correlation in the form of change in the local $\mathrm{CN}$ of the fuel. In turn, the activation energy of the fuel is a function of its $\mathrm{CN}$ [15], [32]. Hence, the relation between the activation energy of fuel blend and its $\mathrm{CN}$, which is a function of the equivalence ratio of the two fuels, is integrated into the 
KIM to account for the variation in reactivity of the charge by changing the premixed ratio of the charge.

- DI injection timing: One of the main advantages of RCCI as a dual-fuel engine over HCCI is the additional control knob for combustion phasing control [4]. Contrary to an HCCI engine in which, after the closure of intake valve, there is no control knob for combustion phasing, direct injection of a more reactive fuel provides a convenient approach for proper timing of combustion. To this end, the MKIM integration is segregated into two parts (see Equation (2.6)). The first section is similar to the MKIM developed by Shahbakhti [26] because RCCI operation is identical to HCCI from IVC to SOI. The second integration is carried out from DI SOI to SOC, which represents the introduction of the more reactive fuel.

Adaptation of the KIM into the MKIM is as follows: the integration of auto-ignition delays at each crank angle is segregated into two sections, as discussed previously:

$$
\begin{aligned}
\int_{S O I}^{S O C} \frac{d \theta}{A_{2} N\left(\varphi_{D I}^{B_{2 D I}}+\varphi_{P F I} B_{2 P F I}\right) \exp \left(\frac{C_{2}\left(P_{I V C} v_{c}^{k_{c}}\right)^{D_{2}}}{T_{I V C} v_{c}^{k_{c}-1}}\right)}=1 \\
-\int_{I V C}^{S O I} \frac{d \theta}{A_{1} N \varphi_{P F I}^{B} \exp \left(\frac{C_{1}\left(P_{I V C} v_{c}^{k_{c}}\right)^{D_{1}}}{T_{I V C} v_{c}^{k_{c}-1}}\right)}
\end{aligned}
$$

$\varphi_{D I}$ and $\varphi_{P F I}$ are the global values of charge equivalence ratio of both fuels, which are defined as: 


$$
\varphi_{x}=\left(\frac{m_{x}}{m_{E G R}+m_{\text {air }}}\right) /\left(\frac{m_{x}}{m_{\text {air }}}\right)_{s t}
$$

where $m$ is mass $(\mathrm{kg})$ and the subscript $x$ indicates either iso-octane or n-heptane. EGR fraction was calculated using measurements from the $\mathrm{O}_{2}$ sensors in the intake and exhaust manifolds. The following equation was used:

$$
\% E G R=\frac{20.97-(\% O 2)_{\text {exhaust }}}{20.97-(\% O 2)_{\text {intake }}} * 100 \%
$$

The intake charge mass flow rate is measured using a Laminar Flow Element (LFE). Knowing the EGR fraction and intake mass flow rate the EGR mass was calculated.

An average value for the equivalence ratio of diesel fuel is assumed, which is consistent with the definition used by Inagaki et al. [6] and the methodology used by Andersson et al. [23]. Andersson et al. [23] stated that as the fuel concentration is varying with time and location in spray, it could not be calculated exactly. Thus, a mean value for equivalence ratio in the spray cloud that is undergoing pre-reactions was assumed.

The introduction of DI fuel has another role of creating a reactivity gradient, which distinguishes the RCCI combustion strategy [4]. The reactivity of the fuel is quantified with its $\mathrm{CN}$ [32]. The $\mathrm{CN}$ of a fuel blend is a function of its composition, which can be modelled as the ratio of [equivalence ratios of the two fuels.

$$
C N_{\text {mix }}=\frac{\left(F A R_{s t, h e p} \varphi_{D I} C N_{\text {nhep }}+F A R_{s t, i s o} \varphi_{P F I} C N_{i s o}\right)}{\left(F A R_{s t, h e p} \varphi_{D I}+F A R_{s t, i s o} \varphi_{P F I}\right)}
$$


where $F A R$ is fuel-to-air ratio, $C N$ is the cetane number, mix indicates the mixture of nheptane and iso-octane fuels, st designates stoichiometric, iso is iso-octane, nhep is nheptane, DI designates direct injection and PFI port fuel injection. The constants $C_{1}$ and $C_{2}$ can be interpreted as the activation energy of the fuel blend divided by the universal gas constant, and the activation energy of fuel is dependent upon its $\mathrm{CN}$ [15], [32], [47]. The activation energy $\left(\frac{\mathrm{J}}{\text { mole }}\right)$ of fuel can be estimated in terms of its $\mathrm{CN}$ using:

$$
E_{a}=\frac{a}{C N+b}
$$

Thus the value for $C_{2}$ can be replaced by the activation energy of the fuel. It must be noted that the universal gas constant is integrated into the constant " $a$ " in the numerator of Equation (2.10). The resulting equation is:

$$
\begin{aligned}
& \int_{S O I}^{S O C} \frac{d \theta}{N \underbrace{A_{2}\left(\varphi_{D I}^{B_{2 D I}}+\varphi_{P F I} B_{2 P F I}\right) \exp \left(\frac{a}{\left(C N_{\text {mix }}+b\right)} \frac{\left(P_{I V C} v_{c}^{k_{c}}\right)^{D_{2}}}{T_{I V C} v_{c}^{k_{c}-1}}\right)}_{\tau}}=1 \\
& -\int_{I V C}^{S O I} \frac{d \theta}{A_{1} N \varphi_{P F I}^{B_{1}} \exp \left(\frac{C_{1}\left(P_{I V C} v_{c}^{k_{c}}\right)^{D_{1}}}{T_{I V C} v_{C}^{k_{c}-1}}\right)}
\end{aligned}
$$

where $A_{1}, B_{1}, C_{1}, D_{1}, A_{2}, B_{2 D I}, B_{2 P F I}, a, b, D_{2}$ are constant parameters which are to be determined such that the MKIM can be used to predict the SOC. The SOC is marked by CAD at which the value of the integral reaches unity. The denominator of the integral term on the left hand side of Equation (2.11) is the instantaneous ignition delay $(\tau)$ in sec. The equivalence ratios outside the exponential term in the denominator of the integrands 
represent the fuel concentration, whereas those in the exponential terms are the determining factors of the $\mathrm{CN}$ of the fuel.

To develop this model, an inherent assumption is made that the DI fuel instantaneously mixes with the charge and neglects the physical delay that arises from the time required for the fuel to mix with the charge. This assumption is made because RCCI involves premixed combustion of a lean mixture and the combustion process is dominated by chemical kinetics rather than physical processes, such as air entrainment and mixing [6].

\subsubsection{Control oriented modelling of combustion duration}

Combustion in an RCCI engine is triggered by the diesel fuel injected directly into the cylinder through the introduction of a more reactive fuel. Flame propagation does not play a dominant role in RCCI combustion since the charge within the cylinder is below the limit of a flame sustainment regime, i.e., it is too lean during most operation modes of engine, except for the high load operating regime of the engine in which the mixture is capable of sustaining propagating flames [17]. However, even in these cases, the role of flame propagation is not dominant and ignoring its role does not introduce a substantial error in predicting the apparent heat release rate [17]. The introduction of the more reactive fuel causes a stratification of the reactivity in the charge. This gradient in reactivity causes sequential auto-ignition of the mixture from multiple auto-ignition points at unknown

locations, creating spontaneous ignition fronts that are the primary mechanism of combustion in the RCCI combustion strategy, as previously depicted in Figure 2-3. 
Since the main combustion mechanism in RCCI is the formation and propagation of ignition pockets in the charge [17], spontaneous ignition front speed $\left(S_{i g}\right)$ is used to find BD. The $S_{i g}$ was correlated with BD as:

$$
B D=K_{2} \times\left(S_{i g}\right)^{t}
$$

where $K_{2}$ and $t$ are fitting parameters which are to be determined so that this model could be used to predict $\mathrm{BD}$.

Spontaneous ignition front speed. The mere determination of SOC is not sufficient for developing a COM of an RCCI engine. The heat release rate and combustion phasing are prominent factors in determining the operating limits of the engine. By widening the span of gradients of equivalence ratio and reactivity, the peak heat release rate can be reduced [12]. This reduces the ringing intensity; thus, expanding the operating limits of the engine [7], [49].

The combustion process in RCCI is similar to HCCI to some extent, both being flameless [43] (due to the highly lean charge that is incapable of sustaining a flame) [17] and luminous flames were not observed in shadowgraph combustion analysis results [50]. The primary combustion mechanism in RCCI is spontaneous ignition front, which results from the presence of a reactivity gradient. Due to the reactivity gradient of the charge within the cylinder, the ignition delay of the charge is not homogenous, causing the formation of a spontaneous ignition front. The dominant factors in stratification of reactivity are gradients in the equivalence ratio and the $\mathrm{CN}$ of the fuel blend [17]. 
Assuming that the port fuel injected gasoline is perfectly mixed with the charge and is homogenous, the stratification of equivalence ratio is tantamount to the $\mathrm{CN}$ of the fuel blend [17], since both are caused by the inhomogeneity of the diesel fuel distribution in the mixture, i.e., the mixture $\mathrm{CN}$ stratification is caused by the inhomogeneity of premixed ratio in the charge. Chen et al. [51] proposed Equation (13) for correlating a subsonic spontaneous ignition front speed as a function of gradients in ignition delay. This speed is used in the present phenomenological model (see Figure 2-3) to determine the BD:

$$
S_{i g}=\frac{1}{|\nabla \tau|}
$$

where $S_{i g}$ is spontaneous ignition front speed $\left(\mathrm{sec}^{-1}\right)$ and $\tau$ is the ignition delay (sec). The gradient of ignition delay of the mixture is not only dependent on the initial state, but also on the amount of compression heating it receives during the combustion process. The amount of compression heating, in turn, is dependent upon the initial distribution of the mixture conditions [51].

The primary factor determining the $\mathrm{BD}$, i.e., the main combustion mechanism, is the spontaneous ignition front speed. This speed is determined by the gradient in ignition delay (Equation (13)) that is caused primarily by the stratification of equivalence ratio, and the following formula is proposed for estimation of the ignition front speed in an RCCI engine:

$$
S_{i g}=\frac{1}{\left|\frac{d \tau}{d \varphi_{S O C}}\right|\left|\nabla \varphi_{S O C}\right|}
$$


in which the ignition delay $(\tau)$ is estimated using the previously parameterized correlation developed to predict SOC, i.e., the denominator of the integral on the left side of Equation (11). A corrected temperature and pressure for the duration of combustion is assumed in estimating the ignition delay of the mixture, calculated using:

$$
\Delta T=\frac{Q_{L H V, n h e p} F A R_{s t, n h e p} \varphi_{\text {nhep }}+Q_{L H V, \text { iso }} F A R_{s t, i s o} \varphi_{\text {iso }}}{c_{v}\left(F A R_{s t, n h e p} \varphi_{\text {nhep }}+F A R_{s t, i s o} \varphi_{\text {iso }}+1\right)}
$$

The value of $\Delta T$ corresponds to a temperature rise corresponding to complete combustion. $Q_{L H V, n h e p}$ and $Q_{L H V, i s o}$ are the lower heating values of n-heptane and iso-octane, respectively. The corrected temperature $\left(T_{c}\right)$ during combustion is calculated as:

$$
T_{c}=T_{\text {soc }}+e_{1} \Delta T
$$

The parameter $e_{1}$ accounts for the heat losses during the combustion as well as any compression heating or expansion cooling. $e_{1}$ is assumed to be a function of the crank angle at which combustion commences. The earlier the combustion starts, the lower the average temperature and pressure during the combustion will be, thus prolonging the combustion duration [43]. A longer combustion duration increases the heat losses, and hence $e_{1}$ drops. The correlation between $e_{1}$ and $\theta_{s o c}$ is assumed to follow a second degree polynomial [43]:

$$
e_{1}=a_{0}+a_{1} \theta_{s o c}+a_{2} \theta_{s o c}^{2}
$$

where $\theta_{s o c}$ is the crank angle at which the combustion commences. Similarly, the corrected pressure $\left(P_{c}\right)$ is calculated as follows: 


$$
P_{c}=P_{S O C}+e_{2} \Delta T
$$

and

$$
e_{2}=b_{0}+b_{1} \theta_{s o c}+b_{2} \theta_{s o c}^{2}
$$

The values of $e_{1}$ and $e_{2}$ are calculated using an optimization method to yield the best fit for predicting the $\mathrm{BD}$.

Assumptions are also made to quantify the gradient of the equivalence ratio in the charge:

The gradient of equivalence ratio is constant with respect to radial distance from the centerline of cylinder, i.e., the point of injection. The maximum value of diesel equivalence ratio is observed near the cylinder liner and its value drops at a constant rate with the radial distance from the cylinder center line [17]. This assumption yields a one-dimensional distribution of equivalence ratio throughout the mixture.

The maximum value for the equivalence ratio is estimated using the fact that the degree of mixing of the diesel fuel is dependent on the ignition delay. Since SOC has already been estimated using Equation (11), the apparent ignition delay (ID) in CAD is calculated using:

$$
I D=S O I-S O C
$$

Knowing the ID, the maximum value of the equivalence ratio of diesel that corresponds to the maximum value of equivalence ratio within the mixture is estimated by: 
$\varphi_{D I, \max }=\frac{K_{1}}{I D^{p}} \varphi_{D I}^{r}$

where $r$ is an empirical constant used to parameterize the correlation for each engine. The

derivative of ignition delay with respect to equivalence ratio, i.e., $\frac{d \tau}{d \varphi_{S O C}}$, is only due to linear spatial distribution of the diesel fuel [17]. Kokjohn [17] observed the linear distribution of equivalence ratio of diesel in CFD simulations. The mixture is most reactive near the cylinder liner and its equivalence ratio drops moving toward the centerline, where the equivalence ratio of diesel is virtually zero. Hence, the gradient in equivalence ratio $\left(\nabla \varphi_{S O C}\right)$ is calculated as follows:

$$
\left|\nabla \varphi_{S O C}\right|=\left(\varphi_{D I, \max }+\varphi_{i s o}\right)-\varphi_{i s o}=\varphi_{D I, \max }=\frac{K_{1}}{I D^{p}} \varphi_{D I}^{r}
$$

\subsubsection{CA50 estimation model}

Knowing the $\mathrm{BD}$ and $\mathrm{SOC}, \mathrm{CA} 50$ is estimated by using a Wiebe function:

$$
x_{b}(\theta)=1-\exp \left(-a\left[\frac{\theta-\theta_{\text {soc }}}{B D}\right]^{m+1}\right)
$$

where, $x_{b}$ is the mass fraction burned and $\theta_{\text {soc }}$ is the SOC crank angle. Here, SOC is defined as CA10 and BD is defined as the crank angle difference between SOC and CA90. Using these definitions, the parameter $a$ was calculated by solving the Wiebe function for CA90: 


$$
\begin{gathered}
0.9=1-\exp \left(-a\left[\frac{C A 90-C A 10}{B D}\right]^{m+1}\right) \rightarrow a=-\ln (1-0.9) \\
=2.303
\end{gathered}
$$

\subsection{RCCl Engine Data}

The RCCI experimental setup in this study is the same as [11-13-14]. Therefore, only a brief description is presented here. A General Motors 1.9-liter Z19DTH 4-cylinder engine was used to perform the RCCI engine experiments, and the engine specifications are listed in Table 2-1. The engine is equipped with a variable geometry turbine (VGT), cooled EGR, and variable swirl intake port geometry. The intake manifold was modified to facilitate the port fuel injection required for RCCI operation. Furthermore, the OEM production engine control unit (ECU) was replaced by a Drivven control system to enable control over the additional port fuel injectors. In addition, the engine piston was modified to obtain a compression ratio of 16.7 .

Table 2-1. Engine Specifications

\begin{tabular}{cc}
\hline Engine Type & GM Z19DTH \\
\hline Bore $\times$ Stroke (mm) & $82 \times 90.4$ \\
Displacement Volume (L) & 1.9 \\
Squish Height (mm) & 0.617 \\
Connecting Rod Length (mm) & 145.54 \\
Compression ratio (-) & 16.7 \\
Swirl Ratio & $1.5-3.2$ \\
& Bosch CRIP2-MI, \\
\hline Common Rail Injectors & $155^{\circ}$ Included angle, 7 holes, 0.141 mm hole diameter, \\
& 440 flow number, 50 MPa fuel pressure \\
Port Fuel Injectors & Delphi, 2.27 g/s steady flow, \\
& 340 kPa fuel pressure \\
\hline
\end{tabular}


The engine operating conditions, including engine speed, equivalence ratio, injection timings, EGR rates, valve timing, intake pressure and temperature for two experiments are shown in Table 2-2. The conditions of these two experiments are representative of RCCI operation at low loads.

Table 2-2. Engine operating conditions

\begin{tabular}{ccc}
\hline Engine Variables & Experiment I & Experiment II \\
\hline Diesel Injection Quantity (mg) & 3.5 & 2.5 \\
\hline Gasoline Injection Quantity (mg) & 2.6 & 6.3 \\
\hline Engine Speed (rpm) & 1500 & 1500 \\
\hline Intake Manifold Temperature (K) & 348.65 & 356.65 \\
\hline Intake Manifold Pressure (bar) & 1.006 & 1.021 \\
\hline Diesel Equivalence Ratio (-) & 0.19 & 0.38 \\
\hline Gasoline Equivalence Ratio (-) & 0.25 & 0.15 \\
\hline EGR (\%) & 49.9 & 44.9 \\
\hline BMEP (bar) & 1 & 2.6 \\
IVC ( ${ }^{\circ}$ aTDC) & -132 & -132 \\
IVO ( ${ }^{\circ}$ aTDC) & 344 & 344 \\
EVO ( ${ }^{\circ}$ aTDC) & 112 & 112 \\
EVC ( ${ }^{\circ}$ aTDC) & 376 & 376 \\
\hline
\end{tabular}

A KIVA computational model was developed and validated against the experimental data. It was used as a virtual RCCI engine in this study. To validate the KIVA model, the pressure trace and HRR of the two experiments (Table 2-2) are used. The simulated and experimental pressure trace and HRR are depicted in Figure 2-5 and Figure 2-6. 


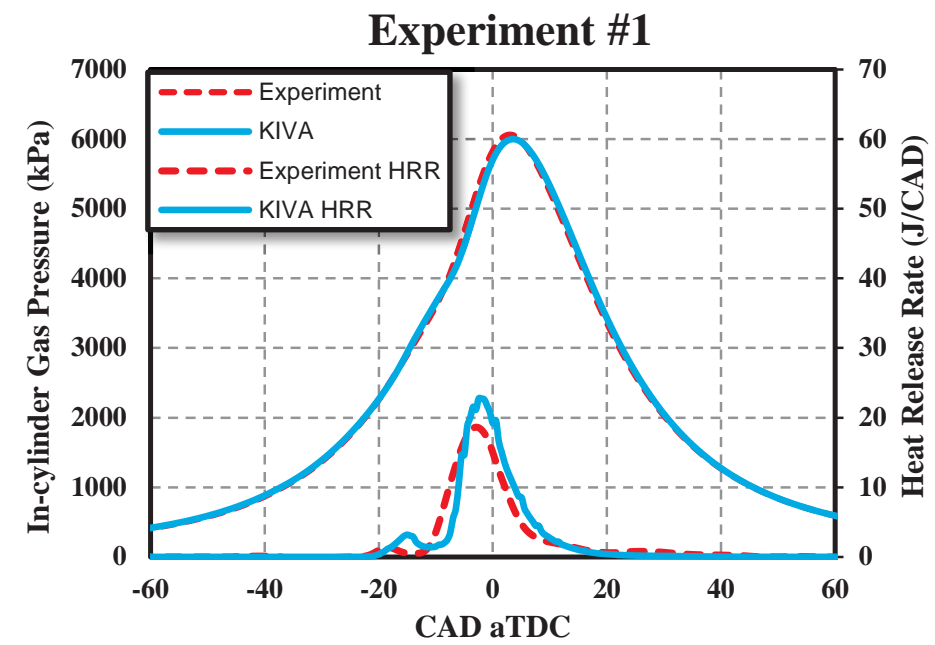

Figure 2-5. KIVA simulation and experimental results for 1 bar BMEP experiment. The data to generate this figure is taken from [10-11].

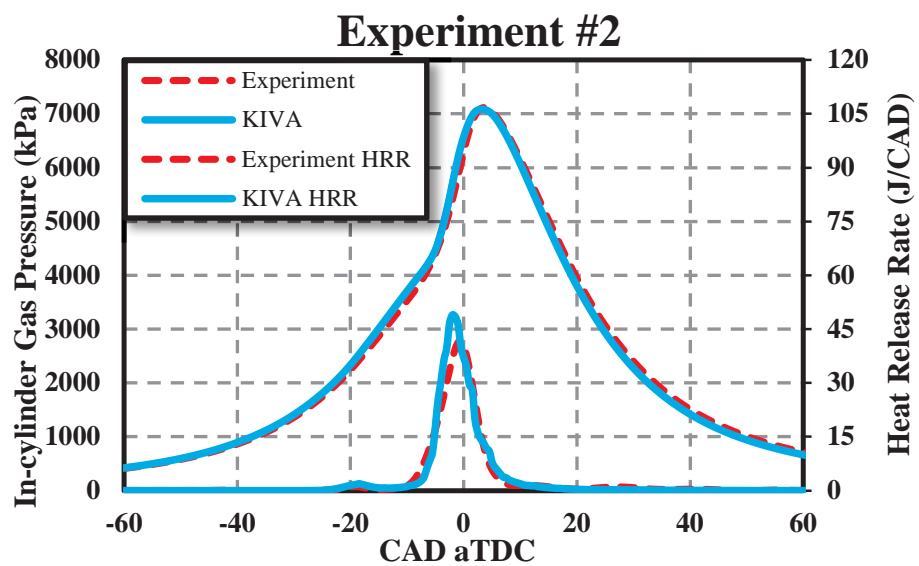

Figure 2-6. KIVA simulation and experimental results for 2.6 bar BMEP experiment. The data to generate this figure is taken from [10-11].

Of significant importance in this study is the accuracy of the KIVA model in the prediction of combustion phasing, i.e. CA10, and CA50, as this computational model will be used to parameterize the COM. A comparison of the KIVA predictions against the experimental 
values is given in Table 2-3. As can be seen, the agreement is within 2 CAD, which is adequate for the present study.

Table 2-3. Combustion parameters; KIVA predictions vs. experimental results

\begin{tabular}{ccc}
\hline Combustion Parameters & SOC (CAD aTDC) & CA50 (CAD aTDC) \\
Experiment (\#1) & -8.0 & -2 \\
Simulation (\#1) & -7.3 & -1.4 \\
Experiment (\#2) & -5.6 & -0.9 \\
Simulation (\#2) & -5.3 & -1.4 \\
\hline
\end{tabular}

The validated KIVA model was also used to perform RCCI combustion simulations over a range of operating conditions, as summarized in Table 2-4. These simulations were used to parameterize the RCCI control model in this study.

Table 2-4. KIVA simulation parameter variations

\begin{tabular}{r|c}
\hline$T_{I V C}(\mathrm{~K})$ & $376-420$ \\
$P_{I V C}(\mathrm{kPa})$ & $117-145$ \\
$E G R(\%)$ & 44.9 and 49.9 \\
$\varphi_{D I}(-)$ & $0.12-0.22$ \\
$\varphi_{P F I}(-)$ & $0.20-0.38$ \\
$S O I(C A D$ aTDC) & -40 and -42 \\
\hline
\end{tabular}




\section{$2.4 \quad$ Results and Discussion}

\subsubsection{Polytropic compression constant}

KIVA simulation data for 69 engine operating conditions (see Table 2-4) were used to derive an average value of $k_{c}$ under these conditions (The KIVA simulation data in this thesis are courtesy of Anand Nageswaran Bharath [11]). Here, $k_{c}$ represents the best numerical fit. The results of the numerical fit are shown in Figure 2-7.

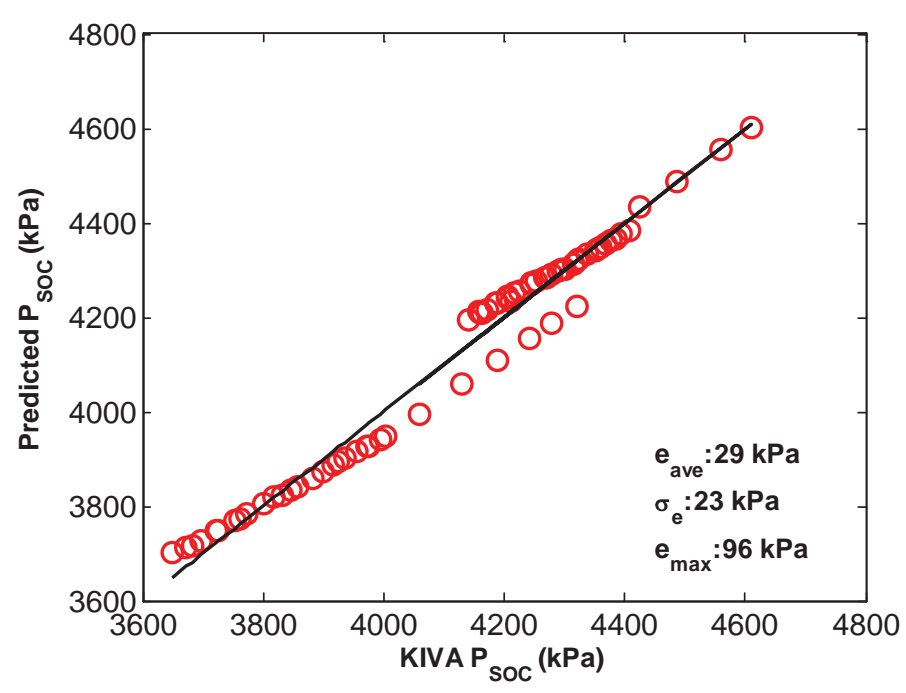

Figure 2-7. Estimated SOC pressures vs. SOC pressures from KIVA simulations using the best numerical fit of $k_{c}=1.35$. $e_{\text {ave }}, \sigma_{\text {ave }}, e_{\max }$ indicate average error, standard deviation of error and maximum error, respectively.

The solid line in Figure 2-7 represents the cases for which the predicted SOC pressures and KIVA simulation results are equal to each other.

It can be inferred from Figure 2-7 that the polytropic model with $k_{c}=1.35$ yields a sufficiently accurate estimation of the SOC pressure as the maximum error $\left(e_{\max }\right)$ in its 
estimation is less than $96 \mathrm{kPa}$ and the mean error $\left(e_{\text {ave }}\right)$ is merely $29 \mathrm{kPa}$. Please note $k_{c}=1.35$ has been calibrated for the RCCI engine in this study and $k_{c}$ value can vary from one engine to another.

\subsubsection{Parameterizing MKIM}

Combustion commences when the integral term in Equation (2.11) reaches unity. Thus to parameterize the model, the error of integration should be minimized when the integral is equal to unity. The Nelder-Mead method [52], which is a numerical optimization method, is used to derive the parameters of the MKIM. A rectangular discretization method is used to compute the integral numerically with a step size of 0.1 crank angle degree. Given a starting point for the optimization algorithm, i.e., minimization of the error of the integral, a program is developed in MATLAB to compute the local optima yielding the parameters of MKIM. The parameterized MKIM is then used to find SOC.

Thirty-five out of the 69 KIVA simulation data points were used to find the MKIM parameters. Then, the MKIM was validated against all 69 data points. The results are shown in Figure 2-8. 


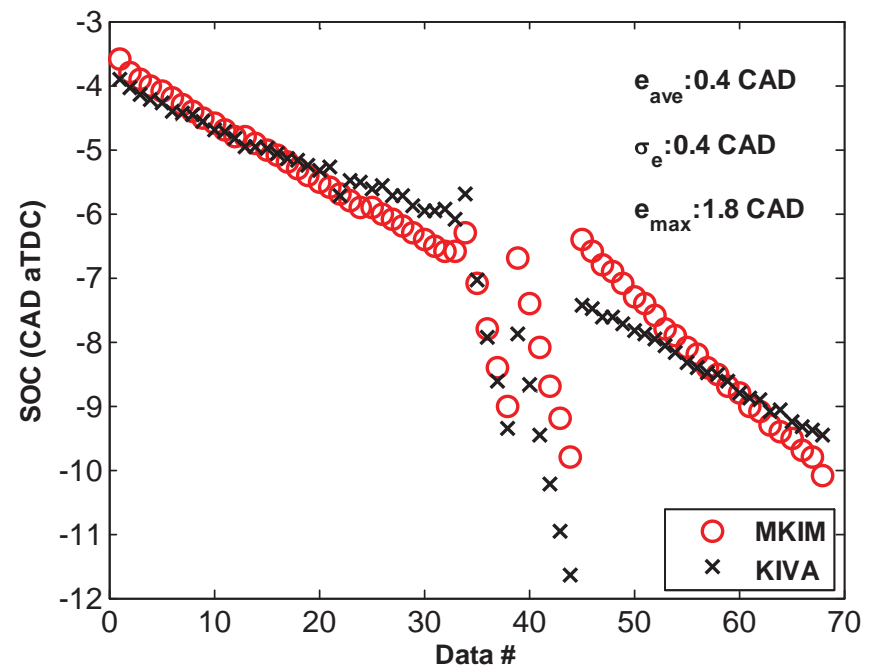

Figure 2-8. MKIM SOC prediction and KIVA simulation Data

As can be seen, the MKIM depicts sufficient accuracy in predicting SOC as the average, standard deviation and maximum estimation errors are $0.4,0.4$ and $1.8 \mathrm{CAD}$, respectively.

Optimized MKIM parameters of Equation (2.11) are given in Table 2-5. By examining the parameters, it is noted that SOC is advanced by increasing the equivalence ratio of diesel. Moreover, an increase in temperature and pressure at IVC causes SOC to advance. An increase in $T_{I V C}, P_{I V C}$ or $\varphi_{D I}$ causes a more reactive charge in the cylinder that results in advancing the SOC.

Table 2-5. MKIM parameters

\begin{tabular}{ccccc}
\hline $\boldsymbol{A}_{1}$ & $\boldsymbol{B}_{\mathbf{1}}$ & $\boldsymbol{C}_{\mathbf{1}}$ & $\boldsymbol{D}_{\mathbf{1}}$ & $\boldsymbol{A}_{\mathbf{2}}$ \\
\hline 1.2693 & -0.00819 & 26304.29 & 0.000228 & 0.00314 \\
\hline $\boldsymbol{B}_{2 D I}$ & $\boldsymbol{B}_{2 P F I}$ & $\boldsymbol{C}_{2}$ & $\boldsymbol{b}$ & $\boldsymbol{D}_{\mathbf{2}}$ \\
\hline-0.118482 & -0.000129 & 440414.09 & 13.40 & 0.6398 \\
\hline
\end{tabular}

In the next step, the effect of each parameter on SOC timing is studied, while keeping the other parameters constant. The results for six different cases are shown in Table 2-6. 
Table 2-6. Effect of individual parameters on SOC

\begin{tabular}{ccccccc}
\hline Cases & $\# 1$ & $\# 2$ & $\# 3$ & $\# 4$ & $\# 5$ & $\# 6$ \\
$\varphi_{P F I}(-)$ & 0.15 & 0.15 & 0.2 & 0.2 & 0.2 & 0.2 \\
$\boldsymbol{\varphi}_{D I}(-)$ & 0.1 & 0.15 & 0.15 & 0.15 & 0.15 & 0.1 \\
$\boldsymbol{P}_{I V C}(\boldsymbol{k P a})$ & 120 & 120 & 120 & 120 & 130 & 120 \\
$\boldsymbol{T}_{I V C}(\boldsymbol{K})$ & 400 & 400 & 400 & 380 & 400 & 400 \\
SOC (CAD aTDC) & -10.1 & -13.6 & -11.7 & -10.3 & -13.1 & -7.8 \\
& & & & & & \\
\hline
\end{tabular}

Table 2-6 shows that, as the equivalence ratio $\left(\boldsymbol{\varphi}_{D I}\right)$ of the diesel surrogate fuel (n-heptane) is increased from 0.1 to 0.15 , SOC is advanced by $3.5 \mathrm{CAD}$. However, as the equivalence ratio of the gasoline surrogate fuel (iso-octane) $\left(\boldsymbol{\varphi}_{P F I}\right)$ is increased by 0.05 , SOC retards by $1.9 \mathrm{CAD}$. This trend is attributed to the fact that as $\boldsymbol{\varphi}_{\boldsymbol{P F I}}$ is increased while keeping the amount of diesel constant, the reactivity of mixture (i.e. $\mathrm{CN}$ of the mixture) drops according to Equation (2-9), causing the SOC to be delayed. The same trend was observed by Wu et al. [13]. They observed that as the premixed ratio $\left(\frac{m_{P F I}}{m_{P F I}+m_{D I}}\right)$ is increased, the combustion phasing retards due to the higher gasoline fuel fraction. This can be observed by comparison of cases \#2 and \#6 in Table 2-6. As the premixed ratio is increased by $16.6 \%$, from $50 \%$ to $66.6 \%$, the SOC retards by $5.8 \mathrm{CAD}$.

As expected, an increase in IVC pressure causes the SOC to advance (see Table 2-6). When the IVC pressure is increased by $10 \mathrm{kPa}$, SOC is advanced by $2.8 \mathrm{CAD}$ (cases \#5 and \#6). Moreover, as the IVC temperature is reduced by $20 \mathrm{~K}$, SOC retards by $1.4 \mathrm{CAD}$. The variation trends in Table 2-6 are consistent with those in references [20], [28], [34], and [43]. 
The results of Table 2-6 demonstrate that the SOC in RCCI is primarily a function of the premixed fuel ratio. This is because the introduction of highly reactive fuel, i.e. high CN fuel, has the role of triggering the combustion [4], [7]. Moreover, a substantial change in temperature at IVC, i.e., $20 \mathrm{~K}$, causes a relatively minor variation in SOC, i.e., 1.4 CAD. This is in contrast to HCCI combustion for which mixture conditions at IVC are primary factors in determination of combustion phasing [26], since the charge premixed ratio is the dominant factor in RCCI combustion. Thus, the charge premixed ratio can be used as a means to control combustion phasing in RCCI [13].

\subsubsection{MKIM Order Reduction.}

The developed MKIM depicts good accuracy in predicting SOC. However, further simplification was applied so that the number of parameters/states in the COM decreases.

The second term on the right hand side (RHS) of Equation (2-11) encompasses the preignition reactions of iso-octane from IVC to SOI. The DI SOI timing in RCCI combustion using a single injection is of the order of 50-30 CAD bTDC. Hence, the IVC-SOI interval is located early in the compression stroke. This implies that the charge pressures and temperatures during the IVC-SOI period are low, rendering the extent of these pre-ignition reactions to be limited [53]. Moreover, the fuel undergoing the pre-ignition reactions during this period is solely iso-octane, which is far less reactive than n-heptane that is injected at SOI. Hence, the integral on the RHS of Equation (11) can be neglected. By removing this term from the MKIM, predictions of SOC are compared to the KIVA data as shown in Figure 2-9. 


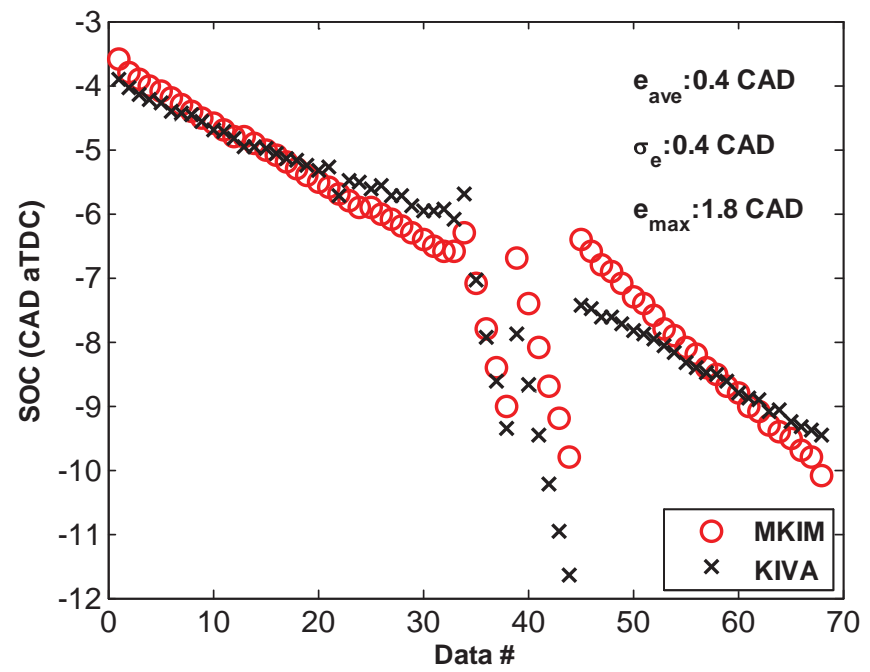

Figure 2-9. SOC estimation by the reduced order MKIM

Ignoring the aforementioned term in the MKIM has negligible impact on the accuracy of the SOC predictions. This term is of the order of $10^{-6}$, thus the average and maximum error remain essentially the same as the case previously shown in Figure 2-8.

\subsubsection{BD Estimation}

CA50 provides a robust feedback parameter for combustion phasing control [13]. Thus, adjusting CA50 is often defined as a control objective for an RCCI combustion controller. To predict CA50, a model is required to estimate BD along with SOC, which is approximated by the reduced order MKIM. Combustion duration in this work is defined as the duration between CA10 (10\% fuel mass fraction burned) and CA90 (90\% fuel mass fraction burned).

BD model (BDM), previously shown in Equation (2-12), was parameterized using the KIVA simulation data. An approach similar to that of the MKIM is used to parameterize 
the BDM. 35 out of the 69 KIVA simulation data points were used to parameterize the model and validation was done against all KIVA data points. The results are shown in Figure 2-10.

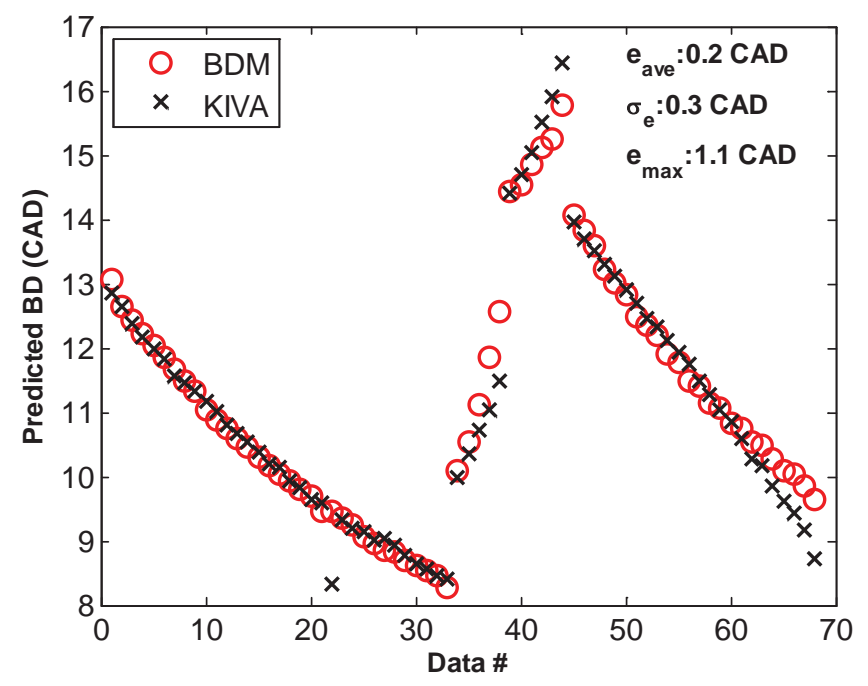

Figure 2-10. Comparison between predicted BDs from the BDM and those from KIVA simulation data

The BDM predicts BD with an average error of $0.2 \mathrm{CAD}$ and maximum error of 1.1 CAD, and the BD model parameters are given in Table 2-7.

Table 2-7. Parameters of BD

\begin{tabular}{|c|c|c|c|c|}
\hline$K_{1}$ & $p$ & $t$ & $K_{2}$ & $\mathbf{r}$ \\
\hline 1.8519 & $1.6316 \mathrm{e}-05$ & -12.1619 & 23.5512 & 1.8115 \\
\hline$a_{0}$ & $a_{1}$ & $a_{2}$ & $b_{0}$ & $b_{1}$ \\
\hline 0.0999 & $2.1707 e-05$ & $-4.6574 e-06$ & 4.0760 & $-3.7482 e-05$ \\
\hline
\end{tabular}

Using the values derived for $a_{0}, a_{1}, a_{2}, b_{0}, b_{1}$ and $b_{2}$ (Table 2-7) in Equations (2-17) and (2-19), it could be noted that as SOC is advanced, the value of $e_{1}$ and $e_{2}$ decrease. As 
mentioned before (due to lower average temperatures and pressures) as SOC is advanced, the BD increases. Longer BD causes an increase in heat losses that leads to a drop in the average gas temperature and pressure during the combustion, exhibited by the drop in $e_{1}$ and $e_{2}$ in the $\mathrm{BDM}$.

\subsubsection{Estimation of CA50}

The parameter $m$ in Equation (23) was determined by applying the Nelder-Mead optimization method on the KIVA simulation data to find the best curve fit for estimation of CA50. Again, 35 out of the 69 KIVA data points were used to parameterize the Wiebe function and the validation was done for all the 69 KIVA data points. The results of the estimation are shown in Figure 2-11.

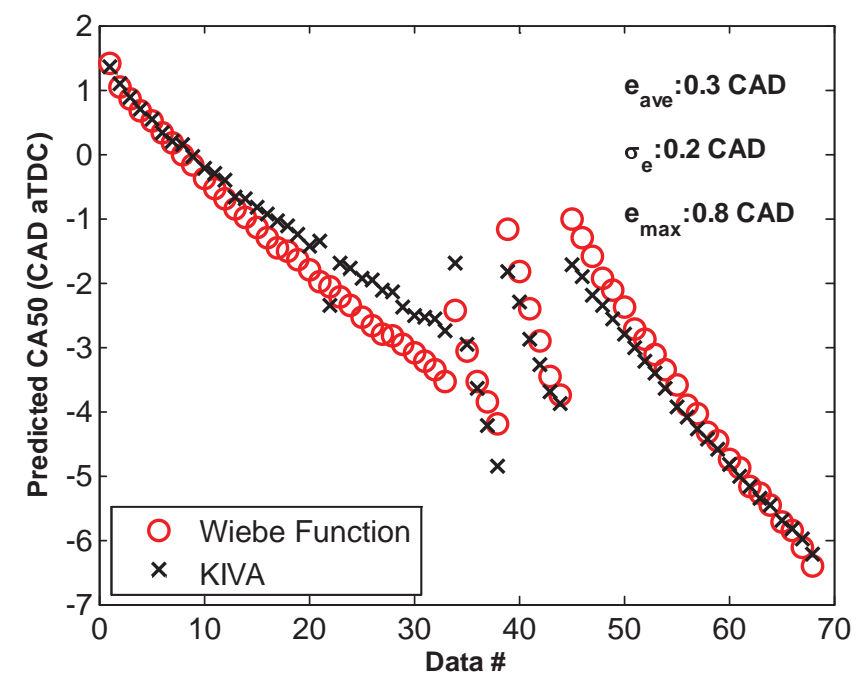

Figure 2-11. Comparison between predicted CA50s from the Wiebe function and those from KIVA simulation 
The optimized value of $m$ is 0.2508 , which yields an average and maximum error of 0.3 and 0.8 CAD, respectively, in estimating CA50. The CA50 estimation error is insignificant; thus, the CA50 model can be used in the COM.

The crank angle resolved comparisons of the Wiebe model for the KIVA heat release pattern for the two cases of 1.0 bar BMEP and 2.6 bar BMEP are given in Figure 2-12 and Figure 2-13:

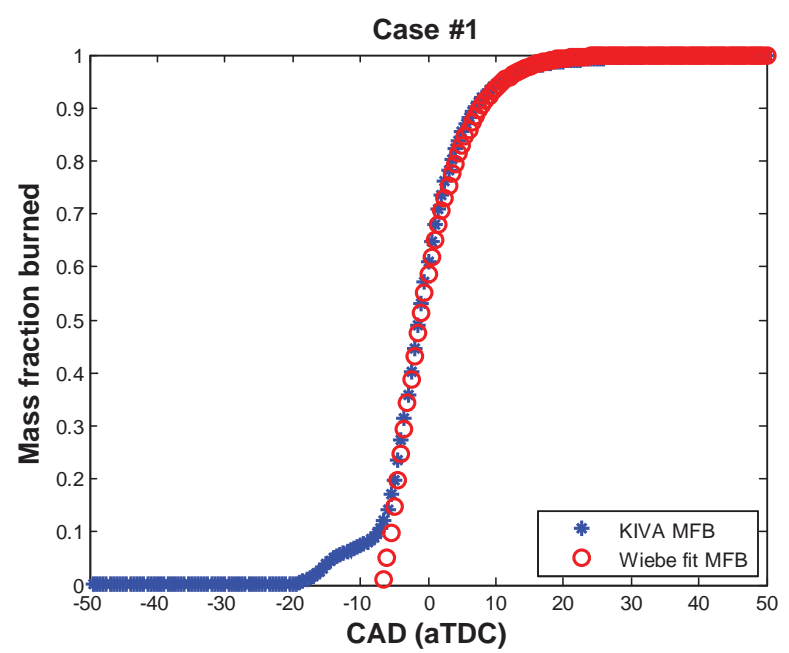

Figure 2-12.Crank angle resolved of the estimated mass fraction burned by Wiebe function and mass fraction burned computed using KIVA heat release for 1 bar BMEP case. 


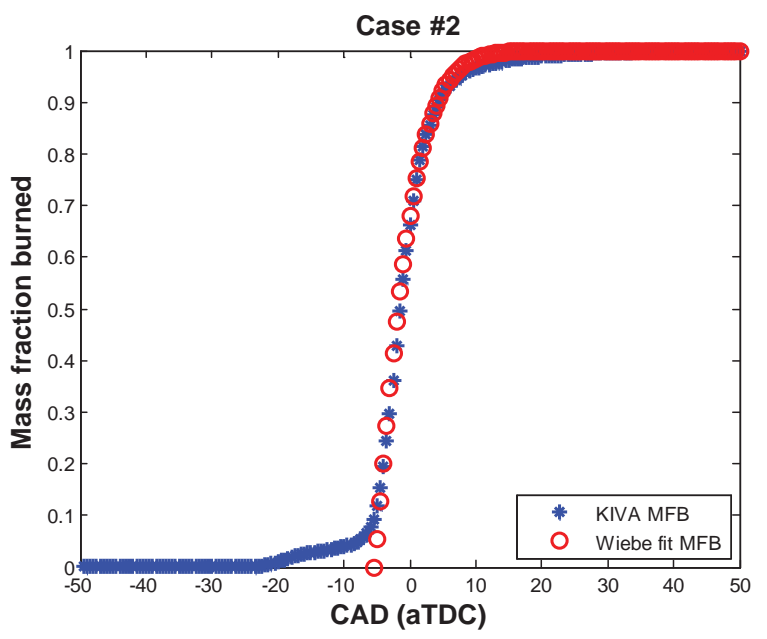

Figure 2-13. Crank angle resolved of the estimated mass fraction burned by Wiebe function and mass fraction burned computed using KIVA heat release for 2.6 bar BMEP case.

The Wiebe function is an accurate representation of the mass fraction burned (CA10 to CA90) corresponding to the heat release rate pattern of an RCCI engine for the cases where only a single injection of diesel is used. In these cases due to an earlier injection timings ( $\sim 40 \mathrm{CAD}$ bTDC) as compared to conventional diesel combustion, which is roughly 15 CAD bTDC, the combustion process is not controlled by the mixing rate and heat release profile is only comprised of one spike as shown in Figure 2-5 and Figure 2-6.

An alternative simplified approach for estimation of CA50 would be to assume that there is a linear relation between SOC and CA90. Hence, knowing the SOC and BD, CA50 would be estimated by:

$$
C A 50=S O C+0.5 B D
$$


It should be noted that in the RCCI combustion strategy, since the combustion commences from the regions in the charge where the blend is more reactive, i.e., a more diesel fuel rich region, a higher proportion of diesel fuel fraction is burned early in the combustion period. Hence, CA50 occurs in the first half of the combustion process. Therefore, assuming a constant burn rate increases the CA50 estimation error (Figure 2-14).

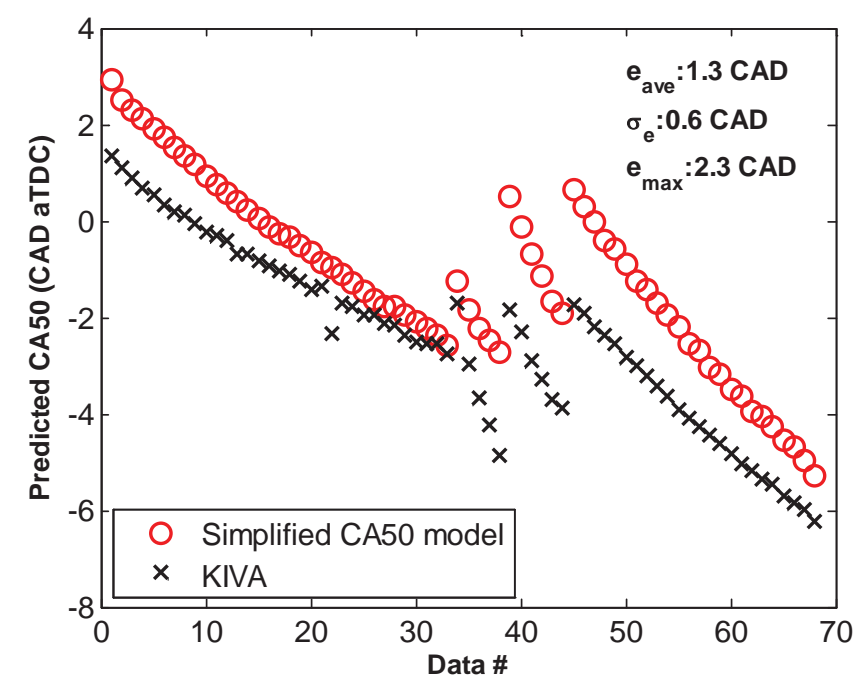

Figure 2-14. CA50 estimation using a simplified linear CA50 model (Equation 2-25)

As shown in Figure 2-14, the alternative approach in predicting CA50 demonstrates lower accuracy, 1.3 CAD of mean error as compared to the $0.3 \mathrm{CAD}$ of the previous case and 2.3 $\mathrm{CAD}$ of maximum error as compared to $0.8 \mathrm{CAD}$ of the previous case (Figure 2-11). However, the simplified linear CA50 model introduces less computational effort in the estimation of CA50. Given that the mean estimation error of the combustion phasing (SOC, CA50 and $\mathrm{BD}$ ) are less than $2 \mathrm{CAD}$, it is concluded that the COM can be used for RCCI combustion phasing control applications for the operating region parameterized. 


\section{Chapter 3}

\section{Dynamic Modelling and Controller Design of Combustion Phasing of an $\mathrm{RCCl}$ Engine}

Consistent control of combustion phasing is critical in terms of achieving high fuel economy and thermal efficiency as well as meeting stringent emission standards [4], [9]. Model-based control strategies provide an effective solution for control of combustion phasing. Conventional map-based controllers require lots of man-hours to develop engine operating maps [33]. However, model-based controllers exploit the merits of utilizing physics-based COMs to determine and modulate control parameters, thus mitigating the need for extraneous costly engine experiments. Moreover, they are capable of efficient control of engine, i.e. increase the thermal efficiency while simultaneously minimizing emissions, during its transient operation. The transient operation of the engine encompasses a significant proportion of its drive-cycle. Hence, model-based controllers have an edge over steady state, map-based conventional controllers [33].

Development of a model-based controller requires a dynamic model which can predict engine operation, i.e., estimation of combustion metrics, on a cycle-to-cycle basis. Hence, the mean-value model developed in Chapter 2 is extended to encompass the full-cycle engine operation by including the expansion and exhaust strokes. In addition, the dynamics stemming from the thermal coupling between cycles are accounted for, that results in a 
dynamic RCCI control-oriented model capable of predicting the transient operation of the engine. This model is then simplified and linearized in order to develop a linear observerbased feedback controller to control the combustion phasing using the premixed ratio of the gas/diesel fuel.

\subsection{RCCI Dynamic Model}

A set of physics-based equations are utilized to describe the complete RCCI engine operating cycle. The engine operation is broken down into four consecutive strokes including: intake stroke, compression stroke, combustion, expansion stroke, and exhaust stroke. The sub-models for each stroke are developed and coupled together to form the entire RCCI engine operating cycle. The following sections describe the empirical correlations as well as thermodynamic equations that comprise the COM for an RCCI engine

\subsubsection{Intake Stroke}

The states of the charge at IVC greatly impact the combustion timing in an RCCI engine [13]. Due to the mixing process between the fresh air, external EGR, and fuel with residual gas within the cylinder, in order to determine the conditions of the charge at the beginning of the intake stroke it is necessary to determine the residual gas fraction and its temperature.

The residual gases from the previous cycle are the primary cause of thermal cycle-to-cycle dynamics due to the mixing process which occurs during the induction stroke. The mixing of the inducted fresh charge with the residual gases of the previous cycle, causes the thermodynamic properties of the charge to be affected by the previous cycles, hence 
causing the thermal coupling between engine cycles which affects the transient operation of the engine [19], [56].

The residual gas fraction is defined as:

$$
R G F=\frac{m_{r}}{m_{t}}
$$

where $m_{r}$ is the mas of residual gases $(\mathrm{kg})$ and $m_{t}$ is defined as:

$$
m_{t}=m_{a}+m_{e g r}+m_{r}
$$

where $m_{t}$ is the total mass of the charge within the cylinder at IVC $(\mathrm{kg}), m_{a}$ is the mass of fresh inducted air $(\mathrm{kg}), m_{\text {egr }}$ is the mass of external EGR $(\mathrm{kg})$.

The main two components forming the residual gases are:

(1) Back-flow of the exhaust gases from the exhaust manifold into the cylinder during the overlap period.

(2) The exhaust gases trapped in the cylinder at EVC.

Hence, Cavina et al. [57] proposed the following mathematical model (white box model) to calculate the residual gas fraction: 


$$
\begin{gathered}
R G F=\overbrace{\sqrt{\frac{1}{C} \cdot \frac{\pi \cdot \sqrt{2}}{360} \cdot \frac{r_{c}-1}{r_{c}} \cdot\left(\frac{O F}{N}\right) \sqrt{ } R \cdot T_{i} \cdot \frac{\left|p_{e}-p_{i}\right|}{p_{e}} \cdot\left(\frac{p_{e}}{p_{i}}\right)^{\frac{k+1}{2 k}}}}^{\alpha} \\
+\overbrace{\frac{1}{C} \cdot \frac{r_{c}-1}{r_{c}} \cdot \varphi \cdot\left(\frac{V_{I V O}}{V_{d}}\right) \cdot\left(\frac{p_{e}}{p_{i}}\right)^{\frac{1}{k}}}^{\beta}
\end{gathered}
$$

where $p_{e}$ is the exhaust pressure $(\mathrm{kPa}), p_{i}$ is the intake pressure $(\mathrm{kPa}), r_{c}$ is the compression ratio and, $O F$ is the valve overlap factor which is defined as:

$$
O F=\frac{Z_{i} \cdot D_{i} \cdot \int_{I V O}^{I V=E V} L_{i} d \theta+Z_{e} \cdot D_{e} \cdot \int_{I V O}^{I V=E V} L_{e} d \theta}{V_{d}}
$$

where $Z_{i}$ is the number of intake valves, $Z_{e}$ is the number of exhaust valves, $L_{i}$ is the intake valve lift $(\mathrm{m}), L_{e}$ is the exhaust valve lift $(\mathrm{m}), D_{i}$ is the intake valve inner seat diameter $(\mathrm{m}), D_{e}$ is the exhaust valve inner seat diameter $(\mathrm{m})$.

The parameter $C$ in equation (3.5) is derived using the following correlation:

$$
C=\left[1+\frac{L H V}{c_{v} \cdot T_{i} \cdot\left(\frac{m_{t}}{m_{f}}\right) \cdot r_{c}^{k-1}}\right]^{\frac{1}{k}}
$$

where $L H V$ is the lower heating value of the fuel and $c_{v}$ is the constant volume specific heat capacity of the charge within the cylinder at IVC. Since RCCI is inherently a dual fuel engine, and in this study a blend of gas and diesel is used, the $L H V$ of fuel blend is calculated via: 


$$
L H V=\frac{\% V_{P F I} \cdot \rho_{P F I} \cdot L H V_{P F I}+\% V_{D I} \cdot \rho_{D I} \cdot L H V_{D I}}{\% V_{P F I} \cdot \rho_{P F I}+\% V_{D I} \cdot \rho_{D I}}
$$

where $\% V$ is the volume percentage and $\rho$ is the density of the fuel.

The term $\alpha$ in equation (3.3) corresponds to the component of RGF which arises from the back-flow of the exhaust gases into the cylinder during the valve overlap period, and the term $\beta$ in equation (3.3) corresponds to the exhaust gases trapped in the cylinder at IVO. Due to the fact that there is no valve overlap in the RCCI engine under study (see timings given in Table 2-2), the term $\alpha$ in equation (3.3) is assumed to be zero in this study. This model establishes a first estimate of the RGF. This first estimated RGF is used to develop an iterative loop to converge to a more accurate approximation of RGF in the first engine cycle. This is achieved by calculation of the mass of trapped gases in the cylinder at EVC which yields the updated RGF. This updated value of RGF is then used in the next iteration to acquire the new RGF value. This process is repeated until the RGF value converges to its terminal value.

The fresh aspirated charge mixes with the residual gases within the cylinder, influencing the mixture temperature at IVC. The mixing process of the intake charge and residual gases is assumed to be constant pressure (i.e. manifold pressure is equal to $P_{I V C}$ ). The following equation is used to estimate the mixture temperature at IVC after the residual gases and the fresh charge have mixed together:

$$
T_{i v c}(i)=T_{f c}(i) \cdot(1-R G F)+T_{e g}(i-1) \cdot R G F
$$


where the subscripts $f c$ and $e g$, correspond to fresh charge and exhaust gases, respectively. This approach for modelling the mixing process is used commonly in literature [43]. The equation (3.7) represents the thermal coupling between the mixture temperature at IVC in cycle $(i)$ and residual gas temperatures in cycle $(i-1)$.

\subsubsection{Compression Stroke}

The MKIM developed in Chapter 2 is used to estimate the SOC. The compression stroke from IVC until SOC can be modelled as a polytropic process [15], [43]. Using the polytropic correlation, the in-cylinder pressures and temperatures are estimated by:

$$
T=T_{I V C} v^{k_{c}-1}
$$

and

$$
P=P_{I V C} v^{k_{c}}
$$

The value for $k_{c}$ is calculated to be 1.35 as shown in Chapter 2.

\subsubsection{Combustion}

The SOC, BD and temperature rise due to combustion, are derived using the MKIM and BDM in Chapter 2, respectively. The temperature and pressure, assuming an instantaneous heat release at EOC, after combustion are derived using the following equations [43]:

$$
T_{E O C}=T_{b c}+\Delta T
$$

where $\Delta T$ is defined by equation (2.15) and 


$$
P_{E O C}=P_{b c} \cdot \frac{T_{E O C}}{T_{b c}} \cdot \frac{V_{b c}}{V_{E O C}}
$$

Where subscript $b c$ designates the charge just before the instantaneous heat release.

\subsubsection{Expansion Stroke}

The expansion stroke is modelled as a polytropic process similar to the compression stroke [15], [43]. The temperature and pressure of the charge at EVO are calculated using the following polytropic correlations:

$$
T_{E V O}=T_{E O C} v^{k e^{-1}}
$$

and

$$
P_{E V O}=P_{E O C} v^{k_{e}}
$$

The value for $k_{e}$ is calculated in a similar approach for estimating $k_{c}$ (see section 2.4.1).

\subsubsection{Exhaust Blow-down}

The exhaust blow-down is modelled by the following correlation [43]:

$$
T_{e g}=T_{E V O} \cdot\left(\frac{P_{e g}}{P_{E V O}}\right)^{\frac{k_{e}-1}{k_{e}}}+\Delta T_{b d}
$$

where subscript $b d$ designates the blow-down process. The blow-down process is modelled by an adiabatic expansion [15]. However, due to the heat transfer throughout the process an offset of $\Delta T_{b d}$ is added to the model. This offset is calculated by comparing the term $T_{E V O} \cdot\left(\frac{P_{e x h}}{P_{E V O}}\right)^{\frac{k_{e}-1}{k_{e}}}$ and measured exhaust temperature. 
The residual gas temperature is assumed to be equal to the exhaust gas temperature [43]. The mass of trapped gas in the cylinder after the blow-down process is calculated via:

$$
m_{e v c}=P_{e x h} \cdot \frac{V_{E V C}}{R \cdot T_{r g}}
$$

where $R$ is the gas constant $\left(\frac{J}{\mathrm{~kg} \cdot \mathrm{K}}\right)$ and subscript $r g$ corresponds to residual gas. Knowing the residual gas temperatures and mass of trapped gas in the cylinder, the residual gas fractions in the next cycle are calculated using:

$$
R G F=P_{e g} \cdot \frac{V_{E V C} \cdot T_{I V C}}{P_{I V C} \cdot V_{I V C} \cdot T_{r g}}
$$

\subsubsection{Physical Model Lay-out}

The structure of the dynamic model of the RCCI engine is shown in Figure 3-1. This includes the full cycle model of the engine, including the cycle to cycle coupling through estimation of residual gas fractions. The inputs to the model are: IVC pressure and temperature $\left(T_{I V C}, P_{I V C}\right)$, exhaust pressure $\left(P_{e x h}\right)$, blending ratio of the two fuels $(P F R)$, total equivalence ratio of the fuels $\left(\varphi_{\text {tot }}\right)$, and engine speed $(N)$.

In order to estimate the RGF during the first operating cycle of the engine, a trial and error method is used. A while loop is developed to estimate the RGF until it converges to a final value. This loop is depicted in Figure 3-1. Out-puts of the model are CA50, $T_{r g}$, and $R G F$. The latter two are used to estimate the CA50 of the next operating cycle of the engine. 


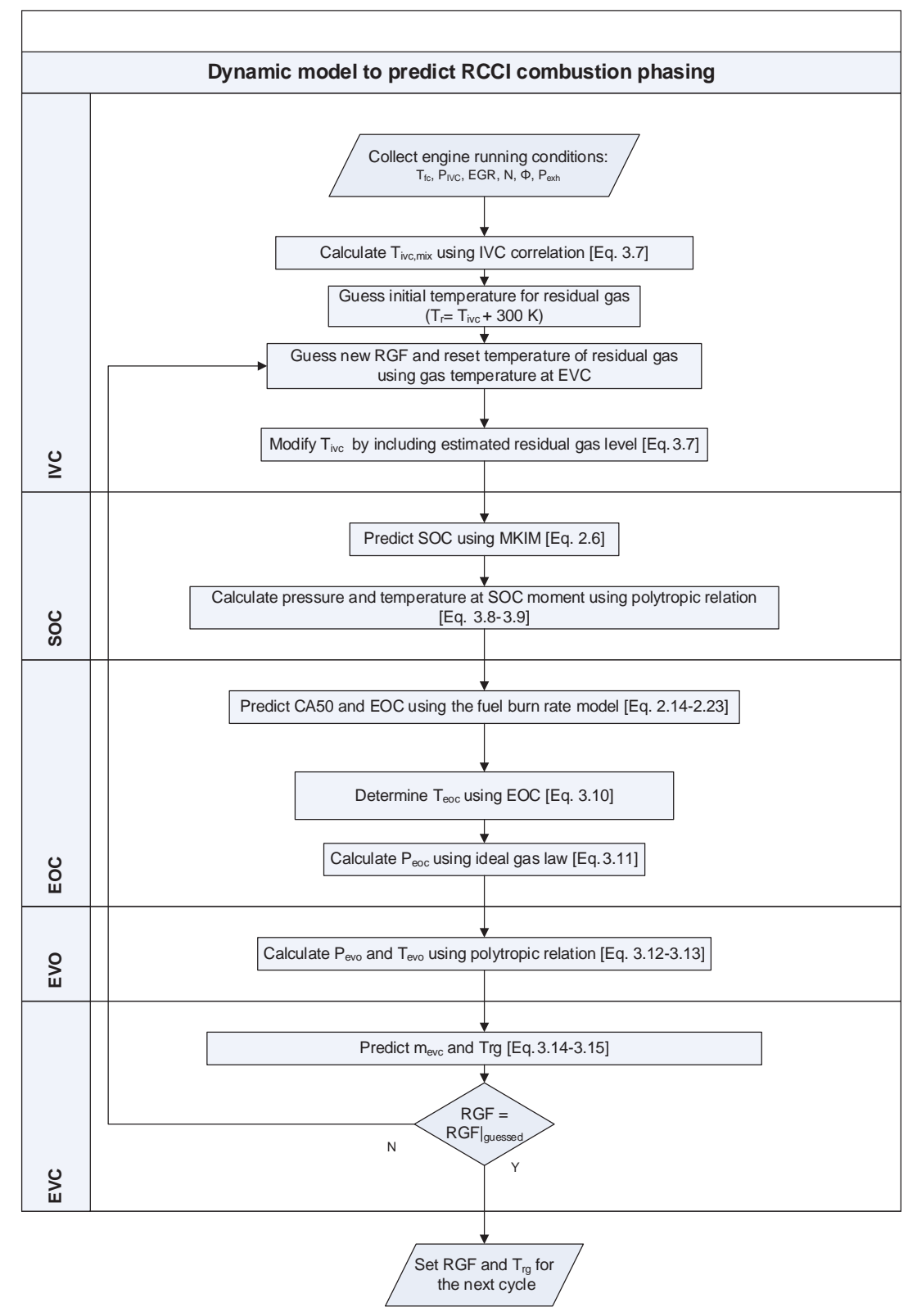

Figure 3-1. Dynamic model of RCCI combustion phasing 


\subsection{Controller Design}

The physical model developed in the previous section needs to be simplified for controller design purposes. More, specifically the MKIM developed in section 2.2.1 being in its integral form is highly non-linear which limits its application for real-time controller design despite its accuracy in SOC estimation. Therefore, in this section an empirical correlation is fitted to the MKIM so as to lower the complexity and thus computational time of the model. Next, the empirical model is linearized and an observer-based state-feedback controller is designed to track a desired CA50 trajectory by modulating the premixed ratio.

\subsubsection{Simplified COM}

The SOC in an RCCI engine depends on various attributes, such as IVC temperature and pressure, equivalence ratio of the two fuels used, and the blend ratio of the two fuels. The MKIM developed in Chapter 2 was previously used to approximate SOC. Even though, the MKIM model is an accurate model for prediction of the onset of combustion its inherent non-linear nature limits its application in a real-time controller design. Hence, for purposes of controller design a correlation is fitted in the MKIM model to predict SOC utilizing the major contributing factors in the following form:

$$
\begin{gathered}
S O C=A(1) \cdot P F R+A(2) \cdot S O I+A(3) \cdot P i v c+A(4) \cdot T i v c+A(5) \cdot \varphi_{t o t} \\
+A(6)
\end{gathered}
$$

where

$$
A=[28.058,-0.063,-0.114,-0.055,-0.615,13.298]
$$


This correlation is derived by performing a sweep on Pivc, Tivc, PFR, $\varphi_{\text {tot }}$ and SOI timing and using least mean square algorithm to derive the curve fit parameters. The sweeps are performed over the range given in Table 3-1:

Table 3-1. The sweep range performed for developing the SOC correlation

\begin{tabular}{|l|l|}
\hline Parameter & Range \\
\hline Pivc $(k P a)$ & $115-145$ \\
\hline Tivc $(K)$ & $370-420$ \\
\hline PFR $(-)$ & $0.5-0.75$ \\
\hline$\varphi_{\text {tot }}(-)$ & $0.18-0.32$ \\
\hline SOI $($ CAD bTDC $)$ & $35-47$ \\
\hline
\end{tabular}

The results of the fitted correlation and the MKIM are compared in Figure 3-2.

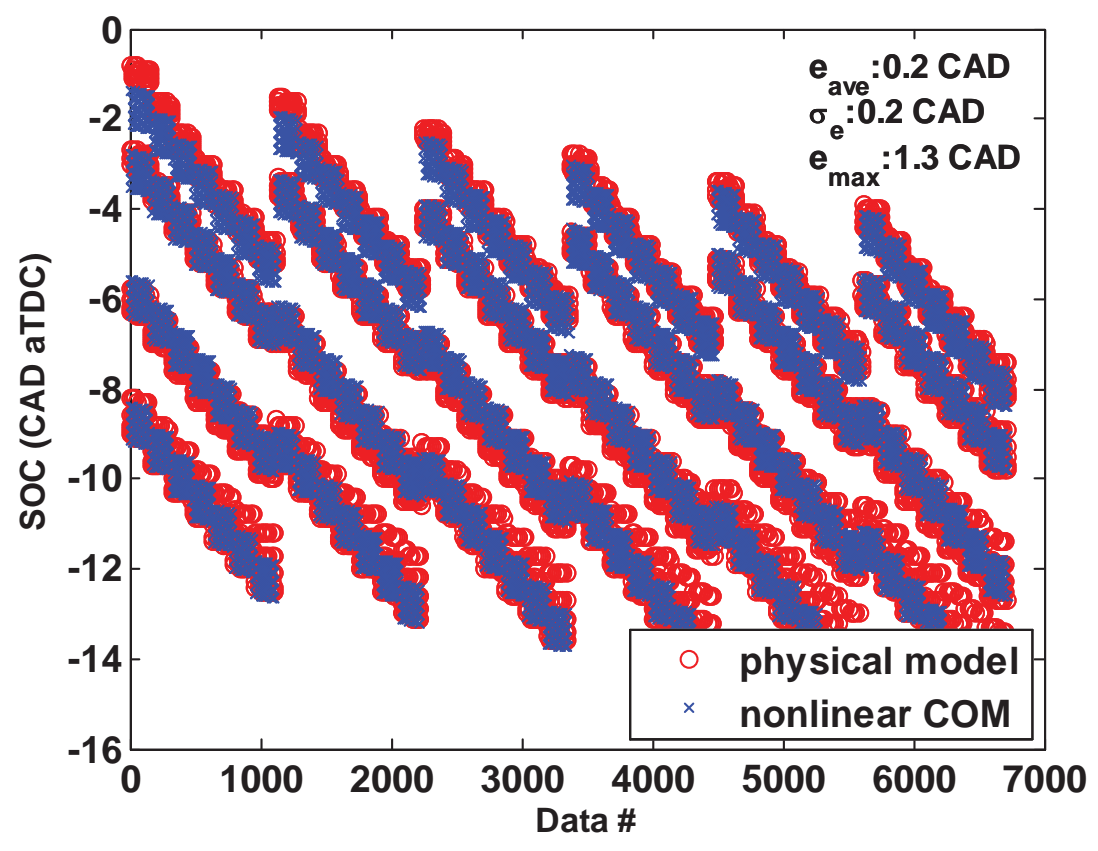

Figure 3-2. The SOC predictions of MKIM and the empirical correlation.

As can be observed in Figure 3-2, the empirical correlation demonstrates an accurate estimation of CA50 as the average error in predictions is merely 0.2 CAD. 
By assuming a constant burn rate (see section 2.4.1) and using equation (3.17) the CA50 could be represented as a function of previous cycle operating parameters:

$$
C A 50_{k+1}=f\left(P_{k}, S O I_{k}, P_{i v c_{k}}, T_{i v c_{k}}, \varphi_{k}\right)
$$

The dynamic model developed in section 3.1 allows for linking two consecutive engine cycles through the thermal coupling induced by residual gases present in the engine at the end of each cycle. In order to describe the engine operation the following parameters are used as the COM states to describe the engine operation:

- $\quad$ Temperature at SOC $\left(T_{\text {soc }}\right)$

- $\quad$ Pressure at $\operatorname{SOC}\left(P_{\text {soc }}\right)$

- $50 \%$ mass fraction burned (CA50)

- Mass of residual gases at EVC moment $\left(m_{e v c}\right)$

- Residual gas temperature $\left(T_{r g}\right)$

Therefore by examining the correlations presented for each cycle the states of current engine cycle $(k+1)$ are represented as a function of the previous cycle $(k)$ engine states, input, and disturbances:

$$
\begin{aligned}
& C A 50_{k+1}=f_{1}\left(P F R_{k}, C A 50_{k}, T_{s o c, k}, P_{s o c, k}, T_{r g, k}, m_{e v c, k}, \varphi_{k}, T_{i v c, k}\right) \\
& T_{s o c, k+1}=f_{2}\left(P F R_{k}, C A 50_{k}, T_{s o c, k}, P_{s o c, k}, T_{r g, k}, m_{e v c, k}, \varphi_{k}, T_{i v c, k}\right) \\
& P_{s o c, k+1}=f_{3}\left(P F R_{k}, C A 50_{k}, T_{s o c, k}, P_{s o c, k}, T_{r g, k}, m_{e v c, k}, \varphi_{k}, T_{i v c, k}\right)
\end{aligned}
$$




$$
\begin{aligned}
& T_{r g, k+1}=f_{4}\left(P F R_{k}, C A 50_{k}, T_{s o c, k}, P_{s o c, k}, T_{r g, k}, m_{e v c, k}, \varphi_{k}, T_{i v c, k}\right) \\
& m_{e v c, k+1}=f_{5}\left(P F R_{k}, C A 50_{k}, T_{s o c, k}, P_{s o c, k}, T_{r g, k}, m_{e v c, k}, \varphi_{k}, T_{i v c, k}\right)
\end{aligned}
$$

Which can be represented in the state space form:

$$
X_{(k+1)}=f\left(X_{k}, u_{k}, d_{k}\right)
$$

and

$$
Y_{(k+1)}=g\left(X_{k}, u_{k}, d_{k}\right)
$$

where the states $(X)$, input $(u)$, and disturbance $(d)$ vectors are:

$$
\begin{aligned}
X & =\left[\begin{array}{lllll}
C A 50 & T_{\text {soc }} & P_{\text {soc }} & T_{r g} & m_{\text {evc }}
\end{array}\right] \\
u & =[P F R]
\end{aligned}
$$

and

$$
d=\left[\varphi T_{i v c}\right]
$$

This non-linear COM is then verified against the physical dynamic which combines the model from Chapter 2 with cycle-to-cycle residual gas thermal coupling model from section 3.1. The results of combining the models are shown in Figure 3-3. 

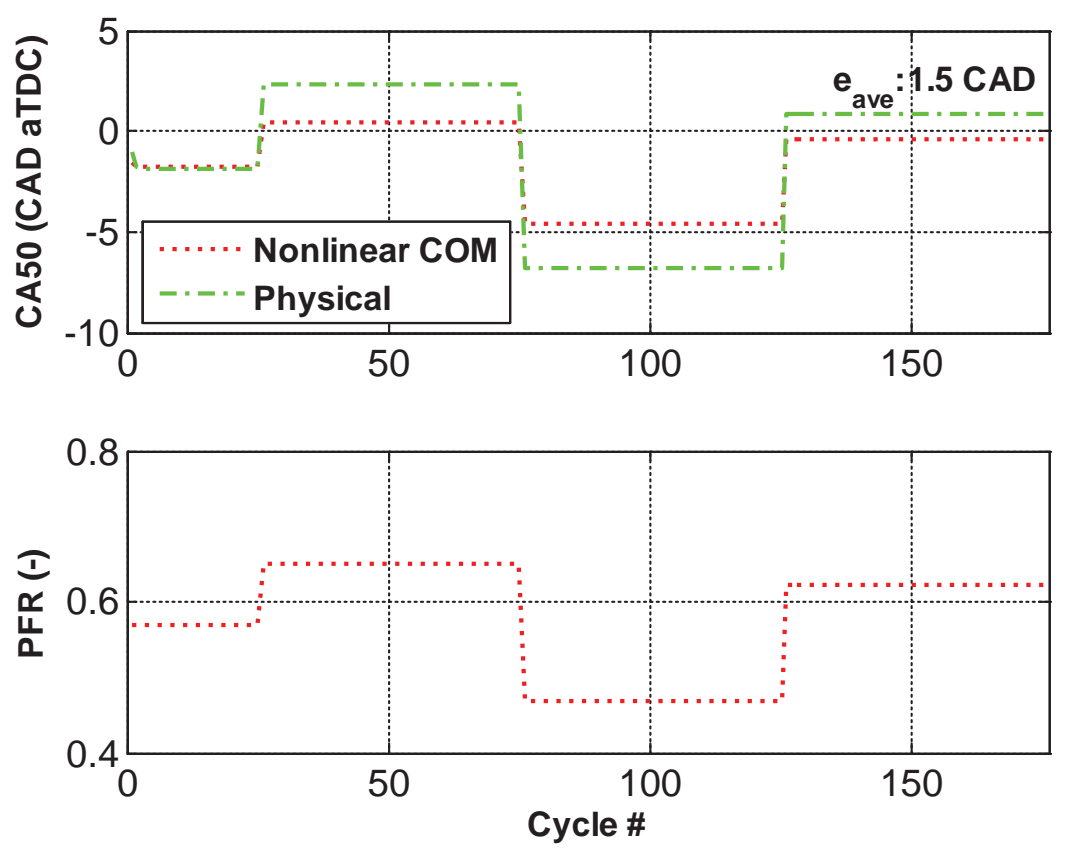

Figure 3-3. Physical model vs. non-linear COM

Figure 3-3 depicts that the non-linear COM developed depicts satisfactory accuracy (average error of $1.5 \mathrm{CAD}$ ) in predicting the CA50 while being much less computational demanding. The processing time for running the models in Figure 3-3 on an Intel® Core ${ }^{\mathrm{TM}}$ i7-3632QM CPU @ 2.2 GHz processor is 26 seconds for the physical model and only 0.14 second for the non-linear COM. This makes the COM suitable for developing a real-time controller design.

\subsubsection{Model Linearization and Linear Quadratic Integral (LQI) Design}

In order to design the controller the empirical COM is linearized around an operating point of the engine. The conditions corresponding to the linearization point are given in Table 3-2. 
Table 3-2. The nominal operating/linearization point

\begin{tabular}{ll}
\hline Parameter & Value \\
\hline$C A 50(C A D$ aTDC $)$ & -1.5 \\
$T_{s o c}(K)$ & 932 \\
$P_{s o c}(k P a)$ & 3980 \\
$T_{r g}(K)$ & 442 \\
$m_{e v c}(g)$ & 0.137 \\
$P F R(-)$ & 0.58 \\
$\varphi(-)$ & 0.23 \\
$T_{i v c}(K)$ & 370 \\
$P_{i v c}(k P a)$ & 117 \\
$E G R(\%)$ & 44.9 \\
\hline
\end{tabular}

The state space equations which are developed by the linearization of the COM are:

$$
X_{k+1}=A \cdot X_{k}+B_{u} \cdot u_{k}+B_{d} \cdot d_{k}
$$

and the output equation is given by:

$$
y_{k}=C . X_{k}
$$

where the $A, B_{u}, C$, and $B_{d}$ are state, input, output, and disturbance matrices. The elements of the linear state space model are given in Appendix A.

The linearized COM is then used to design an observer-based LQI controller to track a desired CA50 trajectory. The state-feedback controller regulates the CA50 at its desired value, while the integral component of the controller removes the steady-state error in the tracking process. It also assists in rejecting any disturbances in engine operation, including temperature and fueling variations $(\varphi)$. Therefore, the model is augmented to enable the utilization of an integral controller: 


$$
X_{\text {aug }}=\left[\begin{array}{l}
X \\
X_{I}
\end{array}\right]
$$

which yields the following state equation:

$$
X_{\text {aug }, k+1}=\left[\begin{array}{ll}
1 & C \\
0 & A
\end{array}\right] X_{\text {aug,k }}+\left[\begin{array}{l}
0 \\
B
\end{array}\right] u_{k}
$$

where $X_{\text {aug }}$ is the augmented model state vector, and $X_{I}$ is the integral state.

The control action is calculated via:

$$
u_{k}=-K \cdot X_{a u g, k}
$$

The controller performance is dictated by the gains in this control law. The gains are determined via carrying out a linear quadratic optimization to minimize the mean square error using the augmented state space model:

$$
J_{\text {aug }}=\frac{1}{2} \sum_{i=1}^{\infty}\left[X_{\text {aug }}^{T}(i) Q X_{\text {aug }}(i)+u^{T}(i) R u(i)\right]
$$

where $Q$ and $R$ are positive definite matrix and scalar, respectively. The index $(i)$ indicates the cycle number. The controller gains are computed by [58]:

$$
K=\left(R+B_{\text {aug }}^{T} P B_{\text {aug }}\right)^{-1} B_{\text {aug }}^{T} P A_{\text {aug }}
$$

where matrix $P$ is derived by solving the discrete-time algebraic Riccati equation (DARE):

$$
P=A_{a u g}^{T} P A-A_{a u g}^{T} P B_{a u g}\left(R+B_{a u g}^{T} P B_{a u g}\right)^{-1} B_{a u g}^{T} P A_{a u g}
$$


Since the states of this model are not measurable (except for CA50), an observer is required to estimate the states of the physical model. The observer is designed in the form of predictor-corrector:

$$
\hat{X}_{k+1}=A \cdot \hat{X}_{k}+B_{u} \cdot u_{k}+B_{d} \cdot d_{k}+G\left(\hat{y}_{k}-y_{k}\right)
$$

where $\hat{X}$ and $\hat{y}$ are the predicted states and output. The matrix $G$ contains the observer gains.

The structure of the observer-based LQI controller is shown in Figure 3-4.

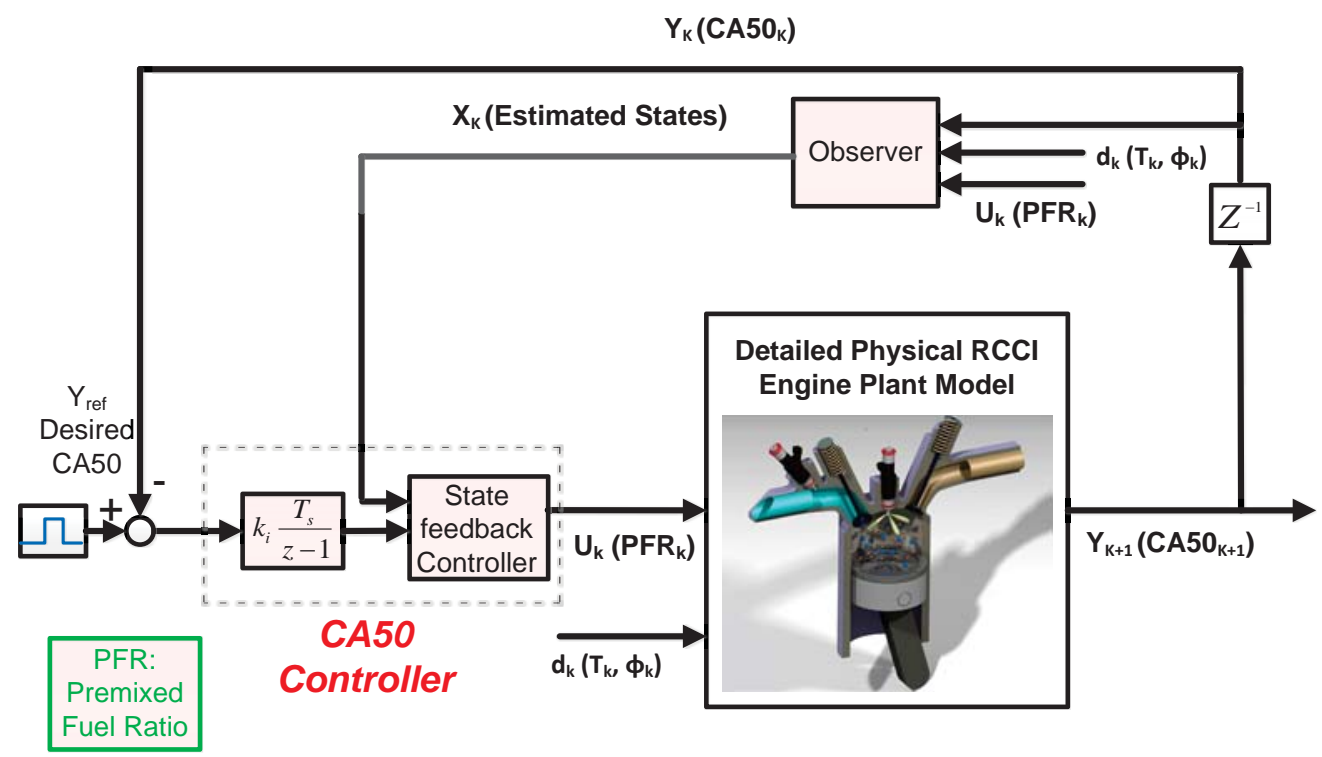

Figure 3-4. Structure of designed RCCI combustion phasing controller

\subsubsection{State estimator performance}

The performance of the observer is examined under transient operation of the engine (Figure 3-5). The state estimator relies on the model to have a prediction of the states based on the input and disturbances to the system. However, due to the model mismatch which 
is introduced through the linearization process, these estimations are corrected via a feedback, i.e. the measurement of the output of the physical model.
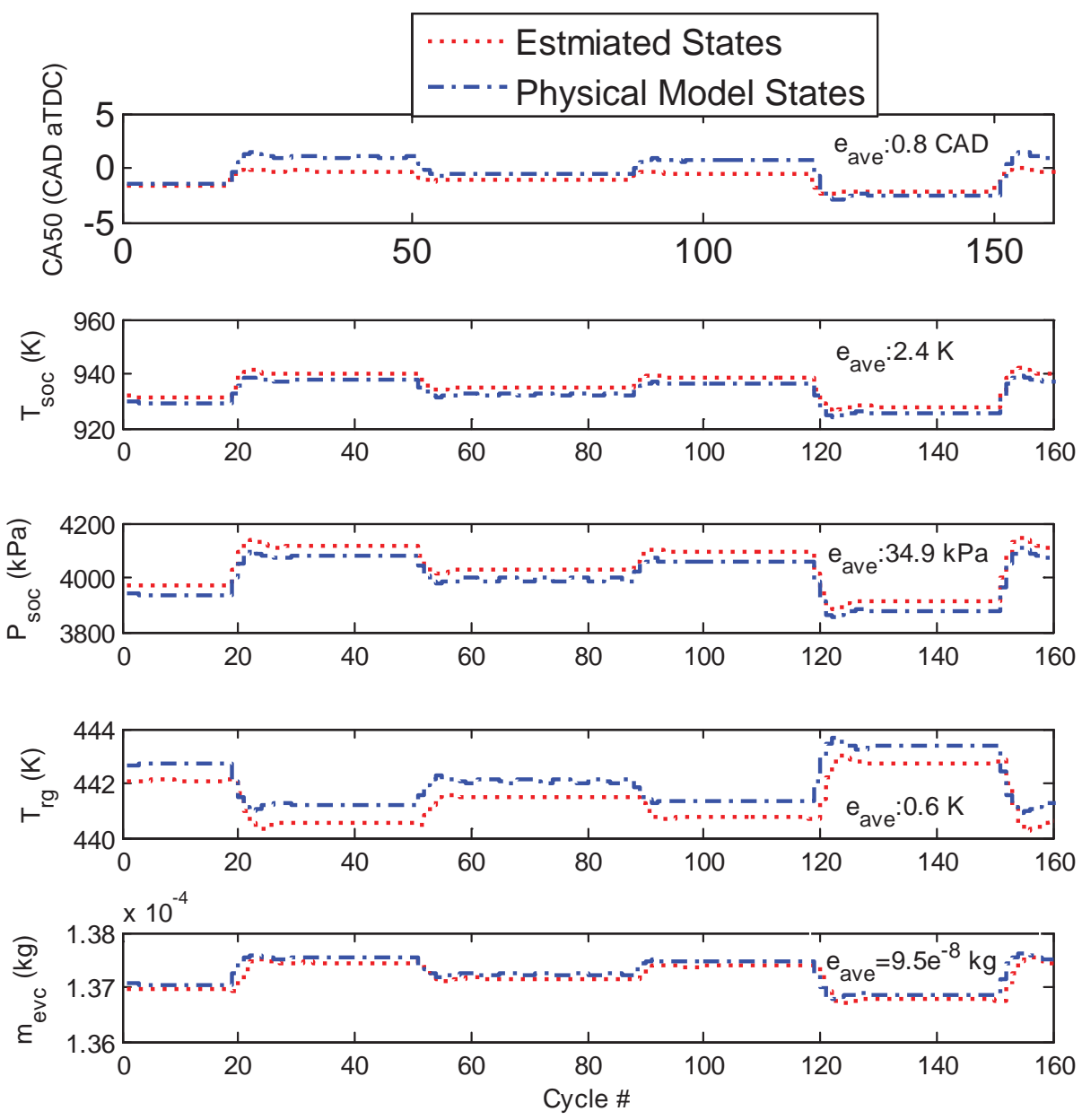

The state estimation results of the observer are demonstrated in Figure 3-5.

Figure 3-5. State estimation performance of observer under transient conditions.

The designed observer, accurately estimates the states of the engine under several step-ups and step-downs in the desired CA50. The estimation error of the states which are the result 
of the model mismatch, but these errors are sufficiently small for designing the LQI as will be shown in section 3.2.4.

\subsubsection{CA50 Tracking Results}

Performance of the controller in tracking a desired CA50 trajectory is demonstrated in Figure 3-6.
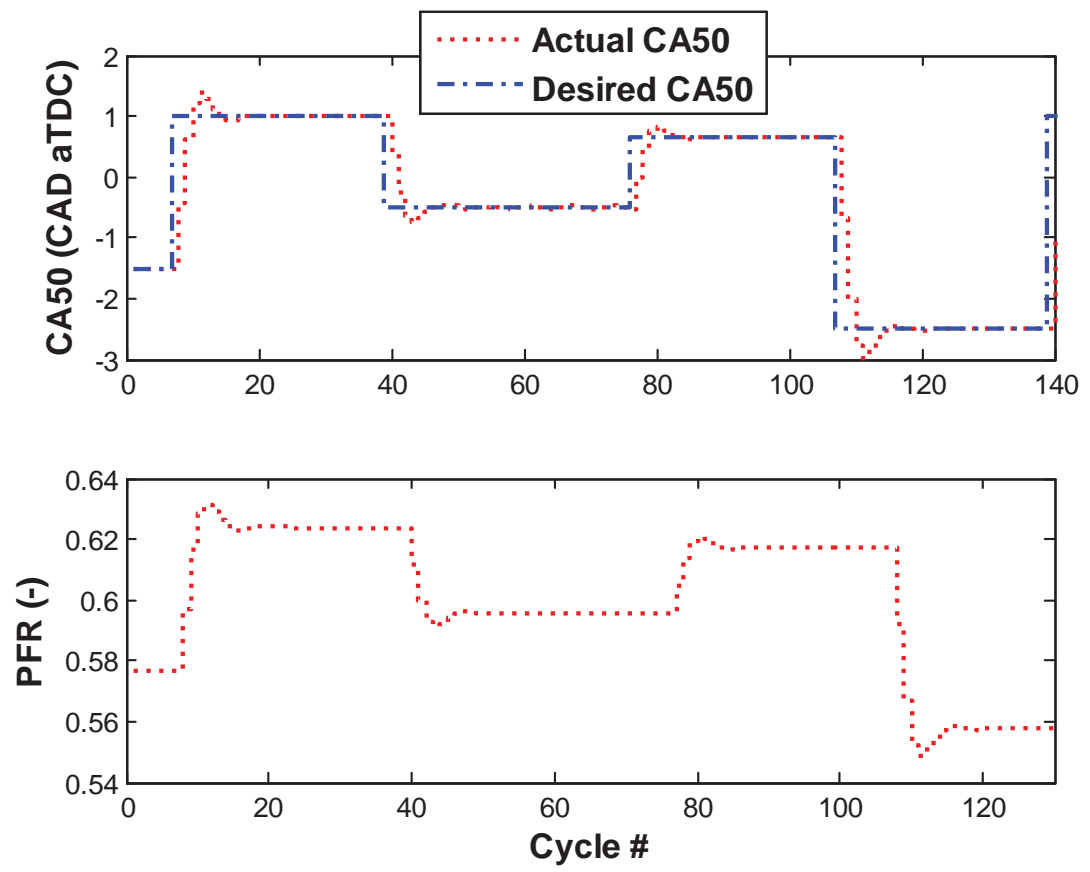

Figure 3-6. Tracking performance of the designed CA50 controller.

Figure 3-6 depicts that the controller is capable of regulating the CA50 to the desired trajectory with satisfactory performance. The quantitative metrics corresponding to the controller performance are given in Table 3-3.

Table 3-3. Tracking performance of LQI. 


\section{Maximum overshoot}

Rise time $\left(t_{r}\right)$

Settling time $\left(t_{s}\right)$

Steady state error $\left(e_{s s}\right)$

\subsection{CAD}

3 Cycles

6 Cycles

0 CAD

Due to the model mismatch between the linearized COM and the physical model of the engine, some level of steady state error $\left(e_{S S}\right)$ is expected. However, as the model is augmented and its order is increased by the addition of the integral controller, this $e_{S S}$ is successfully reduced to zero, thus significantly improving the controller performance. Other characteristics of the controller such as settling time $\left(t_{s}\right)$, rise time $\left(t_{r}\right)$, and maximum overshoot demonstrate fast and accurate controller performance.

\subsubsection{Disturbance Rejection}

In this section the controller's performance in rejecting the external disturbances to the engine is studied. To this end, the variations in intake gas temperature $\left(T_{I V C}\right)$ as well as the amount of fueling are considered to be the main contributing factors for the disturbances in the engine operation. These disturbances represent variations in engine load and thermal operating conditions. The performance of the controller in rejecting step inputs in both $T_{I V C}$ and $\varphi$, which represents the amount of fueling, is shown in Figure 3-7. 


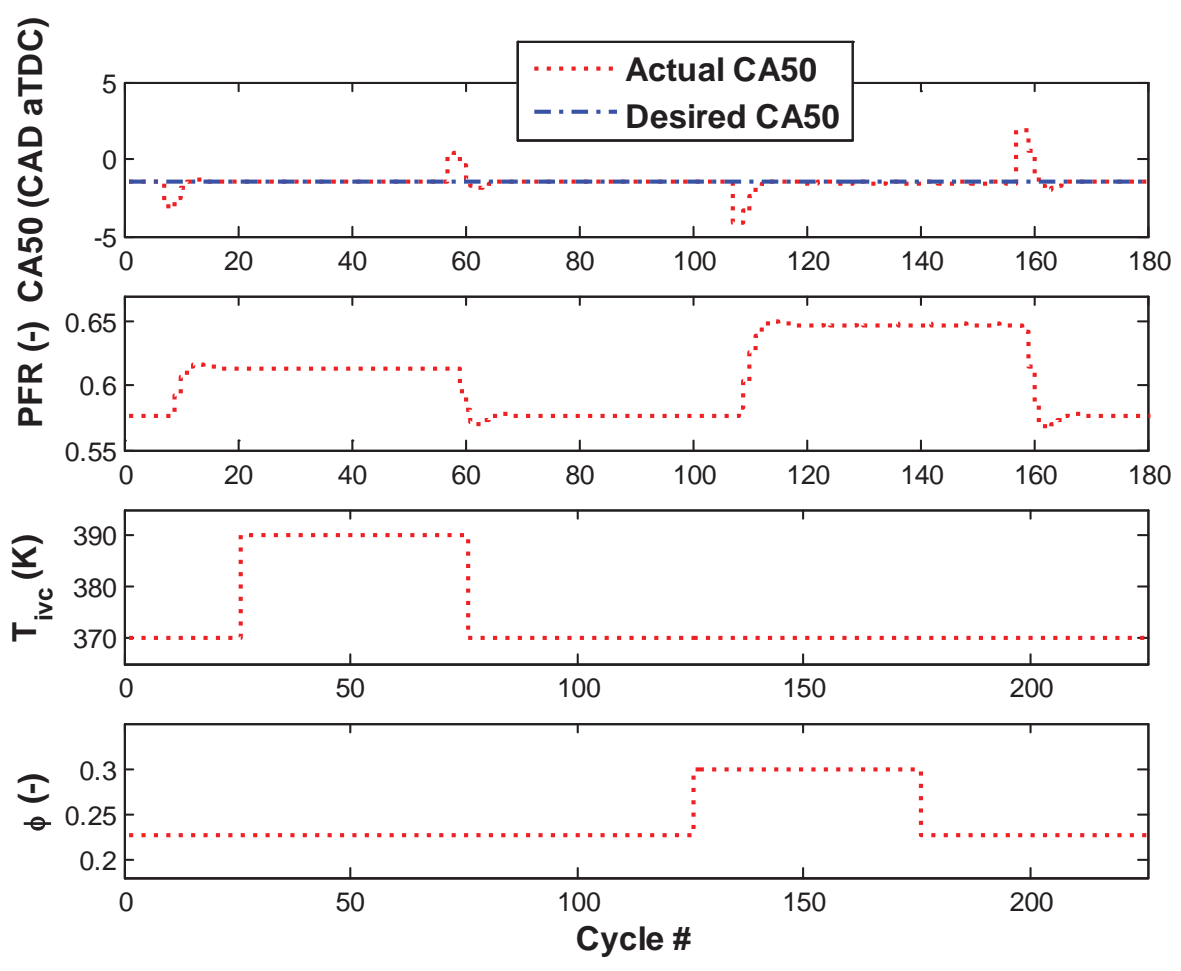

Figure 3-7. Controller performance in disturbance rejection

A sudden increase in $T_{I V C}$ and $\varphi$ by $20 \mathrm{~K}$ and 0.08 , respectively, are used to examine the capability of the controller in regulating the desired CA50 despite the presence of external disturbances. As shown in Figure 3-7 the controller is capable of conditioning the CA50 by modulating the PFR to counter the effect of $T_{I V C}$ and $\varphi$ variations.

A maximum deviation of 1.7 CAD is observed, for a $20 \mathrm{~K}$ step increase and decrease of $T_{I V C}$. A step variation of $\varphi$ by 0.08 , causes a maximum deviation of CA50 by 3.2 CAD. The controller is capable of rejecting both disturbances within 5 cycles. Moreover, the steady state error is zero due to the integral action as previously discussed. 


\section{Chapter 4}

\section{Conclusions and Future Work}

In this thesis a physics-based mean-value COM was developed for prediction of SOC, combustion duration and CA50 in an RCCI engine. The COM includes a modified knock integral model, a fuel burn rate model, and a Wiebe function. This COM was then extended to encompass the dynamics of thermal coupling between consecutive cycles through residual gas factions. This extended model is then linearized and an observer-based LQI was developed to control the combustion phasing of the engine via modulation of the premixed ratio of gas/diesel. Moreover, a PFI systems was designed and fabricated to modify a base GDI engine to operate in RCCI mode (see Appendix A).

\subsection{Summary and Conclusion}

A modified knock integral model was developed to predict the SOC of RCCI combustion. The new model encompasses various attributes of RCCI, including the fuel reactivity gradient introduced by the injection of two different fuels with distinct RON, injection timing of the high $\mathrm{CN}$ fuel into the cylinder, charge composition (i.e., the equivalence ratio of both fuels) and charge conditions (temperature and pressure) at intake valve closure.

Next, a burn duration model was developed based on detailed RCCI simulation results in [17]. A spontaneous ignition front speed was estimated using an approximation of the gradients of equivalence ratio in the in-cylinder mixture. This estimation was used to predict the $\mathrm{BD}$, since the main mechanism of combustion in $\mathrm{RCCI}$ is the propagation of 
auto-ignition pockets causing an ignition front to proceed. Eventually, a Wiebe function was developed to derive an estimation of CA50.

The detailed RCCI combustion model based on the KIVA CFD code was experimentally validated and used to generate RCCI data at 69 different operating conditions. Thirty-five out of the 69 KIVA simulation data were used to parameterize the COM. The validation results showed the COM has good accuracy in predicting SOC, BD and CA50 with a mean error of $0.4,0.2$ and 1.3 CAD, respectively. Thus, the COM from this work can be used for RCCI control applications.

The COM was developed for RCCI with single DI injection with a constant injection pressure. Future work may include extending the $\mathrm{COM}$ for RCCI with multiple in-cylinder injections and variable DI pressures. In addition, the COM can be extended to include fuel flow dynamics [54] from port fuel injectors, boost pressure dynamics [55] from turbocharger/supercharger, and EGR flow dynamics [43], [55], depending on which control actuation techniques are planned to control combustion phasing in an RCCI engine.

The mean-value model, was extended to model the expansion and exhaust strokes through polytropic process. This enabled the calculation of the mass and temperature of residual gases within the cylinder. The calculated values were used to estimate the $T_{i v c}$ based on the mixing of fresh charge and residual gases. This provided a dynamic model capable of modelling the RCCI engine operation on a cycle-to-cycle basis. This model is then further simplified (by developing a non-linear COM as described in section (3.2.1)) and linearized around a stable operating point of the engine. Next a LQI was utilized to control the 
combustion phasing of the engine by controlling the premixed ratio. The controller demonstrated accurate tracking of CA50 $\left(e_{s s}=0 \mathrm{CAD}\right)$ through augmentation of state space equations. Moreover, a state observer was developed to estimate the states of the engine as they are not measurable during the operation of the engine. Furthermore, the performance of the observer was examined during the transient operation of the engine, which exhibited accurate estimation of the states. In addition, the controller successfully rejected disturbance in temperature and $\varphi$ within five cycles.

\subsection{Suggestions for Future Work}

The COM developed here can be improved should an open-cycle combustion model or further experimental data is available:

- Manifold pressure and temperature could be used in lieu of $T_{i v c}$ and $P_{i v c}$. This method will be more practical since manifold pressure and temperature are measurable.

- The blow-down process can be modelled via the flow through the exhaust valve. This model can be predictive with respect to variations in the operating conditions of the engine and can realize a more accurate estimation of the engine operation on a wider range of the operating conditions of the engine.

- In the case of available experimental transient data of the engine, the model can be further fine-tuned and calibrated for the engine. This will allow for a more accurate dynamic model of the engine and hence a more accurate controller. 
- The developed controller can be implemented on a real RCCI engine once the platform is ready to evaluate the real-time operation and its performance.

- The linear COM developed in this work is not a minimal realization of the state space representation of the system. Developing a reduced order-model has the prospect of lowering the computational cost of the controller implementation.

- The RCCI operation and subsequently the RCCI physical model are highly nonlinear, therefore a non-linear control technique could be utilized to realize the RCCI combustion phasing control as opposed to the LQI controller developed in Chapter 3. 


\section{References}

1. United States Environmental Protection Agency, EPA and NHTSA Set Standards to Reduce Greenhouse Gases and Improve Fuel Economy for Model Years 2017-2025 Cars and Light Trucks. Office of Transportation and Air Quality, August 2012.

2. Johnson T, "Diesel Emissions in Review," SAE Int. J. Engines 2011; 4(1):143157.

3. Curran S, Hanson R, and Wagner R. Effect of E85 on RCCI Performance and Emissions on a Multi-Cylinder Light-Duty Diesel Engine. SAE Paper 2012-010376, 2012.

4. Kokjohn SL, Hanson RM, Splitter DA, et al. Fuel Reactivity Controlled Compression Ignition (RCCI): a Pathway to Controlled High-efficiency Clean Combustion. Int. J. Engine Res. 2010; 12(3): 209-226.

5. Dec J, Yang Y, and Dronniou N, "Boosted HCCI - Controlling Pressure-Rise Rates for Performance Improvements using Partial Fuel Stratification with Conventional Gasoline," SAE Int. J. Engines 2011; 4(1):1169-1189.

6. Inagaki K, Fuyuto T, Nishikawa K, et al. Dual-Fuel PCI Combustion Controlled by In-Cylinder Stratification of Ignitability. SAE Paper 2006-01-0028, 2006.

7. Nieman D, Dempsey A, and Reitz RD. Heavy-Duty RCCI Operation Using Natural Gas and Diesel. SAE Int. J. Engines 2012; 5(2): 270-285.

8. Oak Ridge National Laboratory. www.crcao.org. February 2014. [Online]. [Accessed on March 28, 2014].

9. Glewen W, Meyer C, Foster D, et al. Sources and Tradeoffs for Transient NO and UHC Emissions with Low Temperature Diesel Combustion. SAE Technical Paper 2011-01-1356.

10. Khodadadi Sadabadi K, Shahbakhti M, Bharath AN, and Reitz RD. Modelling of Combustion Phasing of an RCCI Engine for Control Applications. Int. J. of Engine Research, 42 pages, Accepted March 2014. 
11. Bharath AN, Kalva N, Reitz RD and Rutland CJ. Use of Early Exhaust Valve Opening to Improve Combustion Efficiency and Catalyst Effectiveness in a Multi-cylinder RCCI Engine System - A Simulation Study. Proceedings of the ASME 2014 Internal Combustion Engine. Columbus, Indiana, USA, 2014.

12. Kokjohn SL, Reitz, Splitter D, et al. Investigation of Fuel Reactivity Stratification for Controlling PCI Heat-Release Rates Using High-Speed Chemiluminescence Imaging and Fuel Tracer Fluorescence. SAE Int. J. Engines 2012; 5(2): 248-269.

13. Wu Y, Hanson R, and Reitz RD. Investigation of Combustion Phasing Control Strategy During Reactivity Controlled Compression Ignition (RCCI) Multicylinder Engine Load Transitions. Proceedings of the ASME 2013 Internal Combustion Engine. Dearborn, Michigan, USA, 2013.

14. Hanson R and Reitz RD. Transient RCCI Operation in a Light-Duty MultiCylinder Engine. SAE Int. J. Engines 2013; 6(3): 1694-1705.

15. Heywood JB. Internal Combustion Engines Fundamentals. ISBN-13: 9780070286375: McGraw-Hill, 1988.

16. Shahbakhti $M$ and Koch CR. Control Oriented Modeling of Combustion Phasing for an HCCI Engine. In: American Control Conference. New York City, NY, USA, 2007, 3694-3699.

17. Kokjohn SL. Reactivity Controlled Compression Ignition (RCCI) Combustion. PhD Dissertation, University of Wisconsin - Madison, USA, 2012.

18. Shaver GM, Gerdes JC, Roelle MJ, et al. Dynamic Modeling of ResidualAffected Homogeneous Charge Compression Ignition Engines with Variable Valve Actuation. J. Dyn. Syst. Meas. Contr. 2004; 127(3): 347-381.

19. Shaver GM. Physics-based Modeling and Control of Residual-affected HCCI Engines Using Variable Valve Actuation. PhD Dissertation, Stanford University, USA, 2005.

20. Vandersickel A, Hartmann M, Vogel K, et al. The Autoignition of Practical Fuels at HCCI Conditions: High-pressure Shock Tube Experiments and Phenomenological Modeling, Fuel 2012; 93: 492-501. 
21. Pickett LM, Siebers DL and Idicheria CA. Relationship between Ignition Processes and the Lift-Off Length of Diesel Fuel Jets. SAE Paper 2005-01-3843, 2005.

22. Kook S, Bae C, Miles PC, et al. The Influence of Charge Dilution and Injection Timing on Low-Temperature Diesel Combustion and Emissions. SAE Paper 2005-01-3837, 2005.

23. Andersson M, Johansson B, et al. A Predictive Real Time NOx Model for Conventional and Partially Premixed Diesel Combustion. SAE Paper 2006-013329, 2006.

24. Loganathan S, Murali Manohar R, Thamaraika R, et al. Direct Injection Diesel Engine Rate of Heat Release Prediction using Universal Load Correction Factor in Double Wiebe Function for Performance Simulation. SAE Paper 2011-012456, 2012.

25. Kim DS, Kim MY, and Lee CS. Effect of Premixed Gasoline Fuel on the Combustion Characteristics of Compression Ignition Engine. Energy \& Fuels 2004; 18(4): 1213-1219.

26. Shahbakhti M. Modeling and Experimental Study of an HCCI Engine for Combustion Timing Control. PhD dissertation, University of Alberta, Edmonton, Canada, 2009.

27. Shaver GM, Gerdes JC, and Jain P. Modeling for Control of HCCI Engines. In: American Control Conference, Denver, Colorado, USA, 2003, 749-754.

28. Halstead M, Kirsch L and Quinn, C. The Autoignition of Hydrocarbon Fuels at High Temperatures and Pressures-Fitting of a Mathematical Model," Combust. Flame 1977; 30: 45-60.

29. Bengtsson J, Gäfvert M, and Strandh P. Modeling of HCCI Engine Combustion for Control Analysis. In: 43rd IEEE Conference on Decision and Control. Atlantis, Paradise Island, Bahamas, 2004; 2: 1682-1687.

30. Sazhina EM, Sazhin SS, et al. The Shell Autoignition Model: Applications to Gasoline and Diesel Fuels. Fuel 1999; 78(4): 389-401. 
31. Hamosfakidis V and Reitz RD. Optimization of a Hydrocarbon Fuel Ignition Model using Genetic Algorithms. Combust. Flame 2003; 132(3): 433-450.

32. Y Kobashi, K Fujimori, H Maekaw, et al. Modeling of Auto-Ignition and Combustion Processes for Dual-Component Fuel Spray. SAE Int. J. Engines 2011; 4(2): 2193-2206.

33. Suzuki Y, Kusaka J, Ogawa M, et al. Modeling of Diesel Engine Components for Model-Based Control (Second Report). SAE Paper 2011-01-2044, 2011.

34. Livengood JC and Wu PC. Correlation of Autoignition Phenomena in Internal Combustion Engines and Rapid Compression Machines. Combust. Flame 1955; 5(1): 347-356.

35. Yates A and Viljoen CL. An Improved Empirical Model for Describing Autoignition. SAE Paper 2008-01-1629, 2008.

36. Hernandez JJ, Sanz-Argent J, Carot JM, et al. Ignition Delay Time Correlations for a Diesel Fuel with Application to Engine Combustion Modelling. Int. J. Engine Res. 2010; 11(3): 199-206.

37. Hillion M, Buhlbuck H, Chauvin J, et al. Combustion Control of Diesel Engines Using Injection Timing. SAE Paper 2009-01-0367, 2009.

38. Lafossas FA, Marbaix M, and Menegazzi P. Development and Application of a OD D.I. Diesel Combustion Model for Emissions Prediction. SAE Paper 200701-1841, 2007.

39. Arsie I, Di Genova F, Mogavero A, et al. Multi-Zone Predictive Modeling of Common Rail Multi-Injection Diesel Engines. SAE Paper 2006-01-1384, 2006.

40. Bidarvatan M, Shahbakhti M, and Jazayeri S. Model-Based Control of Combustion Phasing in an HCCI Engine. SAE Int. J. Engines 2012; 5(3): 11631176.

41. Shahbakhti M and Koch CR. Dynamic Modeling of HCCI Combustion Timing in Transient Fueling Operation. SAE Int. J. Engines 2009; 2(1): 1098-1113.

42. Shaver GM, Gerdes JC, and Roelle MJ. Physics-Based Modeling and Control of Residual-Affected HCCI Engines. J. Dyn. Syst. Meas. Contr. 2009; 132(2). 
43. Rausen DJ, Stefanopoulou AG, Kang JM, et al. A Mean-Value Model for Control of Homogeneous Charge Compression Ignition (HCCI) Engines. In: American Control Conference, Boston, MA, USA, 2005: 355-362.

44. Shaver GM, Roelle MJ, and Gerdes JC. Modeling Cycle-to-ycle Dynamics and Mode Transition in HCCI Engines with Variable Valve Actuation. Control Eng. Pract. 2005; 14(3): 213-222.

45. Cranmer A, Shahbakhti M, and Hedrick JK. Grey-box Modeling Architectures for Rotational Dynamic Control in Automotive Engines. In: American Control Conference, Montreal, QC, Canada, 2012: 1278-1283.

46. Chiang CJ and Stefanopoulou AG. Dynamics of Homogeneous Charge Compression Ignition (HCCI) Engines with High Dilution. In: American Control Conference: New York City, NY, USA, 2007: 2979-2984.

47. Singh S, Liang L, Kong SC, et al. Development of a Flame Propagation Model for Dual-Fuel Partially Premixed Compression Ignition Engines. Int. J. Engine Res. 2006; 7(1): 65-75.

48. Kirchen P. Thermokinetic Modeling of the HCCI Cycle: Predicting the Ignition Timing. MSc Thesis, University of Alberta, 2004.

49. Curran S, Hanson R, and Wagner R. Effect of E85 on RCCI Performance and Emissions on a Multi-Cylinder Light-Duty Diesel Engine. SAE Paper 2012-010376, 2012.

50. Hasegawa R and Yanagihara H. HCCI Combustion in DI Diesel Engine. SAE Paper 2003-01-0745, 2003.

51. Chen JH, Hawkes ER, and Sanka R. Direct Numerical Simulation of Ignition Front Propagation in a Constant Volume with Temperature Inhomogeneities I. Fundamental Analysis and Diagnostics. Combust. Flame 2006; 145(1-2): 128144.

52. Lagarias JC, Reeds JA, et al. Convergence Properties of the Nelder-Mead Simplex Method in Low Dimensions. SIAM Journal of Optimization 1998; 9(1):112-147. 
53. Ravi N, Roelle MJ, Liao HH, et al. Model-Based Control of HCCI Engines Using Exhaust Recompression. IEEE Trans. Control Syst. Technol. 2010; 18(6): 1289-1302.

54. Shahbakhti M, Ghafuri M, Aslani AR, et al. A Method to Determine Fuel Transport Dynamics Model Parameters in Port Fuel Injected Gasoline Engines during Cold Start and Warm-Up Conditions. J. Eng. Gas Turbines Power 2010; 132(7).

55. Shahbakhti M and Koch CR. Physics Based Control Oriented Model for HCCI Combustion Timing. J. Dyn. Syst. Meas. Contr. 2010; 132(2).

56. Ravi N, Liao H, Jungkunz AF, et al. Model Predictive Control of HCCI Using Variable Valve Actuation and Fuel Injection. Control Engineering Practice 2012; 20: 421-430.

57. Cavina N, Siviero C, and Suglia C. Residual Gas Fraction Estimation: Application to a GDI Engine With Variable Valve Timing and EGR. SAE Paper 2004-01-2943, 2004.

58. Burl JB. Linear Optimal Control. ISBN-13: 978-0201808681, Addison Wesley Longman, 1999.

59. Bidarvatan M, and Shahbakhti M. Two-Input Two-Output Control of Blended Fuel HCCI Engines. SAE Paper 2013-01-1663, 2013.

60. Guzzella L, Onder C. Introduction to Modeling and Control of Internal Combustion Engine Systems. Springer, 2010.

61. Bosch-Motorsports. www.bosch-motorsport.com. September 2013. [Online]. [Accessed March 28, 2014]. 


\section{Appendix A}

\section{Designing and fabrication a port fuel injector interface}

In order to achieve the dual fuel combistion strategy (RCCI), in addition to the direct injector a port fuel injectior is required. The port fuel injector has the role of providing a homogenous mixture of fuel and air. This is realized via the the injection of fuel directly behind intake valves. High temperatures of intake valve seats facilitate the fuel vaporization and hence the time required for this process is reduced. This substantially reduces any chance of misfire and ensures a more accurate fuel delivery rate.

The engine for which the port fuel injector system is designed is the Ecotec 2.0L turbo LHU GM engine which is a 4 cylinder gasoline direct injection. The engine intake port is shown in Figure A-1. 


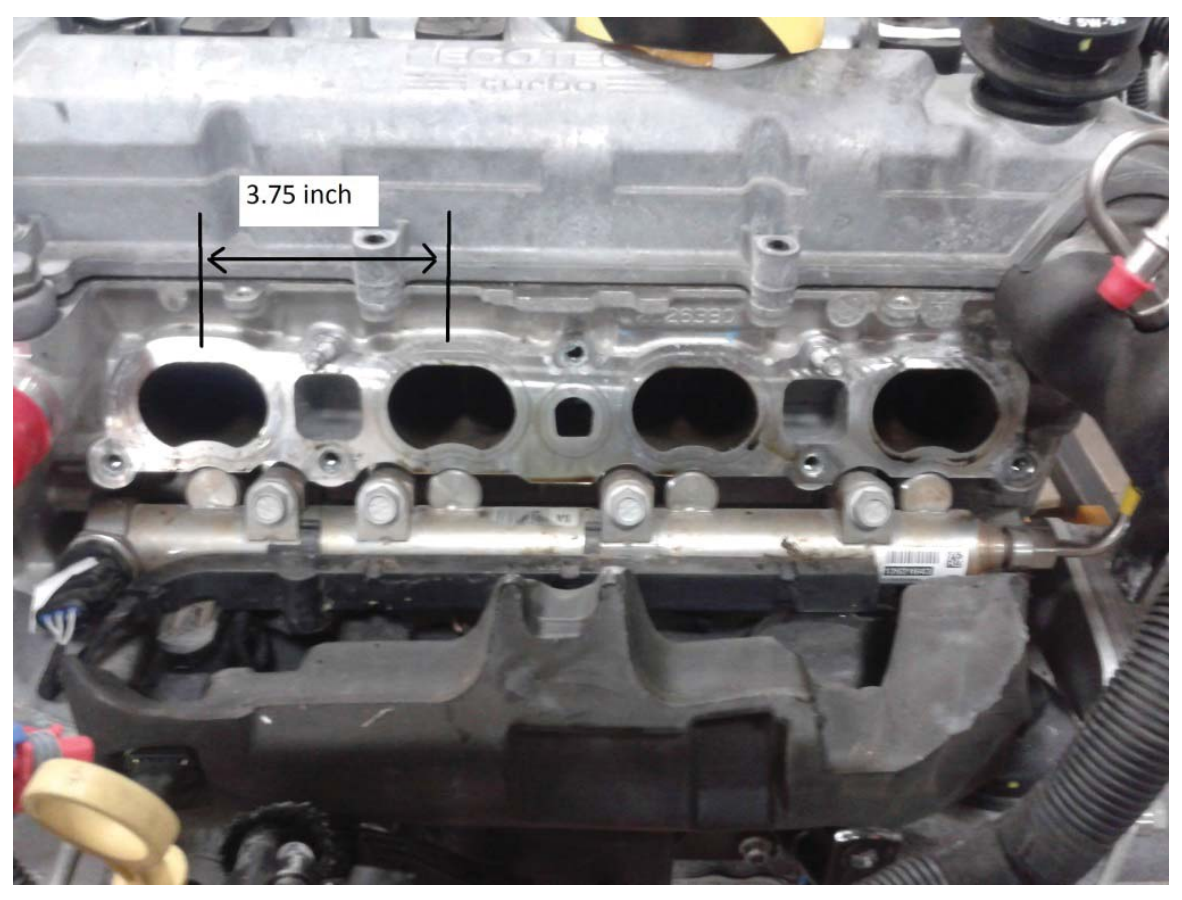

Figure A-1. Intake ports

As per the previous discussion a critical part of designing a port fuel injection system is to ensure that the injected fuel pattern is such that a minimum of wall impingement occurs to avoid fuel accumulation on the intake manifold. This could be realized by delicate design of an interface on which the fuel injector is going to be mounted.

If a simple injector without any tilted injection angle is used there is a significant amount of wall impingement due to the acute angle between the manifold and intrake valve seat as shown in Figure A-2. 


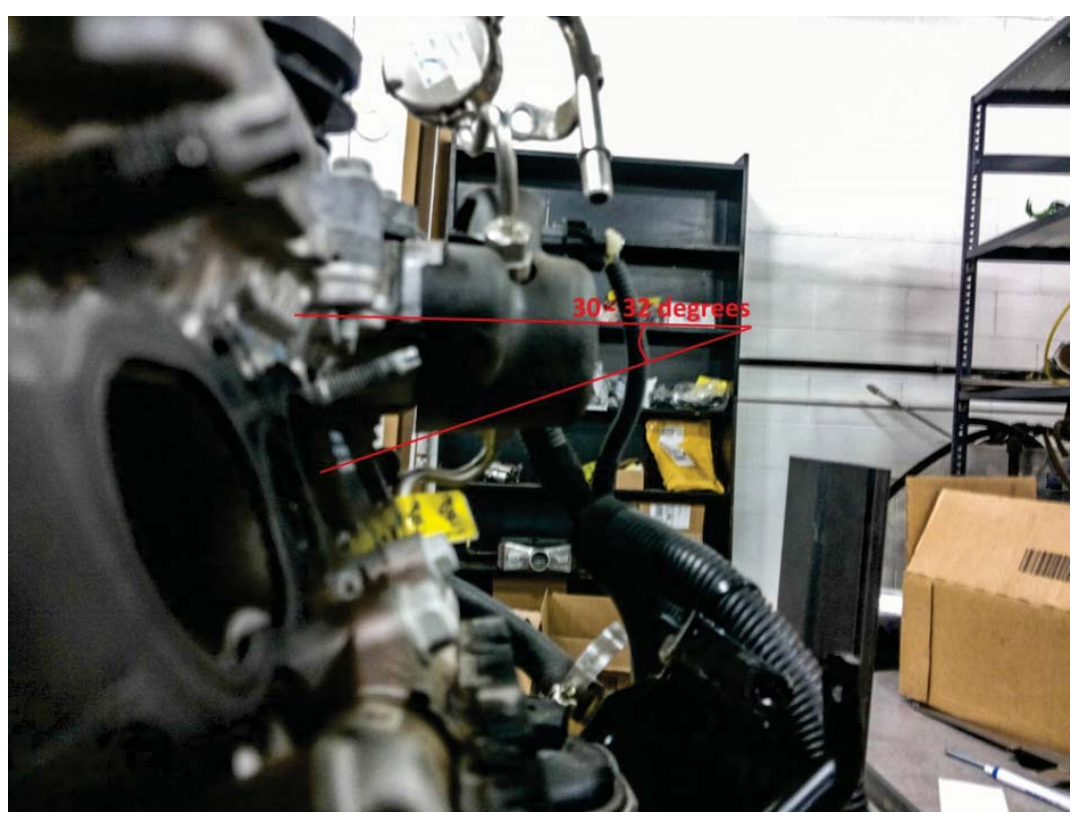

Figure A-2. Angle between the manifold and intake valve seat

This wall impingement of fuel spray is detrimental to engine performance as it causes high levels of HC emissions [60]. In order to minimize this an injector is necessary which is capable of injection of fuel in a tilted angle of around 20 degrees. Moreover, in order to be able to mix two different fuels and control the octane number of PFI fuel, two injectors are used for each cylinder such that each injector is connected to a different fuel tank. Hence after the injection the two fuel impinge on each other and mixing happens. Furthermore, since in the Ecotec 2.0L turbo LHU engine there are two intake valves per cylinder as shown in Figure A-3 the fuel injector needs to have a dual spray pattern. This way one cone is introduced behind each intake valve seat. 


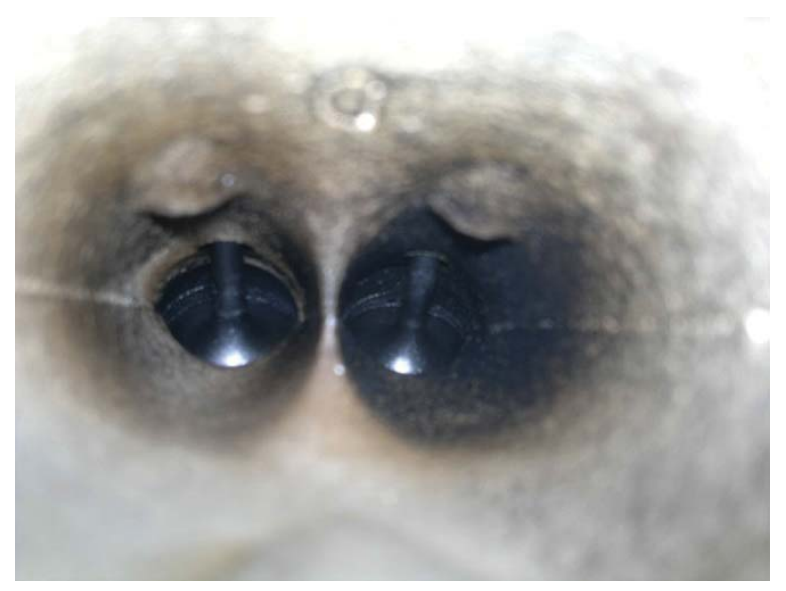

Figure A-3. Intake valves of Ecotec 2.0L turbo GM engine

The fuel injector delivery rate is determined based on a rough estimation that $100 \mathrm{hp}$ is realized at $2000 \mathrm{rpm}$. This is a reasonable estimation as the engine is going to run in LTC mode, i.e. very lean, thus full load operation of the engine is not necessary. Moreover, in order to achieve higher loads the GDI injector could be used as well as the PFI injectors. The corresponding calculations are shown below:

$$
\eta_{t h} \times \dot{m}_{f} \times Q_{L H V}=2 \pi N \tau \rightarrow \dot{m}_{f}=\frac{2 \pi \times 2000 \times 353}{0.3 \times 44 \times 10^{6}}=335.8 \mathrm{~g} / \mathrm{min}
$$

In order to calculate the fuel delivery rate a thermal efficiency of $30 \%$ has been asssumed. The LHV of gasoline has been used $\left(Q_{L H V}\right.$ of gasoline and diesel are relatively the same). Since the engine has 4 cylinders and for each cylinder there are 2 injectors, this fuel flow is to be provided by 8 fuel injectors, therefore the maximum fuel flow rate corresponding to each injector is

$$
\dot{m}_{f}=\frac{335.8}{8}=41.97 \mathrm{~g} / \mathrm{min}
$$


With the aformentioned arguments a bosch EV14 injector was chosen. The injector specifications are given in Table A-1.

Table A-1. EV14 injector specifications [61]

\begin{tabular}{cc}
\hline Part Nr. & $\mathbf{0 2 8 0 1 5 8 1 1 6}$ \\
\hline Flow rate/min & $237 \mathrm{~g} / \mathrm{min}$ \\
Type & $\mathrm{E}$ \\
Housing & $\mathrm{L}$ \\
A & $22^{\circ}$ \\
$\boldsymbol{\gamma}$ & $5^{\circ}$ \\
$\boldsymbol{\delta}$ & $90^{\circ}$ \\
Resistance & $12 \Omega$ \\
\hline
\end{tabular}

The EV14 EL, 237 g/min n-heptane injectors are shown in Figure A-4.

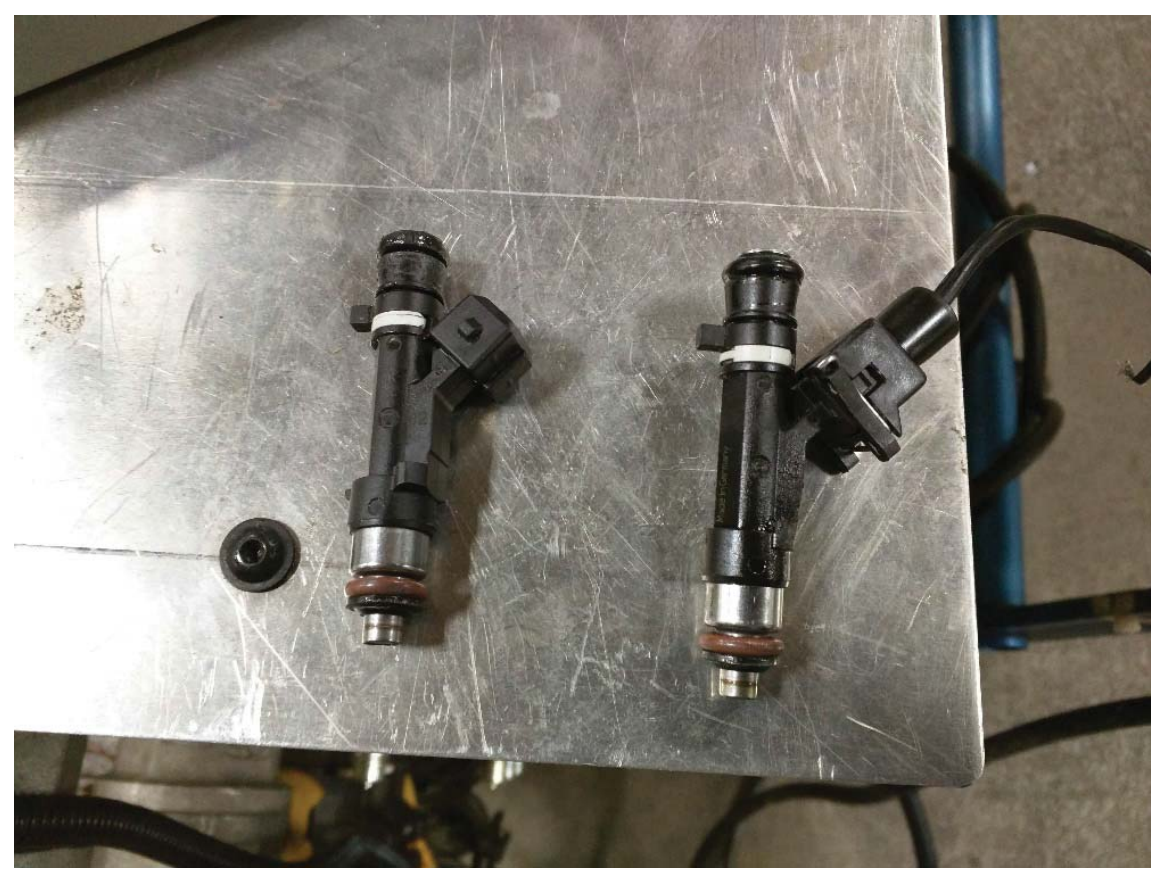

Figure A-4. EV14 EL fuel injectors with the pigtail connector 
The EV14 injector is twin beam injector which has a tilt angle of $22^{\circ}$. This angle is indeed optimum since it minimizing the fuel impingement of spray on the intake manifold.

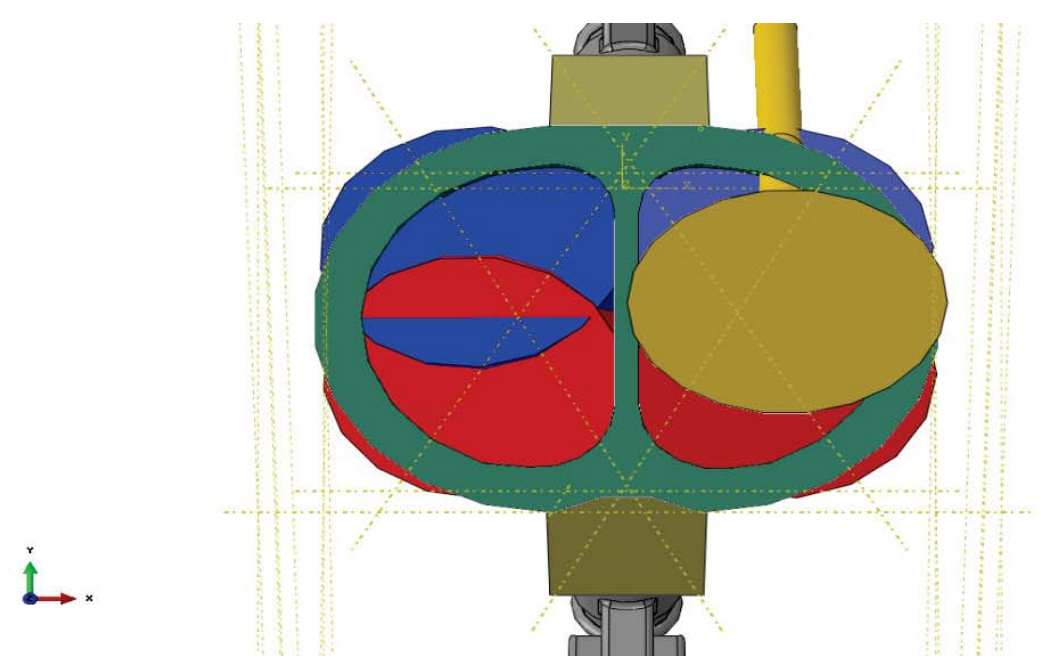

Figure A-5. Front view of fuel spray pattern and intake valve seat

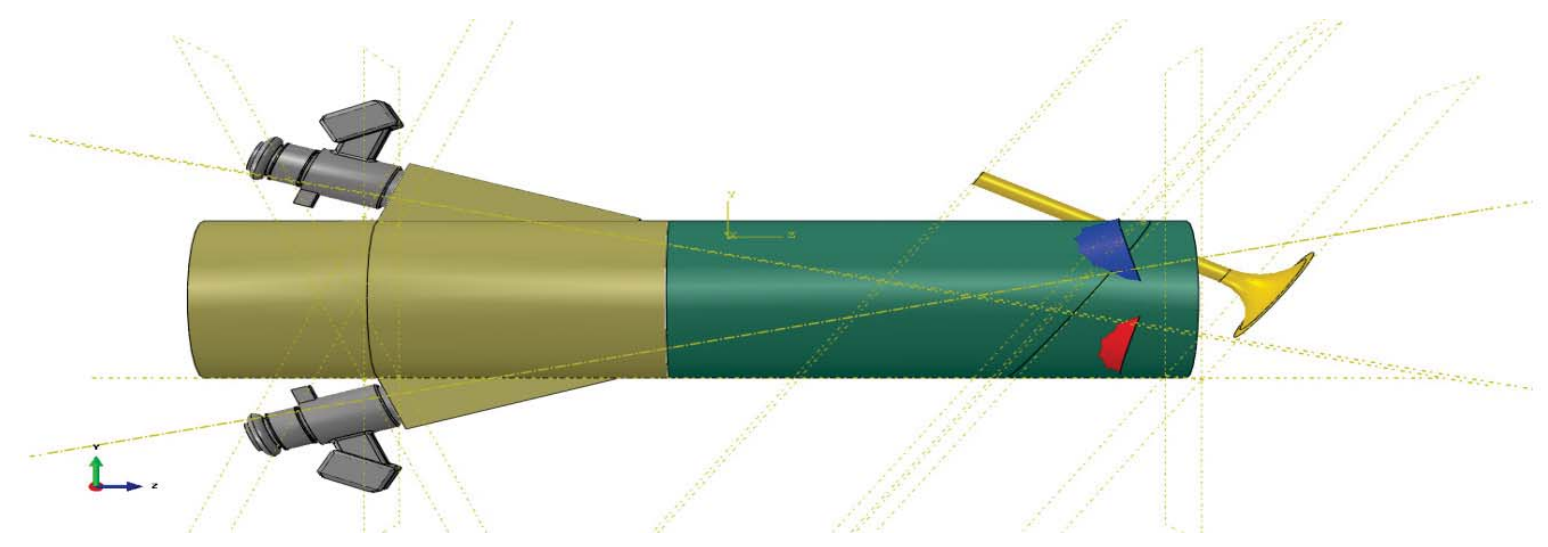

Figure A-6. Side view of fuel spray pattern and intake valve seat

The cross section of the injector and the designed manifold are shown in Figure A-7. 


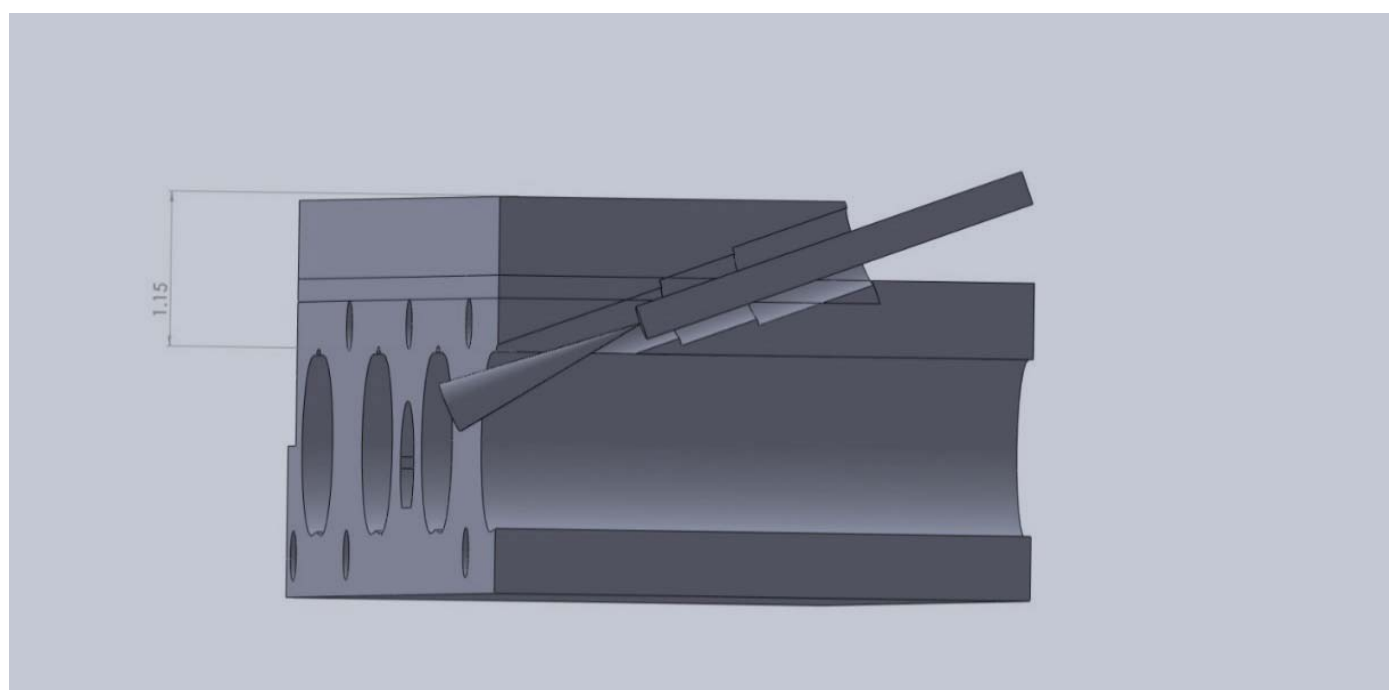

Figure A-7. PFI injector and interface

In order to mount the fuel delivery system (injectors and fuel rails) L shaped clamps were used to fix the injectors on the interface. The final design of the interface, fuel injector models and fuel rails and the corresponding mounting system are shown in Figure A-8. 


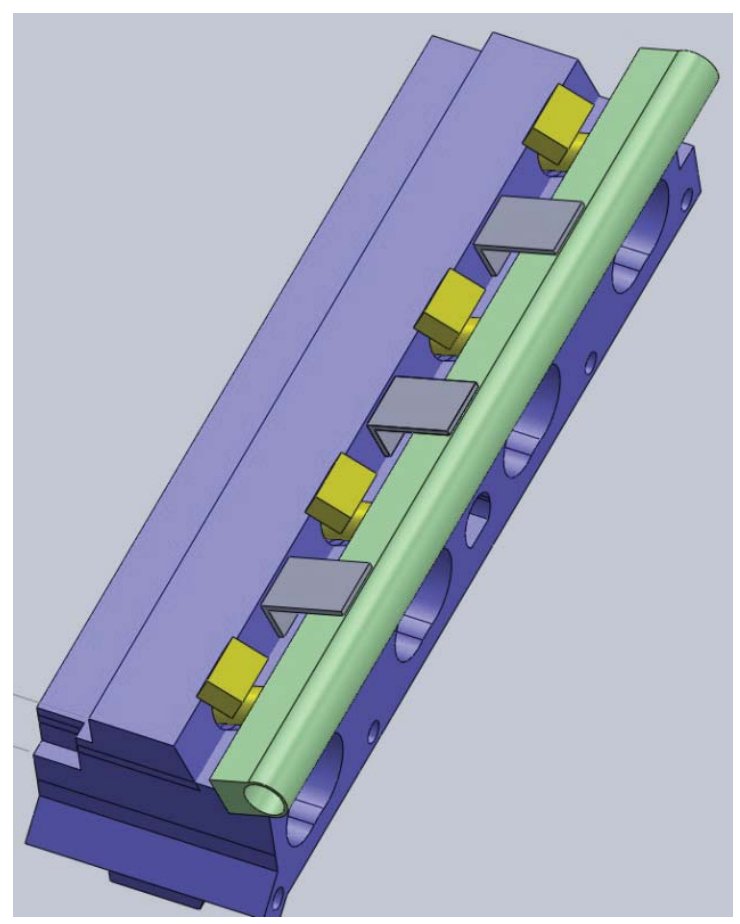

Figure A-8. PFI injector complete mounting design. The gray L shaped metal bars are used to mount the injector on the interface.

After modeling the flange a plastic version of it was fabricated in order to test that the design is consistent with the cylinder head. The fabricated prototype is shown in Figure A-9 with the port fuel injectors, fuel pressure regulators and fuel rail mounted: 


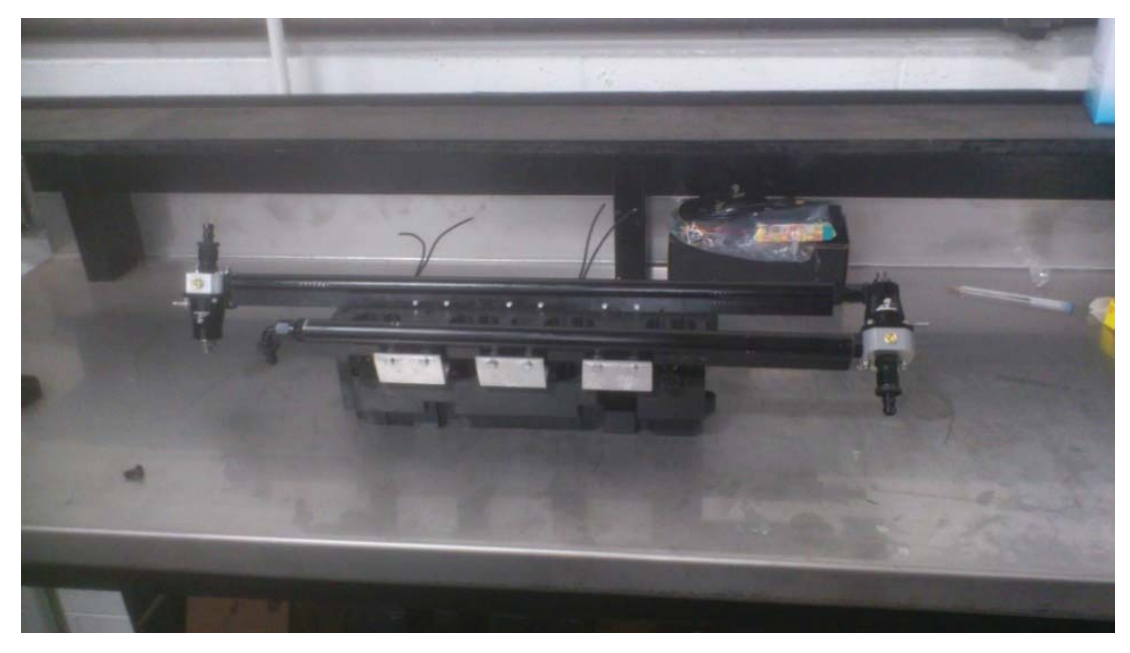

Figure A-9. PFI injector complete mounting.

The final design of the interface was successfully mounted on the engine block as shown in Figure A-10:

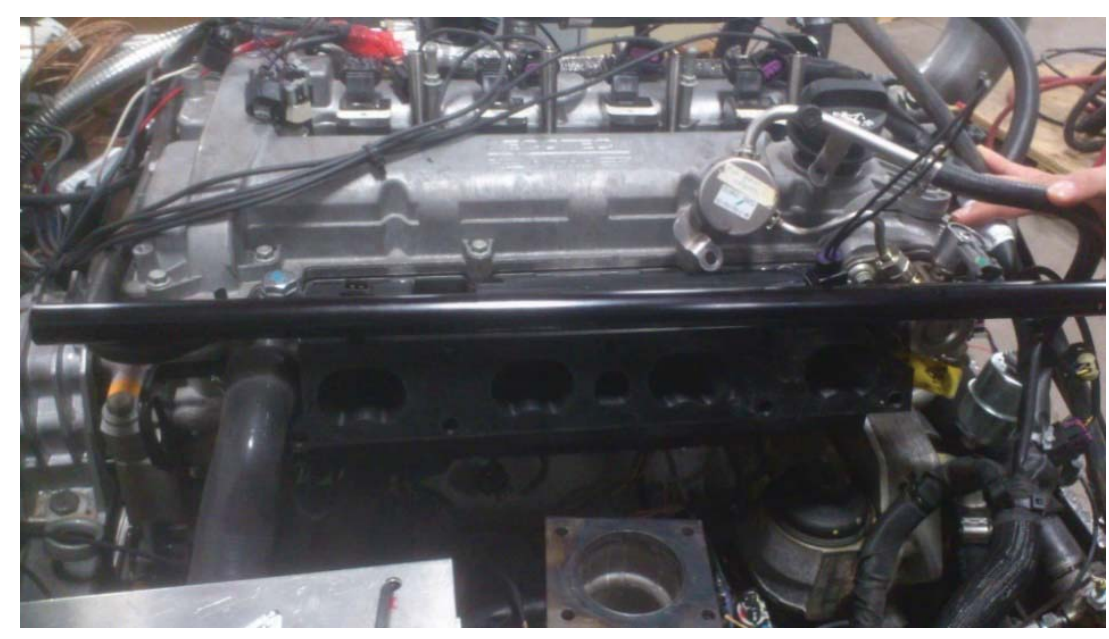

Figure A-10. PFI injector complete interface mounted on the engine.

Ultimately, the metal interface block was fabricated as shown in Figure A-11. 


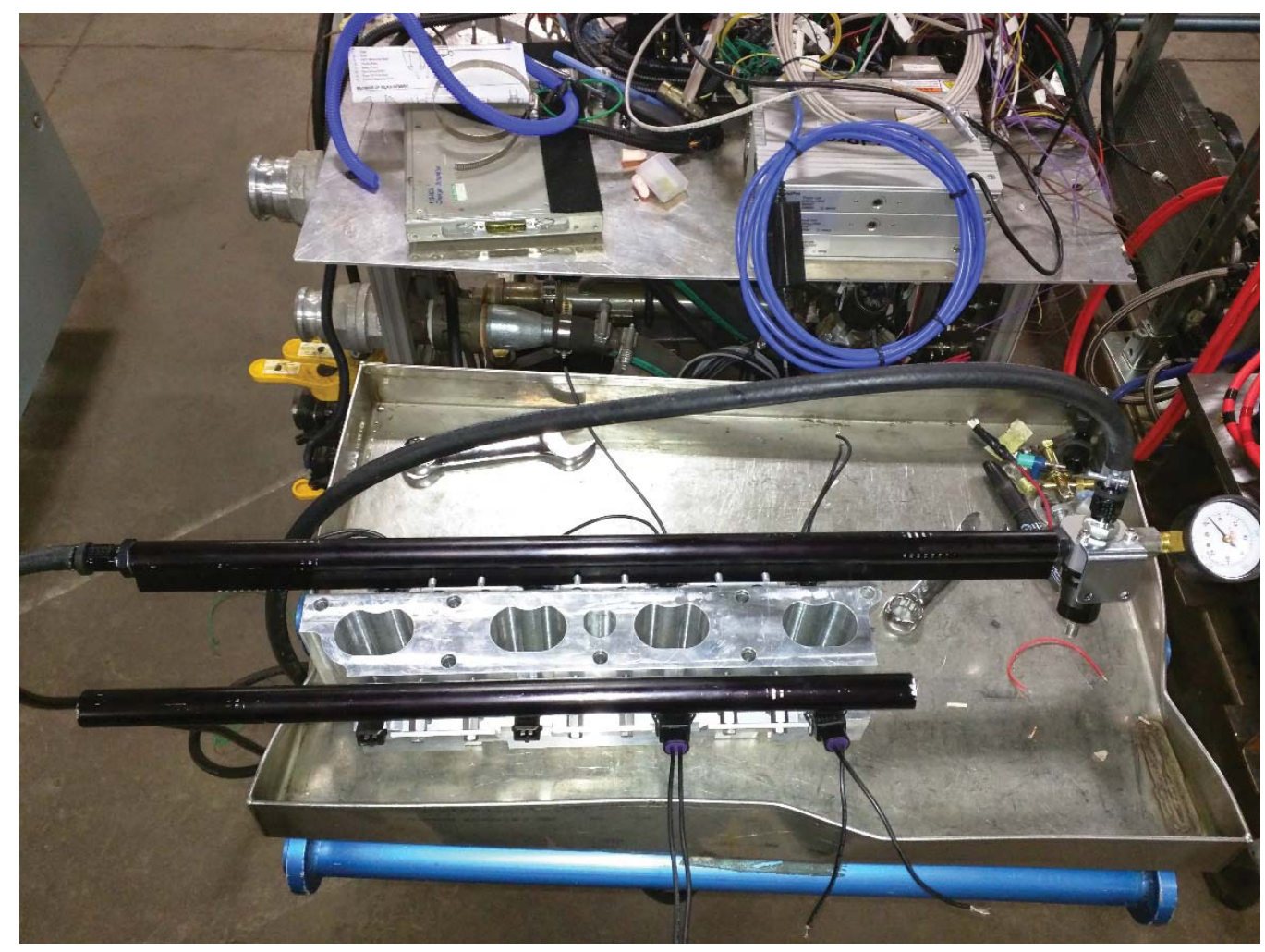

Figure A-11. PFI metal mounting interface. 


\section{Appendix B}

\section{State Space Representation Matrices}

The following are the state, input, output, and disturbance matrices of the linear system representation of the RCCI combustion phasing model given in section 3.2.2.

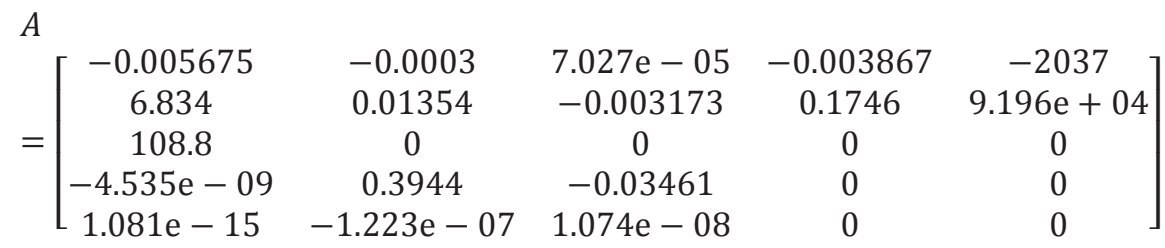

$$
B_{u}=\left[\begin{array}{c}
28.06 \\
0 \\
0 \\
1.792 \\
-5.561 \mathrm{e}-07
\end{array}\right]
$$

$$
C=\left[\begin{array}{lllll}
1 & 0 & 0 & 0 & 0
\end{array}\right]
$$

In order to determine the disturbance matrix, the derivative of the detailed physical model is taken with respect to the corresponding disturbance. Each derivative is taken at the nominal operating point given in Table 3-2, which yields the following disturbance matrix:

$$
B_{d}=\left[\begin{array}{cc}
-0.05 & -0.61 \\
2.09 & -3.92 \\
-5.75 & -65.68 \\
5.55 \mathrm{e}-21 & 670.14 \\
-1.72 \mathrm{e}-27 & -2.08 \mathrm{e}-4
\end{array}\right]
$$




\section{Appendix C}

\section{MS Publication}

[1] Khodadadi Sadabadi K, Shahbakhti M, Bharath AN, and Reitz RD. Modelling of Combustion Phasing of an RCCI Engine for Control Applications. Int. J. of Engine Research, 42 pages, Accepted March 2014. 


\section{Appendix D}

\section{Thesis files summary}

Following files were used for this thesis.

Table D-1. Experimental and KIVA simulation data

\begin{tabular}{|c|c|c|}
\hline Sr. \# & File Name & Description \\
\hline 1 & 26 & $\begin{array}{l}\text { Experimental data for KIVA model } \\
\text { validation }\end{array}$ \\
\hline 2 & Book1 & $\begin{array}{l}\text { Experimental data for KIVA model } \\
\text { validation }\end{array}$ \\
\hline 3 & IVC Pressure Sweep 1 Bar & $\begin{array}{l}\text { KIVA simulation data for } \\
\text { parameterizing and validation of } \mathrm{COM}\end{array}$ \\
\hline 4 & IVC Pressure Sweep 2.6 Bar & $\begin{array}{l}\text { KIVA simulation data for } \\
\text { parameterizing and validation of } \mathrm{COM}\end{array}$ \\
\hline 5 & IVC Temperature Sweep 2.6 Bar & $\begin{array}{l}\text { KIVA simulation data for } \\
\text { parameterizing and validation of } \mathrm{COM}\end{array}$ \\
\hline 6 & IVC Temperature Sweep 1 Bar & $\begin{array}{l}\text { KIVA simulation data for } \\
\text { parameterizing and validation of COM }\end{array}$ \\
\hline
\end{tabular}

Table D-2. MATLAB files

\begin{tabular}{rll}
\hline Sr. \# & File Name & Description \\
\hline $\mathbf{1}$ & MVM & Mean-Value model files \\
$\mathbf{2}$ & sfb12kf & Controller Simulink file \\
$\mathbf{3}$ & RCCid & RCCI dynamic model \\
$\mathbf{4}$ & nonlin_model2 & RCCI empirical COM \\
$\mathbf{5}$ & Observer & Observer \\
$\mathbf{6}$ & sfb & State feedback controller \\
\hline
\end{tabular}

Table D-3. Image files

\begin{tabular}{rll}
\hline Sr. \# & File Name & Description \\
\hline $\mathbf{1}$ & 1Autoignitio lit reviewr & Figure 2-1 \\
$\mathbf{2}$ & 2Chargepreparation & Figure 2-2 \\
$\mathbf{3}$ & 3RCCIcomb & Figure 2-3 \\
\hline
\end{tabular}




\begin{tabular}{lll}
\hline $\mathbf{4}$ & 4KIM & Figure 2-4 \\
$\mathbf{5}$ & 5exp1 & Figure 2-5 \\
$\mathbf{6}$ & 6exp2 & Figure 2-6 \\
$\mathbf{7}$ & 7Ponly & Figure 2-7 \\
$\mathbf{8}$ & 9SOCIVCr & Figure 2-8 \\
$\mathbf{9}$ & 10BDcorr2 & Figure 2-9 \\
$\mathbf{1 0}$ & 11CA50wcorr & Figure 2-10 \\
$\mathbf{1 1}$ & 12CA50corr & Figure 2-11 \\
$\mathbf{1 2}$ & 31ModelSchematic & Figure 3-1 \\
$\mathbf{1 3}$ & 32nonlinphyssoc & Figure 3-2 \\
$\mathbf{1 4}$ & 33physnonl & Figure 3-3 \\
$\mathbf{1 5}$ & 34Controller & Figure 3-4 \\
$\mathbf{1 6}$ & 35state & Figure 3-5 \\
$\mathbf{1 7}$ & 36Control2 & Figure 3-6 \\
$\mathbf{1 8}$ & 37Inoutdist2 & Figure 3-7 \\
$\mathbf{1 9}$ & Intakeports & Figure A-1 \\
$\mathbf{2 0}$ & Angle & Figure A-2 \\
$\mathbf{2 1}$ & valves & Figure A-3 \\
$\mathbf{2 2}$ & Injectors & Figure A-4 \\
\hline $\mathbf{2 3}$ & Frontfuelspray & Figure A-5 \\
$\mathbf{2 4}$ & Sidetfuelspray & Figure A-6 \\
$\mathbf{2 5}$ & injectorandinterface & Figure A-7 \\
$\mathbf{2 6}$ & Mountingdesign, FlangeFinal & Figure A-8 \\
$\mathbf{2 7}$ & completemounting & Figure A-9 \\
$\mathbf{2 8}$ & completeinterface & Figure A-10 \\
$\mathbf{2 9}$ & mountinginterface & Figure A-11 \\
\hline & & \\
\hline
\end{tabular}




\section{Appendix E}

\section{Permissions}

This permission is for Figure 1-2.

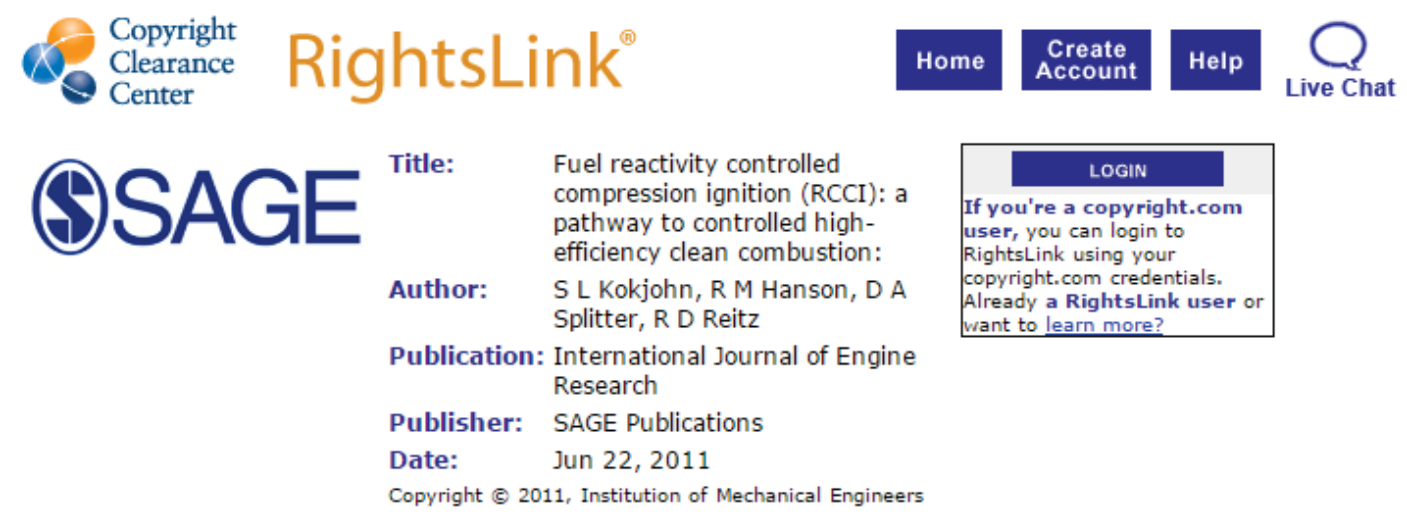

Gratis

Permission is granted at no cost for sole use in a Master's Thesis and/or Doctoral Dissertation. Additional permission is also granted for the selection to be included in the printing of said scholarly work as part of UMI's "Books on Demand" program. For any further usage or publication, please contact the publisher.

\section{BACK}

CLOSE WINDOW

Copyright (c) 2015 Copyright Clearance Center, Inc. All Rights Reserved. Privacy statement. Terms and Conditions. Comments? We would like to hear from you. E-mail us at customercare@copyright.com 